


\title{
How the Biotic Pump links the hydrological cycle and the rainforest to climate: Is it for real? How can we prove it?
}

\author{
Peter Bunyard, MA
}

Instituto de Estudios y Servicios Ambientales -IDEASA

Escuela de Ciencias Exactas e Ingeniería

Universidad Sergio Arboleda

Bogotá, Colombia 


\section{Bunyard, Peter}

How the Biotic Pump links the hydrological cycle and the rainforest to climate: ¿Is it for real? ¿How can we prove it? / Peter Bunyard - Bogotá: Universidad Sergio Arboleda. Instituto de Estudios y Servicios Ambientales-IDEASA, 2014.

114 p. - ISBN 978-958-8745-88-6 (rústica)

ISBN 978-958-8745-89-3 (.pdf)

1. ClimATOLOGÍA 2. CIRCULACIÓN ATMOSFÉRICA 3. CICLO HIDROLÓGICO 4. TEORÍA DE LA BOMBA BIÓTICA

551.6 ed. 21

How the Biotic Pump links the hydrological cycle and the rainforest to climate: Is it for real? How can we prove it?

ISBN: 978-958-8745-88-6 (rústica)

ISBN: 978-958-8745-89-3 (.pdf)

(c) Peter Bunyard

\section{Universidad Sergio Arboleda}

Instituto de Estudios y Servicios Ambientales - IDEASA

Escuela de Ciencias Exactas e Ingeniería

Edición: febrero de 2014

Queda prohibida toda reproducción por cualquier medio sin previa autorización escrita del editor.

El contenido del libro no representa la opinión de la Universidad Sergio Arboleda y es responsabilidad del autor.

Edición: Yadira Caballero Quintero - Carlos Andrés Caho Rodríguez.

Calle 74 No. 14-14

Teléfono: (571) 3257500 ext. 2131/2260

www.usergioarboleda.edu.co

Bogotá, D.C.

Directora de Publicaciones Científicas:

Yadira Caballero Quintero

yadira.caballero@usa.edu.co

Director del Fondo de Publicaciones:

Jaime Arturo Barahona Caicedo

jaime.barahona@usa.edu.co

Impresión: Digiprint

Bogotá, D.C. 


\section{CONTENTS}

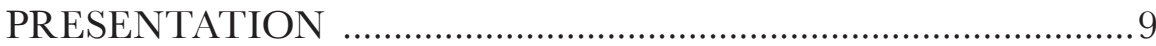

Chapter 1

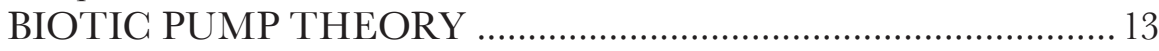

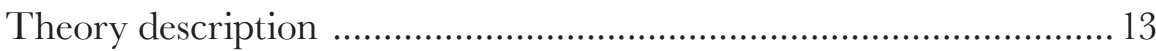

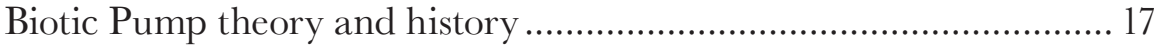

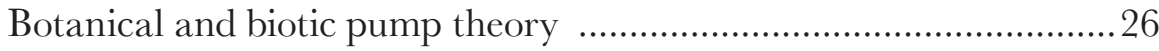

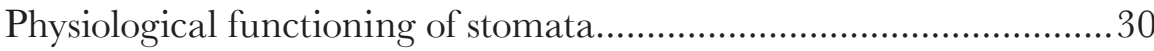

Chapter 2

BIOTIC PUMP THEORY: SEEKING PROOF ............................. 37

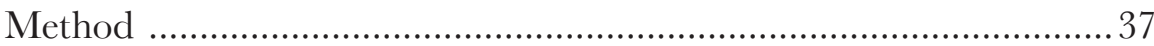

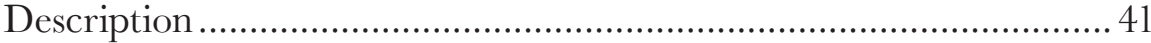

Chapter 3

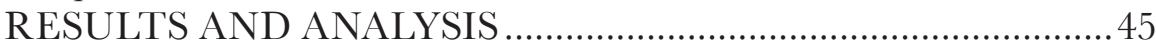

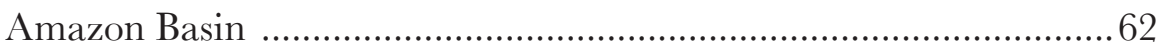

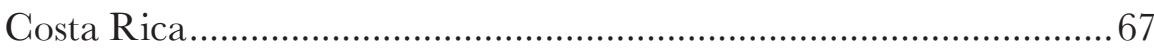

The evaporative-condensation force and winds................................69

Diurnal Barometric Pressure Wave .................................................... 79

Chapter 4

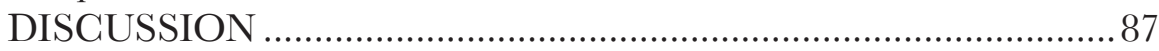

Experimental results: the ultimate proof?........................................... 94

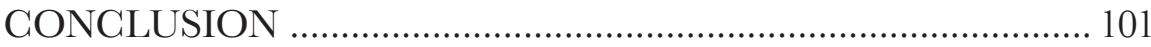




\section{LIST OF ILLUSTRATIONS}

\section{LIST OF FIGURES}

Figure 1. Teleconnections of the Amazon Basin ................................ 15

Figure 2. Deforestation leads to local changes in hydrology............... 16

Figure 3. Past and future deforestation extent over the Amazon basin ................................................................ 19

Figure 4. On-shore and off-shore winds and how coastal forests extend inland penetration ..................................................... 21

Figure 5. Plant available water distribution (PAW) ............................22

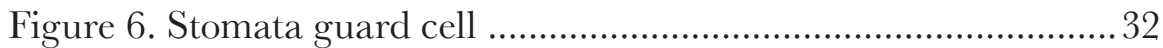

Figure 7. Effects of heat on Rubisco activase, Rubisco activation state and Calvin cycle activity ............................................ 33

Figure 8. Process of transpiration of plants.......................................... 34

Figure 9. Equipment used for the experiment. ....................................38

Figure 10. Scheme of the equipment used for the experiment.............39

Figure 11. Radio-sounding sites on South America.............................. 43

Figure 12. Radio-sounding sites on Africa...........................................4 44

Figure 13. Condensing vapour over forested slope in contrast

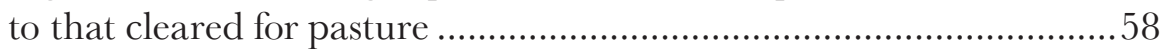

Figure 14. The Colombian Putumayo, deforested for cattle ................ 58

Figure 15. Flow Diagram derived from hydrological equations pertaining to the physics of the biotic pump........................60

\section{LIST OF GRAPHICS}

Graph 1. Relationship between precipitation and deforestation......... 17

Graph 2. Annual Variation of Leaf Area Index (LAI) .......................29

Graph 3. Evapotranspiration and its relationship with broadleaf cover and precipitation 30

Graph 4. Relationship between the net evaporative/condensation force $(\mathrm{hPa} / \mathrm{km})$ and water vapour pressure deficit (VPD). ................. 31 Graph 5. Comparative slope change of $\mathrm{f}_{\mathrm{E}}$ and surface wind........... 36 
Graph 6. La Selva, Costa Rica. Comparative slope change

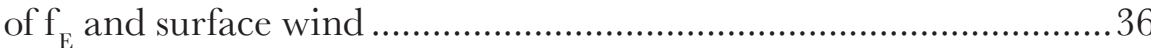

Graph 7. Experiment with three condensing cycles.............................40

Graph 8. Monthly data derived from daily radiosoundings

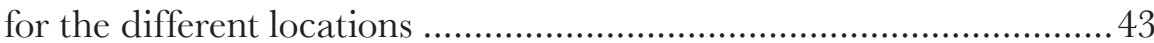

Graph 9. Leticia, partial pressure water vapour against temperature.

Graph 10. Leticia, partial pressures water vapour with Altitude.........48

Graph 11. Theoretical curves of the evaporative force $\mathrm{f}_{\mathrm{E}} \ldots \ldots \ldots \ldots \ldots \ldots \ldots . . . . .19$

Graph 12. Partial Pressure Force. Leticia 9th September 2013 ...........50

Graph 13. Deforestation impact over the biotic pump ........................5 52

Graph 14. La Selva, February 2014. Average temperature and average $\mathrm{f}_{\mathrm{E}}$

Graph 15. Calculations of $\mathrm{f}_{\mathrm{E}}$ and surface humidity from radio-soundings, August 2012

Graph 16. Radio-soundings for January 2012. Comparative

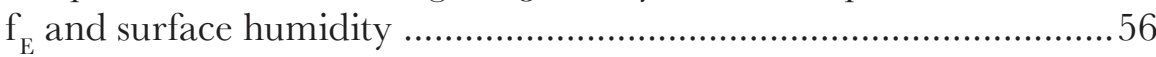

Graph 17. Dependence of precipitation on distance X $(\mathrm{Km}) \ldots \ldots \ldots \ldots . . .57$

Graph 18. Precipitation over non-forested territories ..........................57

Graph 19. Radiosounding for Leticia, Amazonas ................................ 62

Graph 20. Radiosounding calculations based on surface

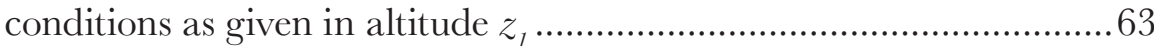

Graph 21. Monthly data from February 2010 to April 2011

and the same for the early part of 2011

Graph 22. The variance of surface water vapour density on a monthly basis 2011-2012.

Graph 23. The variance of surface humidity on a monthly

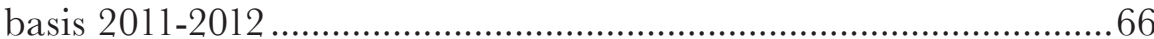

Graph 24. Variance in surface humidity (2001-2012) ........................66

Graph 25. Impact of pressure changes brought about through condensation of water vapour on airflow 68

Graph 26. La Selva OTC biological station, May 20th, 2012............ 70 
Graph 27. La Selva, 15th October 2012. .......................................... 70

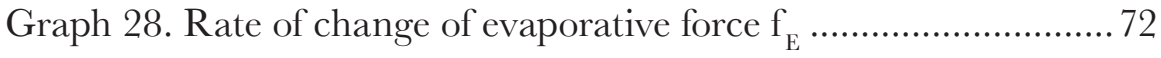

Graph 29. Rate of change of wind ..................................................... 73

Graph 30. La Selva, January 18th, 2013 ............................................ 74

Graph 31. Palo Verde, 4th September 2011 ........................................ 75

Graph 32. Rate of change of $f_{E}$ versus windspeed, La Selva

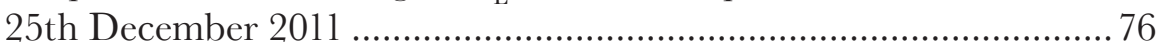

Graph 33. La Selva, 21st October, 2012 ............................................ 76

Graph 34. La Selva December 8th, 2013 ......................................... 77

Graph 35. Regression plot of $f_{E} v s$ windspeed rate of change............. 78

Graph 36. Strong and weaker accumulated correlations

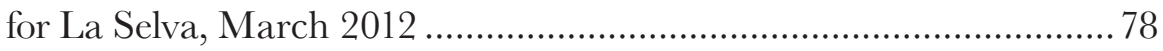

Graph 37. La Selva barometric waves, averaged for different

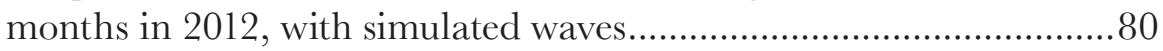

Graph 38. Palo Verde, March to April, 2012, averaged

barometric diurnal wave against simulated curve

Graph 39. Barometric average data for the 10 years, for Jokioinen in Northern Finland

Graph 40. Jokioinen for June 1961-1970

Graph 41. The relationship between the cosine component

of the barometric wave and relative humidity .....

Graph 42. Liquid water path determined over 24 hours .....................84

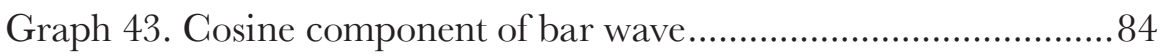

Graph 44. Liquid water path over Pacific............................................. 85

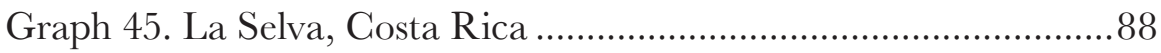

Graph 46. Diurnal barometric tidal wave for La Selva,

Costa Rica

Graph 47. Las Cruces, 2nd May, 2012 ............................................. 93

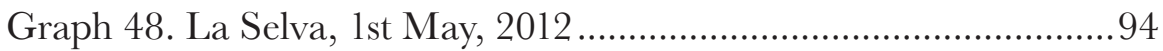

Graph 49. Rate of change in calculated airflow

vs anemometer airflow 96

Graph 50. Condensation rate airflow 96 


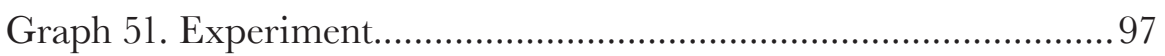

Graph 52. Airflow versus partial pressure change ...............................98

Graph 53. Airflow and partial pressure change ..................................98

Graph 54. Calculated airflow at condenser versus airflow

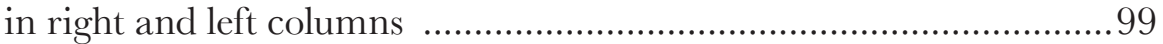

Graph 55. Counterflow in action when the condenser

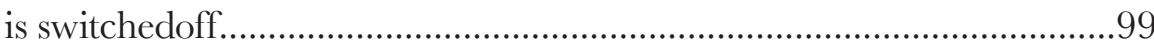

Graph 56. Experiment, air density ................................................. 100

\section{LIST OF TABLES}

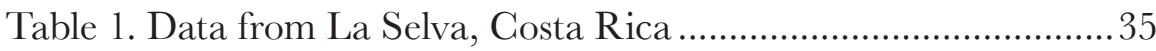

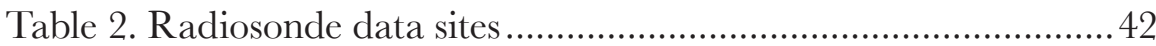

Table 3. Data from radio-soundings for locations from Africa

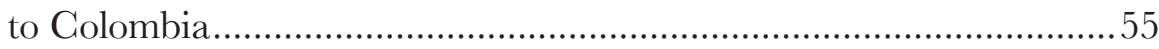

Table 4. Radiosoundings of various locations.....................................56

Table 5. Correlations between $\mathrm{f}_{\mathrm{E}}$ and windspeed, La Selva,

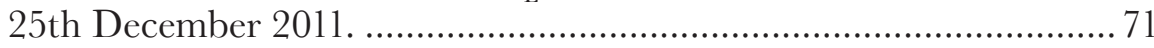

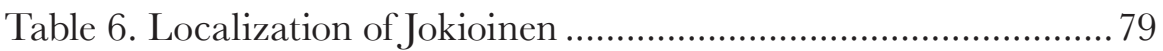





\section{PRESENTATION}

The Biotic Pump Theory, as set forward by Drs. 1 Makarieva and Gorshkov, states that the primary force driving surface winds, certainly in the tropics, is induced by the negative changes in atmospheric pressure caused by condensation of water vapour when clouds form. A high rate of condensation is necessary and therefore the theory requires that a sufficiently high rate of evapotranspiration from large areas of forest provides the 'fuel' for the process. The theory therefore runs contrary to the traditional view, as introduced in climate models, that surface winds are the sole products of differences in surface heating as well as of latent heat release during the process of condensation. Indeed, Makarieva and her colleagues claim that transitions in the phases of water play a far more important role in driving atmospheric dynamics than is currently recognised (Makarieva, Gorshkov, Sheil, Nobre, \& Li, 2013). They show, by means of fundamental physics, that condensation under adiabatic conditions (isolated from the environment) must lead inexorably to a reduction in a pressure even properly accounting for latent heat release. That sharp reduction in pressure follows a rise in pressure as water is evapotranspired from the closed canopy forest and it generates a suction force which translates into a surface airflow.

Contrary to what is often maintained, they point out that the laws of thermodynamics prevent adiabatic condensation under constant volume and the supposed pressure rise from latent heat release that such condensation would imply. Climate models based on such an assumption must inevitably come to false conclusions. The im- 
plications of the Russian theory are important for a wide range of scientific fields as it involves the global regulation and distribution of water, and not least an association with the physiology of different types of vegetation. In effect, Makarieva and Gorshkov propose that forest cover can, by means of moisture evaporation and condensation, generate the large-scale pressure gradients, that create the ocean-to-land moisture convergence that supplies rainfall across continents, contingent on there being sufficient cover of closed canopy forest (Makarieva \& Gorshkov, 2007; Makarieva, Gorshkov, \& Li, 2013). Other than emphasizing the fragile equilibrium of tropical rainforests with regards to human-induced deforestation, the theory could potentially provide answers to questions of angiosperm evolution and the relationship between life on Earth and the interior watering of continents. Indeed, the theory is a serious challenge to the idea that the forest vegetation of Amazonia was largely replaced by savannah vegetation during the cooler, drier period of the Pleistocene, with the re-seeding of the Basin resulting from socalled Biological Refugia.

The challenge is to find empirical data which indicates whether significant correlations exist between surface airflows and cloud condensation. That is not an easy task given the spatial distance between the ground and those atmospheric events which lead to clouds appearing and vanishing. Temperature and humidity undoubtedly play critical roles in generating the right conditions as indeed do the cloud condensation nuclei which are emitted from the surface, not least from vegetation, and which act to prevent super-saturation with water vapour and thereby enable it to condense at dew point temperatures.

Our study therefore aims quantitatively and theoretically at assessing the validity of the Biotic Pump Theory over regions which have or had humid tropical/equatorial rainforest, such as in Costa Rica and the Amazon basin. The study therefore requires a considerable infusion of competent physics and mathematics as well as a grounding in the laws pertaining to atmospheric gases and in particular to water vapour and its phase transition to liquid water and ultimately the relationship between condensation in the lower atmosphere - the troposphere - and precipitation.

The study is highly relevant to the future of Colombia in as much as rainfall patterns are in great measure linked to the air mass circulation over 
the Amazon Basin. Clearly what the Amazon countries, especially Brazil and including Colombia, do to their rainforests will have far reaching consequences for the region and even for the globe. If, for instance, sufficient evidence is brought to bear that the Russian biotic pump theory is in principle valid, then that will have socio-economic implications for notions of sustainable development in the Colombian sector. In essence, the theory is a hydrological theory putting emphasis on the maintenance of a high level of evapotranspiration over the Amazon Basin, such as to supply the piedmont, cloud forests and the upper moorland páramos with adequate rainfall and humidity. For that hydrological process to continue, according to the biotic pump theory, it becomes imperative that rainforest be properly conserved and that regeneration in heavily deforested regions should be mandated, with urgency. 



\section{Chapter 1}

\section{BIOTIC PUMP THEORY}

$\mathrm{W}$

ater plays a critical role in the processes of climate and in making this planet habitable. In addition to dissolving minerals, transporting them to the oceans and lubricating the sliding of one tectonic plate over another, water carries energy around the globe, distributing it as part of a planetary conveyor belt system. While in the ocean it is readily available, most of the water found on land comes from large-scale migration of water vapour transported by winds (Gimeno et al., 2002; Penman, 1948). During that passage a water molecule, whether in the form of ice, liquid or vapour may find itself pushed upwards into the atmosphere, during which time it may form clouds (depending on cloud condensation nuclei), and later bring about precipitation through means of condensation. Air can hold a certain quantity of water vapour, depending on temperature and therefore on the saturation curve of water vapour. Consequently, the position of air in the atmosphere, which latitude it is in, and how much is exposed to direct sunlight, has profound consequences for local weather and, more generally, climate.

\section{Theory description}

The theory describes the mechanism by which water vapour is transported from areas of low evaporation to areas of high evaporation, conveniently termed "donor" and "acceptor" regions, respectively. More water vapour 
in the recipient regions implies greater condensation of water vapour, thereby engendering a reduction in atmospheric pressure, in effect a partial vacuum, which consequently creates a highly-localised flux from high pressure to low pressure systems. We can conceive of the process as a vertical pistonlike movement which acts like a car cylinder in reverse, and rather than generating gas from liquid, condensation leads to liquid forming from gas.

To sustain itself, vegetation requires sufficient soil moisture and subsequently precipitation. As much as 50 per cent of the rainfall over the Amazon rainforest is derived from its own evapotranspiration (Shuttleworth, 1988; Salati \& Vose, 1984; Lettau H., Lettau, K., \& Molion, 1979; Marengo, 2006; Salati, 1987) this process is known as moisture recycling. However, the final result of deforestation is open to question, as indeed must be the climate models, dependent as they are on algorithms which do not include the hydrological connections between vegetation and the atmosphere, as described in the biotic pump theory. Extensive deforestation will inevitably lead to a reduction in evapotranspiration as well as rainfall based on current climate models, (Hutyra et al., 2005); the prediction is that extensive deforestation will result in savannization. Meanwhile, deforestation and edge effects in the forest surrounding large scale clearings increase the likelihood of destructive fires and forest die-back, as was indeed the case during the 2005 and 2010 Amazon droughts (Cochrane \& Laurance, 2002; Hutyra et al., 2005; Laurance et al., 2002; Phillips et al., 2009).

Through the use of climate models (i.e. Global and Regional Climate Models; GCMs and RCMs, respectively) a number of scientists, have predicted the effects of tropical rainforest removal on precipitation; (Henderson-Sellers, Dickinson, Durbridge, Kennedy, McGuffie, \& Pittman, 1993; Marengo, 2006; Werth \& Avissar, 2002). An outcome of such research show a connection between the deforestation of the Amazon Rainforest and statistically-significant changes in precipitation at other tropical and mid-latitude regions (Werth \& Avissar, 2002). These "teleconnections" have been determined to affect parts of North America, Europe and South Africa (see figure 1). The South American low level jet stream is also known to transport a considerable amount of water vapour from the Amazon Basin to the Plata River Basin, where as much as 50 per cent of the Plate basin's rainfall is derived from the Amazonian teleconnection (Poveda, Jaramillo, \& Vallejo, 2014). 
Figure 1. Teleconnections of the Amazon Basin

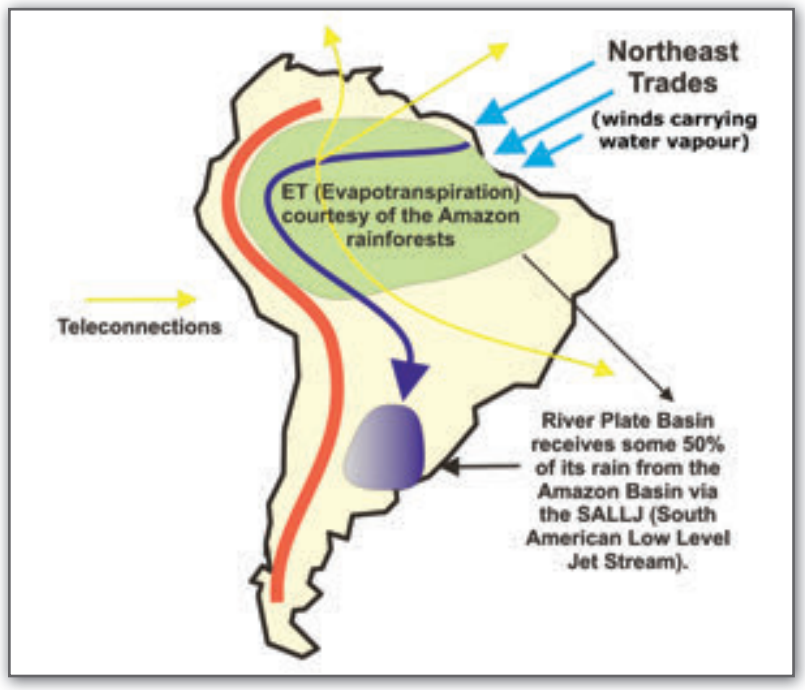

Source: Illustration adapted from Marengo, 2006.

The biotic pump theory indicates desertification must be the result of deforestation that is sufficiently widespread to exceed the effective fallout distance of water molecules in their transit inland from the neighbouring ocean (approximately $600 \mathrm{~km}$ ). Such impacts may be more permanent than was originally anticipated. As reported by Jonathan Watts in The Guardian, January $18^{\text {th }}$, 2013, NASA has found from analysing satellite data that an area of the Amazon twice the size of California has continued to show signs of further and unexpected degradation since the drought of 2010. Fearnside (2000) has long warned of such consequences. Nevertheless, such a finding goes against the conventional view that the trade winds, with their substantial cargo of water vapour, will continue to blow across the Amazon Basin, irrespective of deforestation, but rather supports the biotic pump theory by which the forest is a vital component in sucking in humid air from the tropical Atlantic and therefore, as the forest ecosystem degrades so will a diminished forest result in reduced winds with the result that the associated reduction in moisture leads to further degradation.

That said, Makarieva, Gorshkov and colleagues (Makarieva \& Gorshkov, 2007; Makarieva, Gorshkov, \& Li, 2013) believe that, although GCMs take 
deforestation of tropical rainforests into account, they do not encapsulate all of the observed dynamics of rainforests and thus fail in producing realistic predictions. The Biotic Pump Theory (BPT) states that the major physical cause of moisture fluxes is not the non-uniformity of atmospheric and surface heating, but that water vapour is invariably upward-directed as a result of the rarefaction of air from condensation. The physical meaning of this behaviour results in densely vegetated forests "sucking-in" atmospheric moisture from the ocean with water vapour travelling from regions of lower evaporation and less condensation (donor regions, i.e. ocean) to regions of high evaporation and high condensation (acceptor regions, i.e. forested land). Extensive deforestation will hence lead to a tipping point where the forest cover is too sparse to exercise this mechanism, thereby engendering changes in the local and global water vapour regime (see figure 2 and graph 1). It is a moot question as to how large the deforested area must be before critical points are reached and the forest in the vicinity of the clearing degrades spontaneously. Avissar has suggested that the deforested area would be greater than $100 \mathrm{~km}$ across before such degradation occurred (personal communication, October 2002).

Figure 2. Deforestation leads to local changes in hydrology
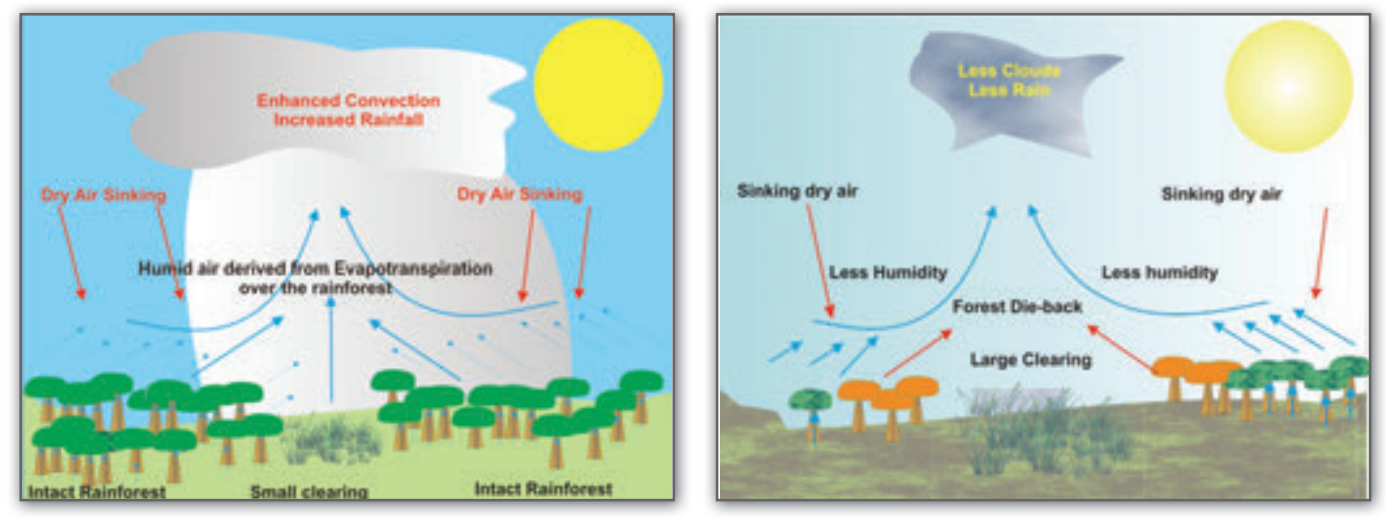

Source: Bunyard, 2011. 
Graph 1. Relationship between precipitation and deforestation

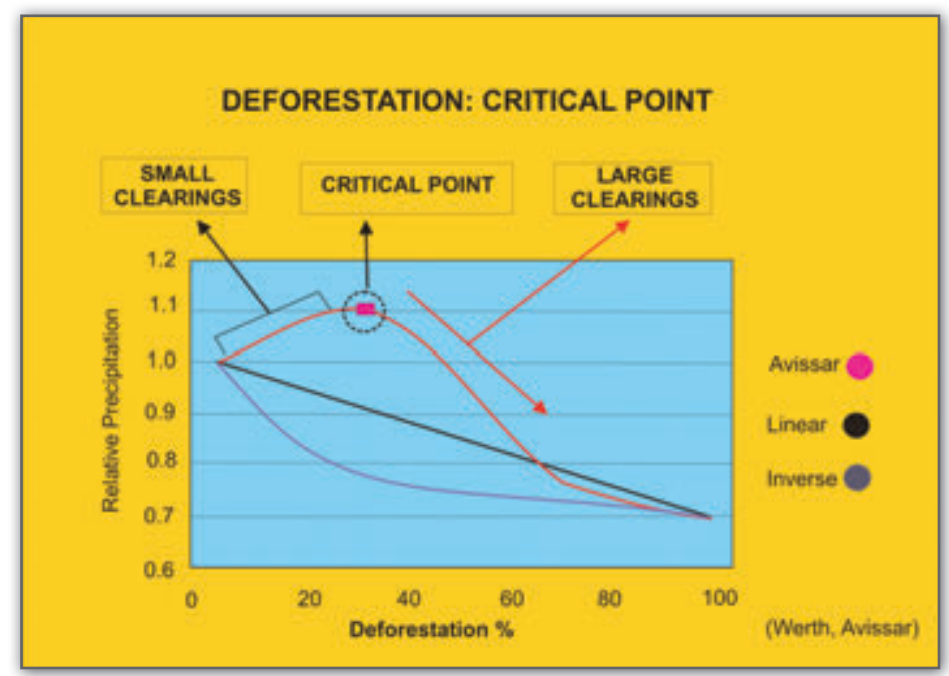

Note: The upper curve is that favoured by Avissar. Source: Werth and Avissar, 2002.

However logical the physics of the biotic pump, to-date the great majority of climatologists have ignored the theory or have vociferously denounced it as not fitting the meteorological facts. They base their rejection on the notion that whatever the dynamics of evaporation and condensation, with consequent changes in local pressure, the lower atmosphere quickly finds its hydrodynamic equilibrium and therefore will not be a factor in sucking in surface winds on a horizontal plane 2009 (Makarieva \& Gorshkov, 2009c; Makarieva, Gorshkov, \& Li, 2013). Makarieva, Gorshkov and colleagues rebut that widely-used idea of hydrological equilibrium, instead claiming that when the atmosphere contains significant quantities of water vapour, with partial pressures of the vapour providing 2.5 per cent and more of total barometric pressure at the surface, the lower atmosphere cannot physically be in dynamic equilibrium and the resulting vertical force is of sufficient strength to suck in surface air.

\section{Biotic Pump theory and history}

In recent years, primarily as a result of satellite imaging, the idea has taken hold that water vapour over the Amazon Basin and outlying regions, 
such as over the Chocó and western Caribbean, forms reasonably dense atmospheric rivers which flow along specific courses, such as in the South American low level jet stream, or in the low level current of air from the eastern Pacific Ocean to the west coast of Colombia and into the interior, (Poveda \& Mesa, 2000) or indeed in the flow from the western Caribbean, across Central America to the Pacific Ocean. But, whereas ground-based rivers are fed through rainfall and lose water through evaporation, atmospheric rivers gain water vapour through forest-derived evapotranspiration and lose it through precipitation.

Meanwhile, a handful of climatologists, including Germán Poveda of the Geosciences and Environment Faculty of the Colombian National University in Medellín, are seriously considering the biotic pump theory as a much needed mechanism to explain the movement of air currents over Latin America and the formation of atmospheric rivers. In a recent article, (Poveda, et al., 2014) Germán Poveda, who is a distinguished member of the IPCC and holder of the prestigious Gold Award for ground-breaking hydrological research in Colombia, together with his students, Liliana Jaramillo, and Luisa F. Vallejo provide evidence that when the low level jet streams pass over forested regions precipitation levels stay high and constant, whereas over regions which lack forest, precipitation levels decline exponentially, just as the biotic pump theory dictates should happen.

As part of their far-reaching study, Poveda and his colleagues look at the low level Chocó jet and comment that the change in direction of the Pacific Austral Trade Winds from Westerlies to Easterlies just over the Equator at $4^{\circ} \mathrm{N}$, may owe their abrupt switch in great part to the unsurpassed degree of evapotranspiration and subsequent condensation over the Chocó rainforest. Without question, the Chocó jet carries an extraordinary quantity of water vapour, some 3,774 cubic metres per second, the result of which are the highest run-off rates in the world, with the feeding of the Atrato and San Juan Rivers and their combined average streamflow of approximately 5,000 cubic metres per second. In fact, the Chocó low level jet is responsible for precipitation over the central part of Colombia as well as over some regions of Central America. It should certainly be of concern that piecemeal the Chocó rainforest is being destroyed to make way for African Palm and gold mining operations, with all the displacement of well-established Afro-Colombian communities that such 'development' implies. 
With more than 380,000 cubic metres per second of water vapour being brought in from the Tropical Atlantic Ocean, (Salati, 1987) the Amazon Basin functions on a far grander scale compared with the Chocó or anywhere else in the world for that matter. Given the extraordinary finding that average atmospheric levels of precipitable water are consistently higher over the western reaches of the Basin compared with the east, over the island of Fernando de Noronha, for example, it would appear not only that evapotranspiration rates are high over the rainforest, but that they actually pump sufficient water vapour into the atmosphere such as to increase the volume of the Amazonian atmospheric river in the form of the South American Low Level Jet Stream, as Bunyard has determined from calculating the precipitable water for a range of radio-soundings from different locations across the Amazon Basin all the way to Bogotá at 2,625 m; that being so, it provides further evidence of the vital functioning of the biotic pump (graphs 9 and 21, table 4).

The Amazon Rainforest is hence considered to play a vital role in maintaining the fragile equilibrium of global climate and its deforestation may therefore have a profound impact on local and global precipitation patterns. Figure 3 illustrates past and future deforestation extent over the Amazon basin as predicted by Soares-Filho et al., (2006). Forest cover for scenarios assuming (a) that recent deforestation trends will continue and (b) the Brazilian environmental legislation is implemented through the refinement and multiplication of current experiments in frontier governance.

Figure 3. Past and future deforestation extent over the Amazon basin

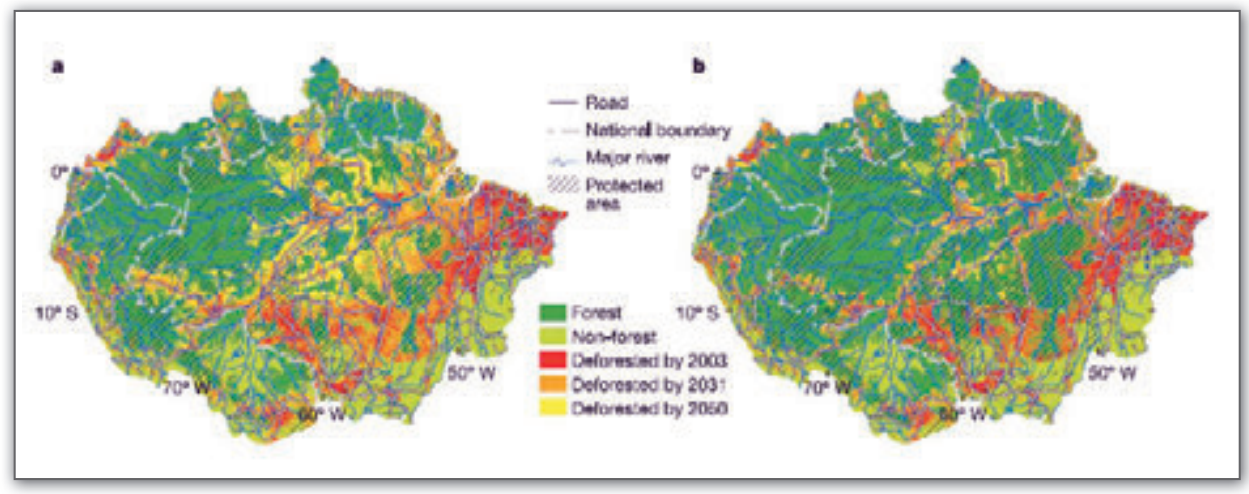

Source: Soares-Filho et al., 2006. 
Meanwhile, Spracklen and his colleagues (Spracklen, Arnold, \& Taylor, 2012) from Leeds University have shown from their recent pan-tropical study of rainfall and land-cover, as indicated by the leaf area index (LAI), that satellite-derived rainfall measurements are positively correlated with the degree to which model-derived air trajectories have been exposed to forest cover. Even though Makarieva and colleagues (Makarieva et al., 2014) have some essential criticisms of the methodology used by Spracklen, they conclude that the Spracklen results confirm the influence of forest on regional rainfall patterns. Indeed, as Makarieva and colleagues point out, rainfall occurs when moist air ascends and cools, so from simple mass balance considerations rainfall rate, $\mathrm{R}$, is equal to $\mathrm{R}=\mathrm{wq}\left(1-\gamma_{c} / \gamma_{s}\right)$, where $w, q$ and $\nu$ are, respectively, the upward air velocity, absolute humidity and water vapor mixing ratio at the level where condensation commences and $\gamma_{c}$ is mixing ratio at a height where condensation stops.

Clearly, other local factors may be involved in the processes of convection that lead to storm conditions, including the formation of cumulo-nimbus clouds. Heat differences, the result of a heterogeneous landscape, with natural and man-made breaks in forest cover, may lead to increased rainfall over deforested regions, at the expense of rainfall over the forest, even though it is the forest itself which, through evapotranspiration, has provided most of the local water vapour in the first place, as Garcia Carreras has shown for Africa and Ramos da Silva, Roni Avissar and others have shown for the Amazon (Garcia-Carreras \& Parker, 2011; Ramos da Silva \& Avissar, 2006). Such local impacts are similar to the generation of on-shore and off-shore winds, the former arising from the day-time heating up of the coastal land and the latter from the local sea retaining for longer its day-time warming compared to the land, which, with clear night skies, undergoes rapid radiative cooling (figure 4). 
Figure 4. On-shore and off-shore winds and how coastal forests extend inland penetration

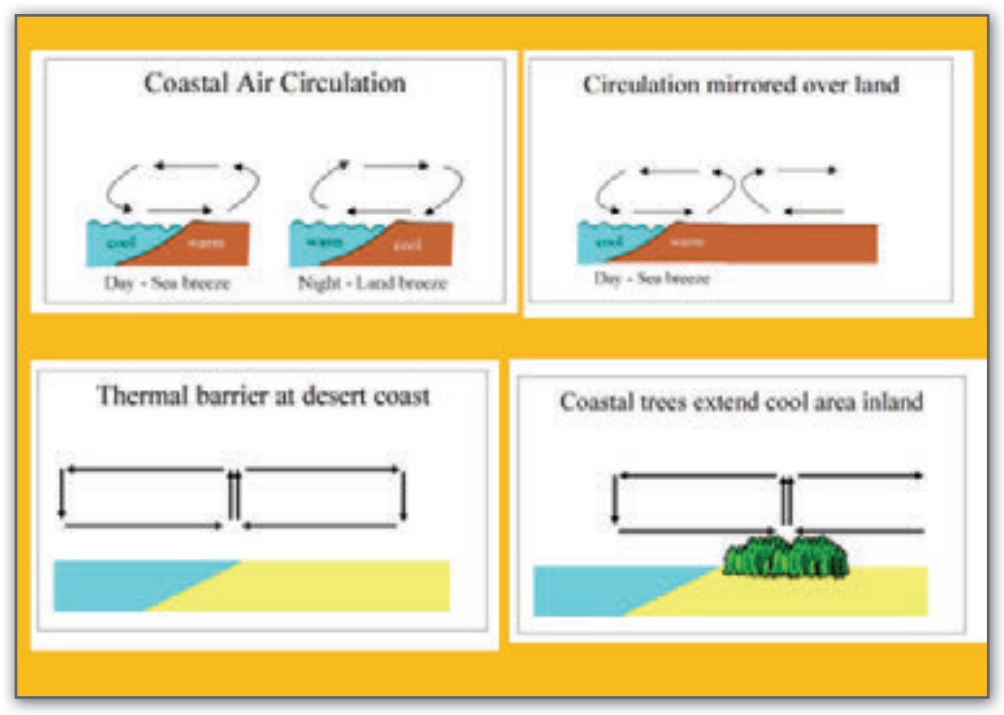

Source: Fletcher, 2012.

Nevertheless, it is important to stress, as Avissar and his colleagues have shown, (Roy \& Avissar, 2002) that once the degree of deforestation has exceeded a certain threshold or critical point, the remaining forest at the perimeter of the clearing may no longer have the capacity to provide sufficient water vapour such as to maintain humidity over the clearing and thereby feed into the convective process (figure 2). As a result, an excessively large clearing, on a scale of square kilometres rather than hectares, will leave the forest depleted of sufficient water resources to maintain adequate evapotranspiration. Excessive deforestation may then engender forest dieback and a positive vicious circle by which the dehydration penetrates beyond the forest edge and deeper into the interior. The overall impact of largescale deforestation causes 'edge-effects' whereby winds, no longer restrained by the trunks and foliage, penetrate into the flanking forest, causing it to dry out such that it becomes vulnerable to fire, whether from ignition sources such as lightning strikes or from man-made burnings that run out of control (Cochrane, et al., 1999; Cochrane \& Laurance, 2002). Certainly, the continuing degradation of the drought-affected regions of the Amazon, as clearly indicated in the plant available water (PAW) distribution graph, 
fits the bill of excessive deforestation having tipped the balance towards a vicious cycle of further degradation (figure 5).

Figure 5. Plant available water distribution (PAW)

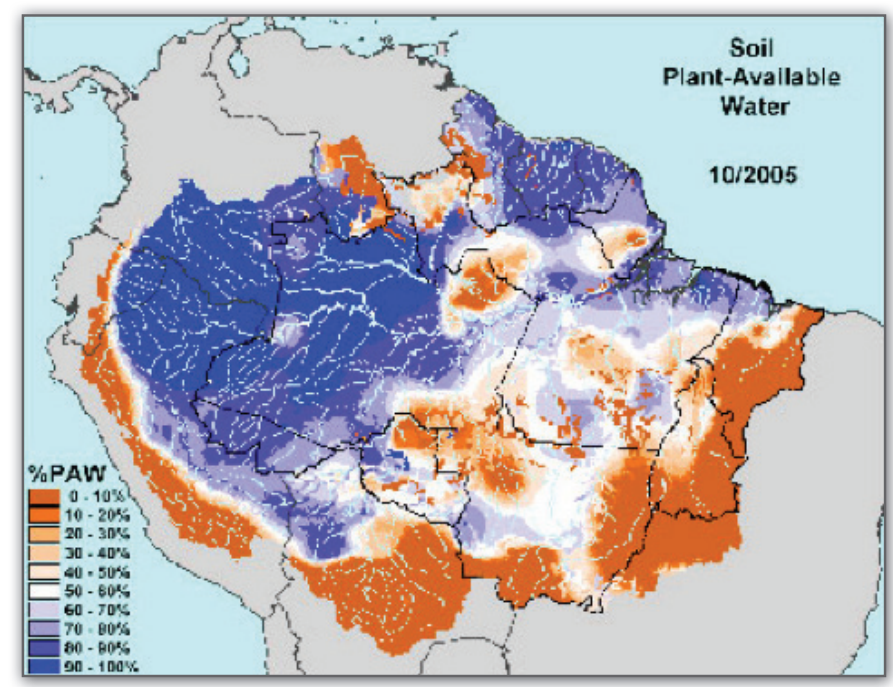

Source: Butler, 2010.

According to the WHRC, the above map is "a product of our ongoing drought monitoring effort from October, 2005, the worst month we have in our record going back to 1995. It shows moisture stored in the soil which is available for use by plants, what we call 'Plant-Available Water' or 'PAW', expressed as a percentage of the total water-holding capacity of the top $10 \mathrm{~m}$ of soil at any given point; \% $\%$ PAW is one of the strongest indicators we have of severity of drought and of forest susceptibility to fire.

Although the importance of the Amazon rainforest has been emphasized in an extensive collection of publications, the interaction of its vegetation on precipitation and global water vapour circulation is still poorly understood (Werth \& Avissar, 2002; Myneni et al., 2007). Not only the lack, but also the coarseness of available data over the Amazon basin makes evaluating the existence of the Biotic Pump mechanisms difficult. Available datasets covering the extent of the Amazon basin (mostly interpolated from local stations measurements) have horizontal resolution in the order of several $100 \mathrm{~km}$. At this scale, much of the sub-grid-scale features and dynamics, such as topographi- 
cal features, convective processes and hydrological processes, are lost (Roy \& Avissar, 2002).

Surface temperatures differences between the Equator and higher latitude regions, up to the Poles, mean that considerably more water will evaporate from surface water bodies in tropical and equatorial regions compared with the higher latitudes. In fact the evaporation of water follows an exponential curve with temperature, adhering closely to the ideal gas law of Clausius-Clapeyron which dictates atmospheric saturation with water vapour according to temperature. Essentially, a parcel of air, when saturated, will carry up to 4 times more water vapour at $20^{\circ} \mathrm{C}$ than will air at $0^{\circ} \mathrm{C}$ and air at $40^{\circ} \mathrm{C}, 15$ times more. That enhanced evaporation results in heavier downpours of rain in tropical regions compared with the high latitudes as well as the maintenance of a high rainfall of as much as 8,000-12,000 mm per year such as occur over the Colombian Chocó.

Naturally, how much water can evaporate depends partly (the other part is supplied by energy availability) on surface humidity which in turn is the result of rainfall and not least the capacity of vegetation to enhance evaporation through the process of transpiration whereby water is drawn up through the roots and is conducted, according to the principle of cohesion-tension, up the xylem from the roots and into the leaves from where it can escape via the stomata to the surface air (Cruiziat, 2006; Tyree, 1997). Pressure differences between the multitude of evaporating surfaces in the leaves, the water in the xylem and the interface between the soil and the roots, combined with the hydrogen-bonding characteristics of water, all critically maintained in a metastable state by the diameter and conducting form of the xylem and tracheids, provide the potential for water to flow upwards against gravity for as much as 40 metres, as enumerated in the Cohesion-Tension Theory (CTT). Closed canopy forest, in particular, can maintain a relatively constant stream of water vapour to the atmosphere on a diurnal basis because of the temperature inversion below the canopy which maintains a high relative humidity at ground level such as to prevent drying-out of the top surface of the soil (Collatz, Ball, Grivet, \& Berry, 1991). Deforested areas will therefore more easily dry out.

When the canopy is opened up through tree-felling, then the sunlight can penetrate to the surface and cause the soil to dry out by warming the 
surface layers such as to draw water upwards from the phreatic, groundwater zone. Intense exposure to sunlight and lack of rain may then lead to drought conditions (Kigomo, 2003). By contrast, closed canopy forests may not only prevent the degree of drying-out, but may actually encourage rainfall by maintaining humidity through evapotranspiration and by seeding cloud formation through the release of cloud-condensation nuclei (CGNs) which may include organic chemicals such as terpenes and isoprenes, as well as Pseudomonas and other bacteria species. Pollen, too, may help in the formation of clouds (Pöschl et al., 2010; Tyree, 1997).

How much rainfall depends on natural forests, with their closed canopies, has become a moot question for climatologists and hydrologists. Over the 3,000 km longitudinal stretch of the Amazon Basin, from the Atlantic Coast at the mouth-waters of the Amazon River, all the way westwards to the Andes Mountains, the rainfall remains high and even increases over the piedmont and up into the cloud forest. The isotopic studies of hydrogen and oxygen carried out by Eneas Salati and Peter Vose (Salati \& Vose, 1984) during the 1970s and 80s showed that between 50 and 75 per cent of rainfall over the Amazon rainforest was recycled through evapotranspiration, with the recycling of a water molecule taking place every 5.5 days on average such that the same water molecule may get recycled as many as 5 times just over the Legal Amazon of Brazil (Poveda, Bunyard, \& Nobre, 2008). On that basis, it would take up to one month for a molecule of water derived from the western tropical Atlantic Ocean, for instance close to Fernando de Noronha, to reach the piedmont of the Andes, on the assumption that it would be immediately recycled through evapotranspiration. That gives an easterly windspeed for the Walker Circulation over the surface of Amazonia of approximately $1 \mathrm{~m} / \mathrm{s}$ (Lettau et al., 1979).

The quantities of energy involved in the transformation of water into water vapour are prodigious. Over the Amazon Basin, the incidence of sunlight provides up to the equivalent of the energy released from 20 atomic bombs (each 15KT of TNT equivalence) per second; one can calculate that the transformation of that energy into water vapour absorbs the energy equivalent of 15 atomic bombs worth per second, hence up to 75 per cent of the incident sunlight (Bunyard, 2011). Put another way, as Antonio Donato Nobre has done: 
20,000 million tonnes of water are evapotranspired each day over the Legal Amazon of Brazil (5 million square kilometres), in comparison with 17,000 million tonnes of water that flow into the Atlantic Ocean via the River Amazon. The energy for that daily evapotranspiration is equivalent to the total energy production for 135 years of Itaipú, the largest hydroelectric plant in the world (Nobre, personal communication, 2006)

Simply because of the surface area covered, most evaporation and precipitation occur over the oceans, where 84 per cent of all evaporation and 74 per cent of precipitation take place. The 10 per cent difference between oceanic evaporation and precipitation consists of water vapour carried inland over the continents by prevailing winds. But whereas, no more than 6 per cent of rainfall over Arizona is of local continental origin and 10 per cent of rainfall over the Mississippi Basin, over the Amazon as much as 50 per cent of all rainfall is recycled within the Basin area (Salati, 1987; Brubaker, Dara, \& Eagleston, 1993). Thermodynamics and temperature differences undoubtedly play a significant part in the movement of the air masses across the planet. For obvious reasons of exposure to sunlight, the most powerful air mass movement resides in what is called the Hadley Cell circulation which operates in each hemisphere between the tropical extremities of the Tropic of Cancer and Capricorn and the Equator, with the actual solar Equator moving seasonally north and south of the geographical Equator. The trade winds form the returning limb of the Hadley Cell circulation, beginning their trajectory at the descent of the air mass over the eastern portion of the Cell and ending with the vertical convective movement of the air mass over the western portion.

In effect, the trade winds between Africa and South America skim the surface of the Tropical Atlantic and thereby accumulate vast quantities of water vapour by the time they have reached the Intertropical Convergence Zone (ITCZ) over the Amazon Basin. It is precisely that accumulation, as much as $12 \times 10^{12}$ metric tonnes per year (cubic metres), which provides the necessary precipitation for the maintenance of the humid tropical rainforests which stretch for more than 3,000 kilometres across the Basin and up the piedmont of the Andes to the cloud forests of the higher altitudes (Salati, 1987). 


\section{Botanical and biotic pump theory}

The thesis of Makarieva and Gorshkov implies that the evolution of trees and then closed canopy forests would have been a necessary stage in the development of the panoply of intra-continental life. That idea has also been advanced in relation to the evolution of angiosperms some 100 million years ago when Pangaea had begun its division into the continents as we know them today. In a recent publication of the Missouri Botanical Garden, (Boyce, Brodribb, Field, \& Zwieniecki, 2009), suggest that only with the arrival on the scene of angiosperm trees could rainforests, stretching for thousands of kilometres, survive the long distances from the coast.

Boyce and his colleagues note that:

Transpiration capacity is closely correlated with leaf vein density, and the average vein density of angiosperm leaves is four times greater than that of all other plants, living or extinct. A rapid transition to high vein densities occurred separately in three or more flowering plant lineages about 100 million years ago. Climate modelling of the impact of this physiological revolution indicates that the tropics would be hotter, drier, and more seasonal in the absence of the angiosperms, and the overall area of tropical rainforest would decline substantially. Because angiosperm diversity is influenced by rainforest area and by precipitation abundance and evenness, the high diversity of angiosperms is partially a product of a positive feedback loop with the climate modifications initiated by the angiosperms themselves. Lineage diversifications among vertebrate and invertebrate animals and non-angiosperm plants in the wake of the angiosperm radiation may be tied to the unprecedented impact of angiosperms on climate (Boyce, Lee, Field, Brodribb, \& Zwieniecki, 2010, p. 527).

Boyce, and his colleagues continue:

The changes in plant physiology heralded by greatly increased leaf vein density suggest that:

The radiation of angiosperms was accompanied by more than a doubling of photosynthetic capacity and approximately a fourfold increase in transpirational capacity (Boyce, et al., 2009) on a leaf 
area basis. The impact of these changes on the global carbon and hydrologic cycles is likely to have been profound. Because the recycling of rainfall through evapotranspiration can be an important contributor to precipitation, any increase in transpiration capacities that accompanied angiosperm evolution should strongly influence climate, particularly in the tropics and during the growing season at higher latitudes (Boyce, et al., 2010, p. 529).

They conclude:

The influence of transpiration on climate is largest in South America where the projected loss in annual rainfall in the absence of angiosperms can be greater than $1500 \mathrm{~mm}$ per year (Boyce, et al., 2010, p. 529).

The explanation by Boyce and his colleagues as to how the evolution of the vascular plants led to the interior watering of the continents lacks the physical pumping process resulting from condensation. The biotic pump theory of Makarieva and Gorshkov therefore provides the actual mechanism by which angiosperm forests in the tropics would have maintained a high rate of precipitation across a continent, with the prime example being the Amazon Basin. Put simply, the theory provides the mathematical tools to calculate what Makarieva and Gorshkov call "the evaporative-condensation force" or even more graphically "the biotic pump" (Makarieva \& Gorshkov, 2007).

Biologists have debated at length over what happened to the Amazonian rainforests during the Pleistocene and presumably during other ice-ages before then. Haffer in 1969 and later supported by Van Der Hammen and Absy in 1994 came up with the notion that the cooler oceans would have evaporated less water into the atmosphere compared with warmer climatic spells and the inter-glacials. Hence, they argued that the rainforest dried out and was largely replaced by savannah, nevertheless leaving behind spots of rich biodiversity to which they gave the name 'biological refugia'. Some of those biological refugia were supposedly in the western Amazon, therefore far from the ocean to the east (Haffer, 1969; Maslin, Ettwein, Boot, Bendle, \& Pancost, 2012; Van der Hammen \& Absy, 1994). 
Doubts have arisen as to whether such refugia truly existed (Maslin et al., 2012) but, if they did, the fact of their existence would be a challenge both to the biotic pump theory, which essentially maintains that the forests to the west of the Amazon Basin depend for the transport of recycled water vapour on a contiguous extension of forests to the east, and on the supposition of Boyce and Lee that the evolution of a relatively high leaf vascular system to leaf area in angiosperms led to the maintenance of a high rate of evapo-transpiration even under cooler, drier conditions, as long as water could be mined effectively by a deep-rooting system.

Axel Kleidon (2004), suggests that the rainforests will have optimised conditions through the high rate of evapotranspiration and deep roots such as to buffer the climatic switches between glacial and inter-glacial periods. Daniel Nepstad (et al., 1994), from his field studies in Amazonia has found the rainforest to be deeply-rooted in certain areas and has suggested that phreatic resources of water as near the surface as two metres, will contribute substantially to dry season transpiration. Meanwhile, Kleidon and Heimann have demonstrated from climate modelling that continuous transpiration during the dry season leads to a more vigorous hydrological cycle, thereby affecting large scale atmospheric circulation (Kleidon \& Heimann, 2000).

Satellite-imaging of the leaf area index (LAI) during different seasons over the entire Amazon Basin indicates that the rainforest actually augments the LAI by as much as 25 per cent during the dry season, thus anticipating the increased insolation which will accrue from clear or less cloudy skies. In the Proceedings of the National Academy of Sciences, Myneni R. B. and his colleagues argue that the enhanced LAI will lead to a higher rate of transpiration compared with the rainy season and will therefore kick-start the process of convection, with the net result of drawing in humid air from the ocean to replace that moving upward in the vertical plane (Myneni et al., 2007; Negrón et al., 2008). It must be said, however, that reflected infra-red light and the angle of the satellite image may distort significantly the seasonal change in LAI, thus casting some doubt on the conclusions reached by Myneni and his colleagues. (Morton et al., 2014). From Morton and his colleagues' analysis, it appears that light for photosynthesis is not the limiting factor for forest productivity, whatever the season. Moreover, as Gorshkov and Mariekeva indicate, the forest as a whole has evolved to function at an 
optimum rhythm in its need for both light and water, while exerting some control over near-surface humidity through regulated evapotranspiration (personal communication, 2014).

An important finding from Kleidon's climatic model is that increasing values of ET (evapotranspiration) during the drier, cooler conditions of a glacial period, largely maintain inland precipitation, thereby decoupling it from the oceanic source of moisture. Both the modelling and empirical data put into question the tenet that the Amazon Basin converted to savannah during the Pleistocene and that the current form of the Amazonian rainforests was derived from pockets of biodiversity known as 'biological refugia' (Kleidon, 2002).

Graph 2. Annual Variation of Leaf Area Index (LAI)

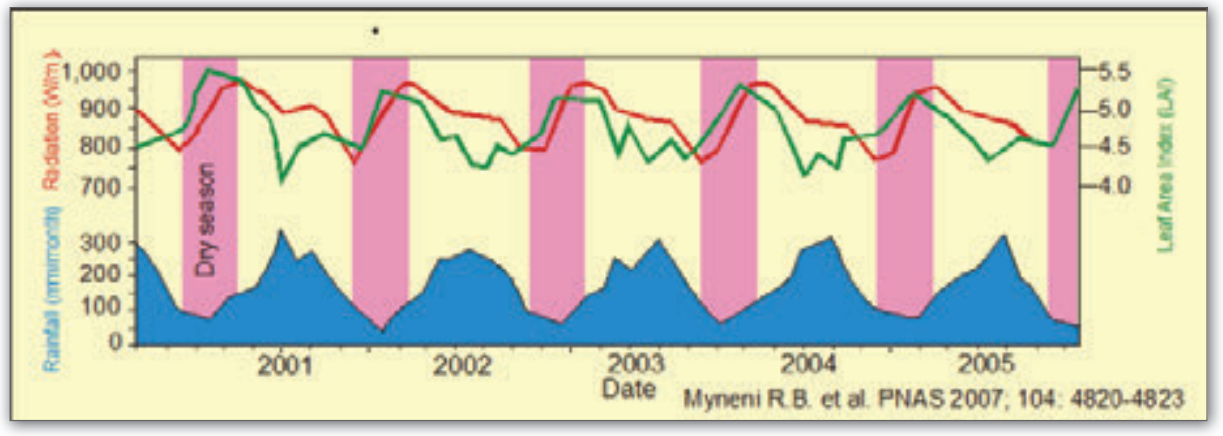

Source: Myneni et al., 2007.

According to Myneni et al., (2007) the Amazonian rainforests anticipate the dry season by increasing their Leaf Area Index (LAI) by one quarter. Some doubt has now been cast on that phenomenon. Nevertheless, the forest functions at an optimised rhythm in its need for light and water, the latter contingent on the functioning of the biotic pump.

Sharon Cowling and her colleagues have also modelled the impact of a cooler climate, combined with lower $\mathrm{CO}_{2}$ concentrations in the atmosphere, on plant physiology and their models indicate that broad-leafed angiosperm forests, with their closed canopy, would better 'weather' such climate conditions than would savannah. In one set of experiments with the UK Hadley Centre climate model, HadGM3, coupled to a vegetation model, 
Cowling showed (figure 8) that were the Amazon Basin to lose 35 per cent of its forest cover, from 85 per cent to 50 per cent, then average evapotranspiration would fall by 50 per cent or so: from an average of some $4 \mathrm{~mm} / \mathrm{d}$ to less than $2 \mathrm{~mm} / \mathrm{d}$. Such conclusions would indicate that the rainforest's best strategy in resisting climate change is to maintain its ecological structure as intact as possible. Conversely, deforestation will inevitably increase the remaining forest's vulnerability to climate change and potentially lead to the demise and therefore transformation of the entire ecosystem (Cowling, Maslin, \& Sykes, 2001; Cowling, Shin, Pinto, \& Jones, 2008).

Graph 3. Evapotranspiration and its relationship with broadleaf cover and precipitation
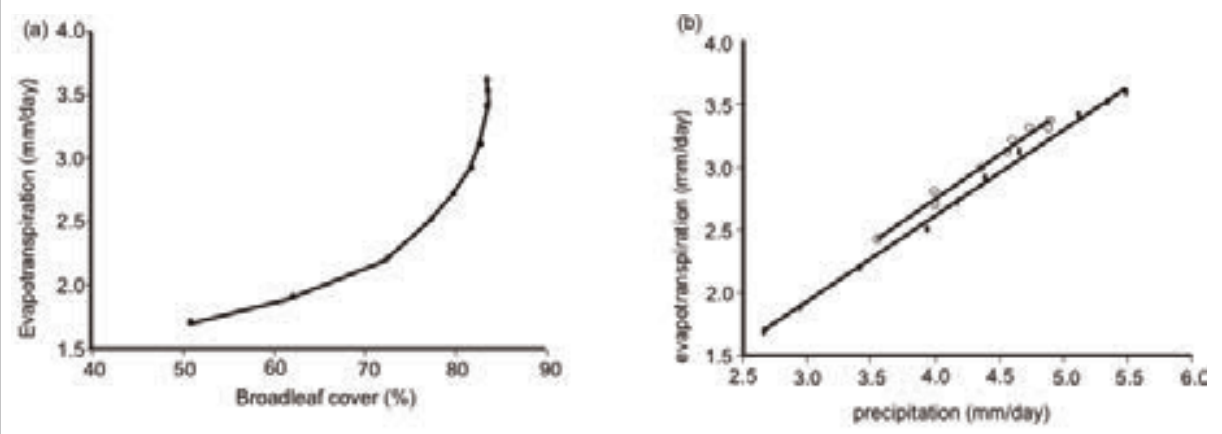

Source: Cowling et al., 2008.

The graph of (a) rate of ET $\left(\mathrm{mmd}^{-1}\right)$ versus per cent broadleaf cover for our coupled simulation $\left(\mathrm{r}^{2}=0.95\right)$ and $(\mathrm{b})$ rate of ET $\left(\mathrm{mmd}^{-1}\right)$ versus precipitation $\left(\mathrm{mmd}^{-1}\right)$ for both coupled $\left(\mathrm{r}^{2}=0.997\right.$; filled circles, $\mathrm{P}$ versus ET-coupled $)$ and uncoupled $\left(r^{2}=0.984\right.$; open circles, $P$ versus ET-uncoupled) simulations. Solid lines, regression plot.

\section{Physiological functioning of stomata}

The density of stomata in a leaf, depending on species and external factors, such as the atmospheric carbon dioxide content, may vary between 1,000 and 60,000 per square centimetre of the leaf surface. Monocotyle- 
dons tend to have equal densities and hence numbers of stomata on both leaf surfaces, whereas dicotyledons tend to have more stomata on the lower leaf surface (abaxial). Stomata vary in width between 3 and 12 micrometres and in length between 10 and 14 micrometres. Perhaps the evolution of abaxial stomata confers benefits to the plant in question through enabling evapotranspiration at temperatures which cause the upper surface stomata to close. That way, in the rainforest for example, vegetation can maintain humidity at ground level.

Graph 4. Relationship between the net evaporative/condensation force (hPa/km) and water vapour pressure deficit (VPD)

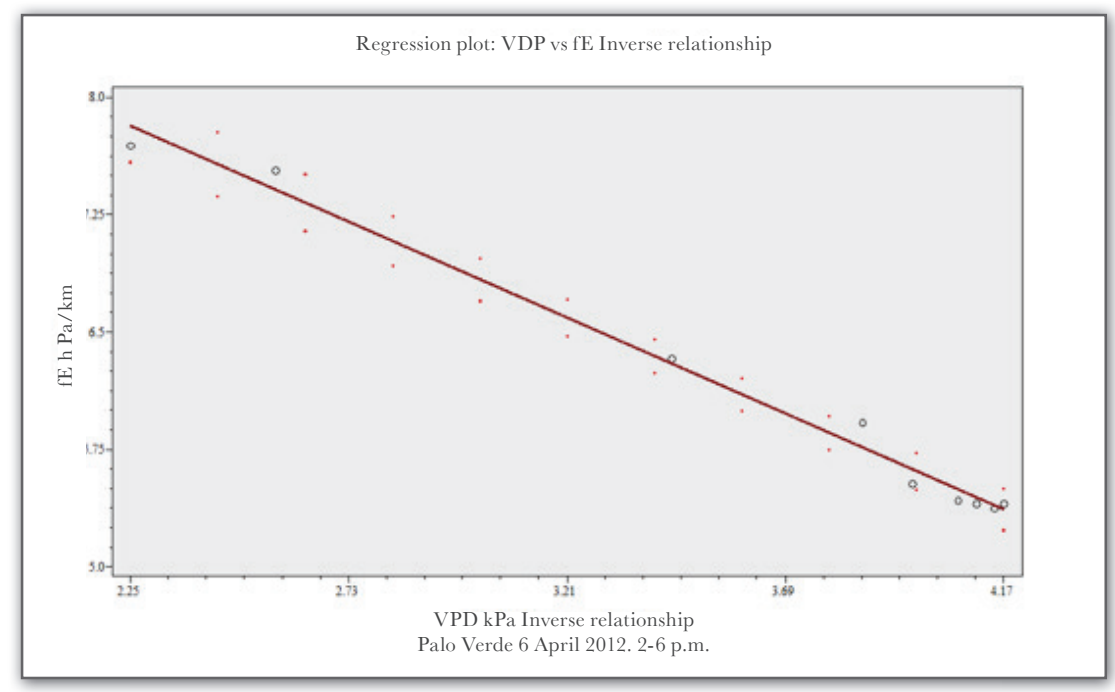

Note: The meteorological data taken from Palo Verde, Costa Rica, 6 April 2012. Source: Author.

Each stoma has two 'guard' cells which effectively open and close the pore through changes in the osmotic pressure as governed by intakes or secretions of potassium ions. When potassium ions flow into the guard cell, the osmotic pressure increases and water flows in from the surrounding mesophyll cells, thereby increasing turgidity such that the guard cell changes shape, becoming rounder, and hence opens. With the outward flow of potassium ions, the guard cells become flaccid and more elongated such as to close the pore. The positive charge of the potassium, $\mathrm{K}^{+}$, is balanced by an 
intake of chloride ions, $\mathrm{Cl}^{-}$, and the formation of malate from the hydrolysis of starch.

\section{Figure 6. Stomata guard cell}

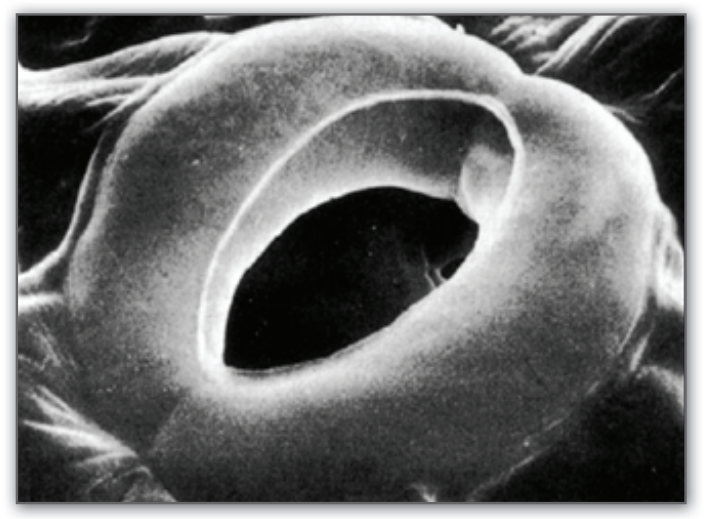

Note: Stomata guard cells, showing how, when turgid, they open fully, allowing interchange of water vapour and carbon dioxide. Source: Kishore, February, 2010.

In general, stomata tend to open with increasing temperatures, but above $30^{\circ} \mathrm{C}$ may shut down. If that is the case, then it would help explain why we obtain a sudden surge in the water vapour partial pressure as the temperature falls from its peak of $33^{\circ} \mathrm{C}$ to temperatures below $30^{\circ} \mathrm{C}$. In graph 4 we see that as the water vapour pressure deficit increases from more than $2 \mathrm{kPa}$ (kilopascals) to $4 \mathrm{kPa}$ so does the surface humidity (absolute humidity indicated as the evaporative/condensation force, $\mathrm{hPa} / \mathrm{km}$ ) decline. The suggestion is that the marked reduction in surface partial pressure of water vapour as the VPD rises may be a consequence of the stomata closing so as to prevent cavitation in the water-bearing xylem channels in the vegetation. However, as seen in figure 7 below, Feller (2006) suggests that stomata may open under hot conditions, even though no photosynthesis takes place on account of the inactivated state of Rubisco.

Water Use Efficiency (WUE) is generally taken to mean the net gain in dry weight divided by the water loss, whether just from vegetation or from vegetation and soil combined, over a given period. The WUE is usually measured for crops and therefore the word 'loss' creeps into the equation, as if water loss is a trade-off of biomass growth. As we discussed above, the 
so-called water loss is an essential component of the hydrological cycle, especially over closed-canopy forests, where the 'loss' of water in one locality will become essential rainfall in another, maybe as much as 600 kilometres distant. In fact, experiments on various crops, including spring wheat, soya beans and citrus fruits show that a doubling of ambient atmospheric $\mathrm{CO}_{2}$ will lead to a daytime WUE that may be double that brought about through current $\mathrm{CO}_{2}$ (400 ppmv).

Environmental conditions therefore play an important role in terms of feedbacks between vegetation and the hydrological cycle. We must be well aware that whatever agronomists and plant physiologists determine for monoculture crops grown under particular conditions may well not apply to native humid tropical rainforests where as many as 200 different tree species may be found per hectare.

Figure 7. Effects of heat on Rubisco activase, Rubisco activation state and Calvin cycle activity

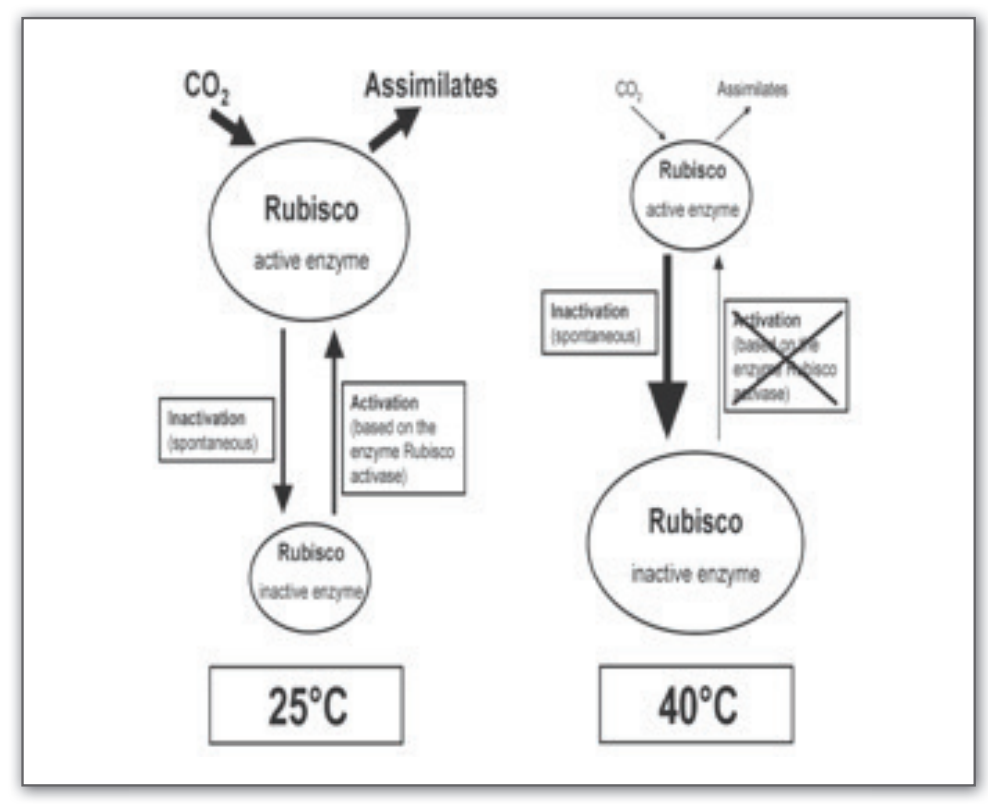

Source: Feller, 2006. 
Figure 8. Process of transpiration of plants

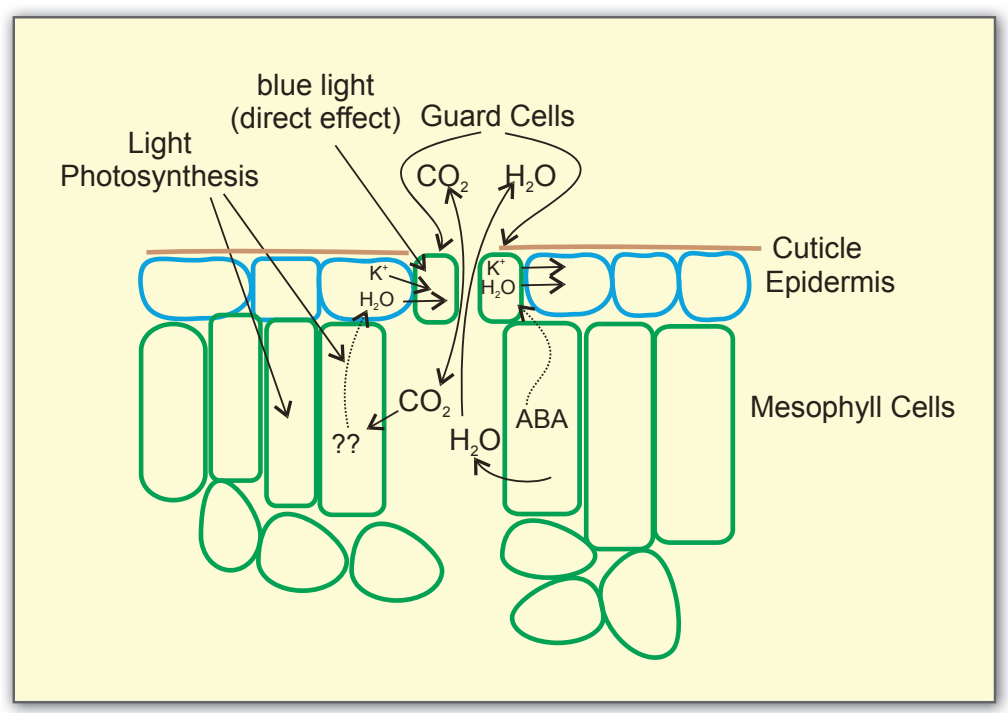

Source: Feller, Anders and Mae, 2008.

Blue light perceived by Guard Cells may result in $\mathrm{K}^{+}$ions being actively pumped into the guard cells, thereby increasing osmotic pressure such that the cells increase their turgor and in so doing open up. When the water potential declines in the leaf (as a result of water stress), $\mathrm{K}^{+}$ions and water exit the guard cells and the stomata close. Abscisic acid (ABA) induces stomatal closure under water stress.

The prime purpose of the research undertaken by the author is to determine whether the partial pressure force derived from surface concentrations of water vapour (specific humidity), followed by condensation at some $4 \mathrm{~km}$ altitude, could be responsible for drawing-in local winds. Given the millions of square kilometres covered in Amazonian rainforests, with as much as $5 \mathrm{x}$ $10^{12}$ cubic metres evapotranspired per year, those winds would become sufficient in size to comprise a significant component of mass circulation systems such as embodied in the Hadley Cell circulation and surface Trade Winds.

Meanwhile, the research carried out on meteorological data from the Organization of Tropical Studies (OTS) Biological Stations in Costa Rica indicates a close relationship between surface winds and $\mathrm{f}_{\mathrm{E}}$, the evaporative/ condensation force $(\mathrm{hPa} / \mathrm{km})$, with an average of some ten peaks and 
troughs during daylight hours. Temperature changes during daylight hours undoubtedly play their part, in affecting the opening and closing of the stomata and, as the temperature increases, permitting an increased concentration of water vapour. An important and necessary component of the research is to determine whether the peaks and troughs encountered in the daytime water vapour partial pressure measurements can be associated with vegetation- and therefore stomata-regulated fluxes of water vapour. If that were shown to be the case and the relationship between changes in wind speed and the partial pressure evaporative force were seen to hold that would give validity to the thesis that a biotic pump is an essential component of the hydrological cycle and, moreover, that vegetation controls air flows in a far more direct and powerful way than has been recognised to date, especially in the Tropics.

Table 1. Data from La Selva, Costa Rica

\begin{tabular}{|l|c|c|c|}
\hline \multicolumn{1}{|c|}{ Date } & $\begin{array}{c}\text { Evaporative/condensation } \\
\text { force }(\mathbf{h P a} / \mathbf{k m})\end{array}$ & $\begin{array}{c}\text { Windspeed } \\
\mathbf{m} / \mathbf{s}\end{array}$ & $\begin{array}{c}\text { Temperature } \\
{ }^{\mathbf{0}} \mathbf{C}\end{array}$ \\
\hline October & 10.06 & 9.94 & 9.55 \\
\hline November & 10.47 & 9.87 & 9.9 \\
\hline December & 10.42 & 10.68 & 9.74 \\
\hline January & 10.35 & 10.52 & 9.58 \\
\hline February & 10.14 & 10.29 & 9.68 \\
\hline March & 10.29 & 10.29 & 9.84 \\
\hline April & 10.39 & 10.35 & 9.71 \\
\hline
\end{tabular}

Source: Author.

The table 1 gives the average monthly rates of peak change of the evaporative/condensation force, $\mathrm{f}_{\mathrm{E}},(\mathrm{hPa} / \mathrm{km})$, of windspeed $(\mathrm{m} / \mathrm{s})$ and of temperature $\left({ }^{\circ} \mathrm{C}\right)$ between the daylight hours of 6:00 and 19:30. For instance, from one day's results as seen in graph 5 and graph 6 below, we obtain some 9 to 11 peaks for both variables, namely $\mathrm{f}_{\mathrm{E}}$ and windspeed. The extraordinary consistency of the number of peaks for all three variables, with a closer correlation between $\mathrm{f}_{\mathrm{E}}$ and windspeed, suggests that the vegetation, hence tropical rainforest, may be the controlling factor through physiological regulation of the stomata. 
Graph 5. Comparative slope change of $\mathrm{f}_{\mathrm{E}}$ and surface wind

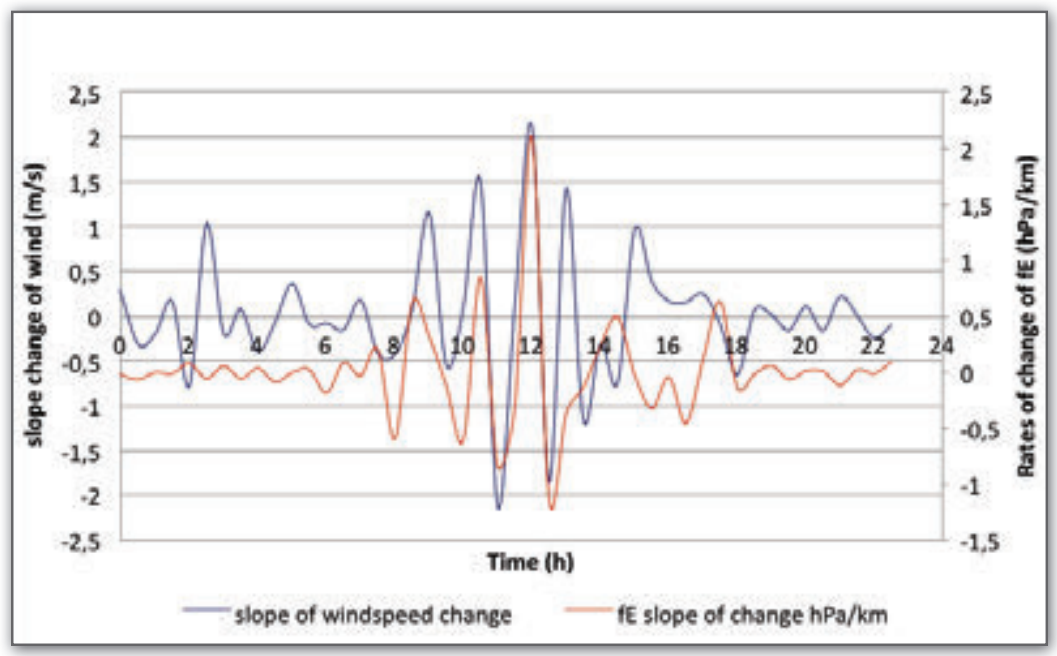

Note: This graphic shows the peaks and troughs of the rates of change of $\mathrm{f}_{\mathrm{E}}(\mathrm{hPa} / \mathrm{km})$ and windspeed. Source: Author.

Graph 6. La Selva, Costa Rica. Comparative slope change of $f_{\mathrm{E}}$ and surface wind

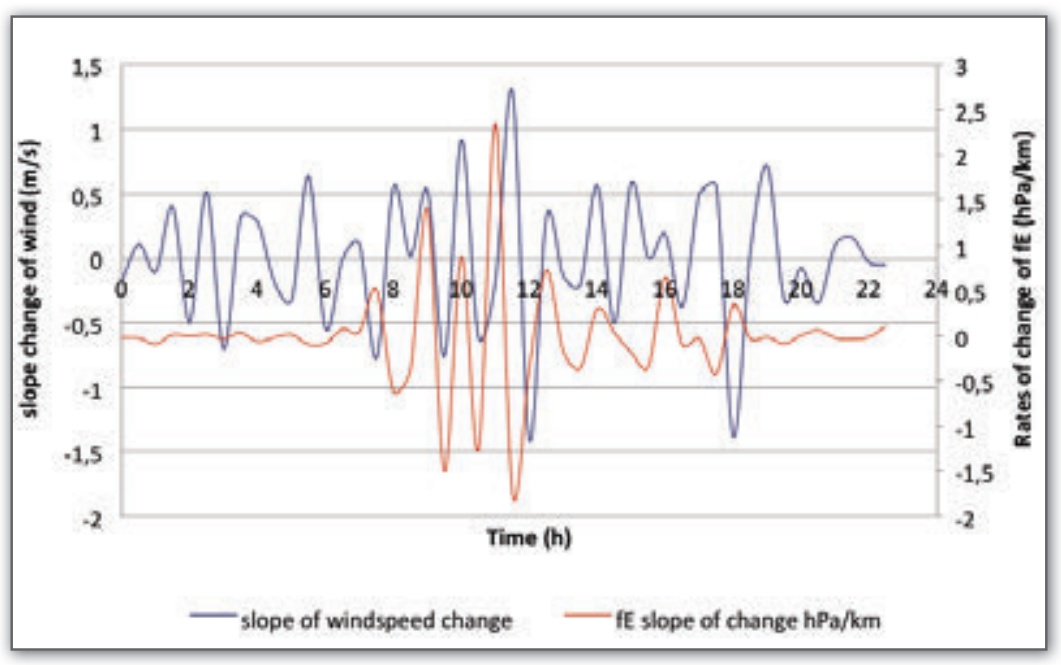

Source: Author. 


\section{Ghapter 2}

\section{BIOTIC PUMP THEORY: SEEKING PROOF}

\section{Method}

$7 \mathrm{O}$ prove the biotic pump theory and its relevance to deforestation, it has not been enough to gather meteorological data from specific sites in the tropics, such as from La Selva in Costa Rica, even though such data show undeniable correlations between changes in surface humidity during daylight hours and changes in surface airflow (table 1). To answer the obvious question as to whether we can determine that condensation must, by the laws of physics, result in surface air flow, we have therefore devised a set of experiments to measure surface airflows consequent to water vapour condensation. Preliminary results indicate that the rate of condensation as calculated from the changes in the partial pressure of water vapour in the enclosed air columns significantly affects the airflow. Furthermore, the kinetic energy of partial pressure change as well as air density change, as calculated from temperature and humidity data, gives a highly directional windspeed, which mirrors quite precisely the air movement detected by a 2D ultrasonic anemometer (Gill Windsonic). In essence, before the compressor is switched on, airflow is minimal, then within less than a minute of switching on, the air begins to flow, as determined by anemometers and judiciously placed strips of light gauze which can be monitored through web cams. Figure 9, shows the equipment used. 
Figure 9. Equipment used for the experiment

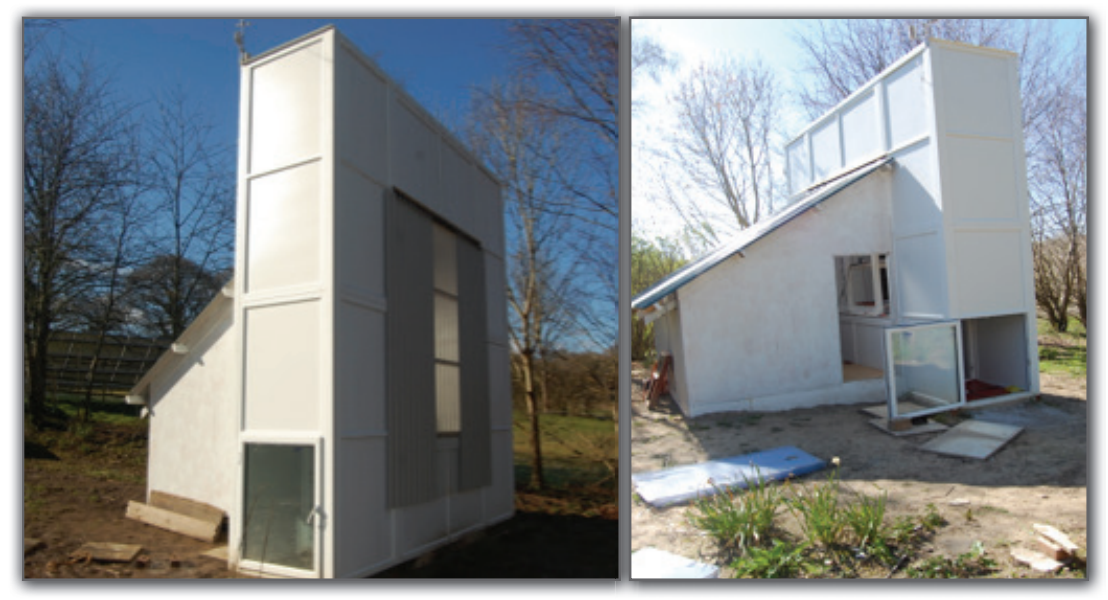

Source: Author.

A physical experiment, in which atmospheric air is enclosed in two interconnecting 4.8 metres high insulated PVC columns, consistently gives results showing that the condensation of water vapour, precipitated by means of refrigeration coils, gives rise to detectable air movements, with air speeds of up to $0.2 \mathrm{~m} / \mathrm{s}$. Calculations of the expected air speed from straightforward kinetic physics give excellent correlations with the actual anemometric measurements, using a sensitive 2D ultrasonic sensor (Gill) (see graphs 7 and 8). Once the compressor, sited well away from the two columns, is shut down, heavy drops of precipitated water are obtained which funnel into a flask for collection and measurement. The results in kg.m $\mathrm{m}^{-2}(\mathrm{~mm})$ from the $20 \mathrm{~m}^{3}$ volume of enclosed air accord well $(>90 \%)$ with the physical calculations based on water vapour as an ideal gas. Air flow, resulting from the highly localized condensation, is measured through the movement of light-weight gauzes and anemometers. It has a circulation time of some two minutes, such that both columns show cooling and a significant reduction in specific humidity from 0.01 to 0.005 ( $\mathrm{kg}$ water vapour to $\mathrm{kg}$ dry air, $r$ ) with a drop in relative humidity of up to 40 per cent. Air flow is minimal during the control, non-refrigeration period of the experiment but becomes substantial within a minute of the compressor being switched on. The negative partial pressure change peaks at as much as $0.4 \mathrm{~Pa} / \mathrm{s}$ during the first 30 minutes but reduces to approx. $0.08 \mathrm{~Pa} / \mathrm{s}$ during the latter part of the 110 minute-long experiment. Airflow 
displays an inverse relationship to the partial pressure change, initially rising rapidly and then reducing before returning to zero once refrigeration has been switched off. Inverse correlations of up to 0.8 or higher between the partial pressure reduction and the airflow are obtained routinely. Semi-aquatic vegetation from the nearby marshland enhances precipitation, suggesting that evapotranspiration adds significantly to humidity. Overall, the partial pressure change during the course of condensation may amount to as much $16 \mathrm{hPa}$. That change accords well with that expected from cloud formation $(20 \mathrm{hPa})$ over the humid tropics (Makarieva et al., 2013) and it indicates that the small scale of the experiment may give results that can be scaled up to the outer low level troposphere.

Figure 10. Scheme of the equipment used for the experiment

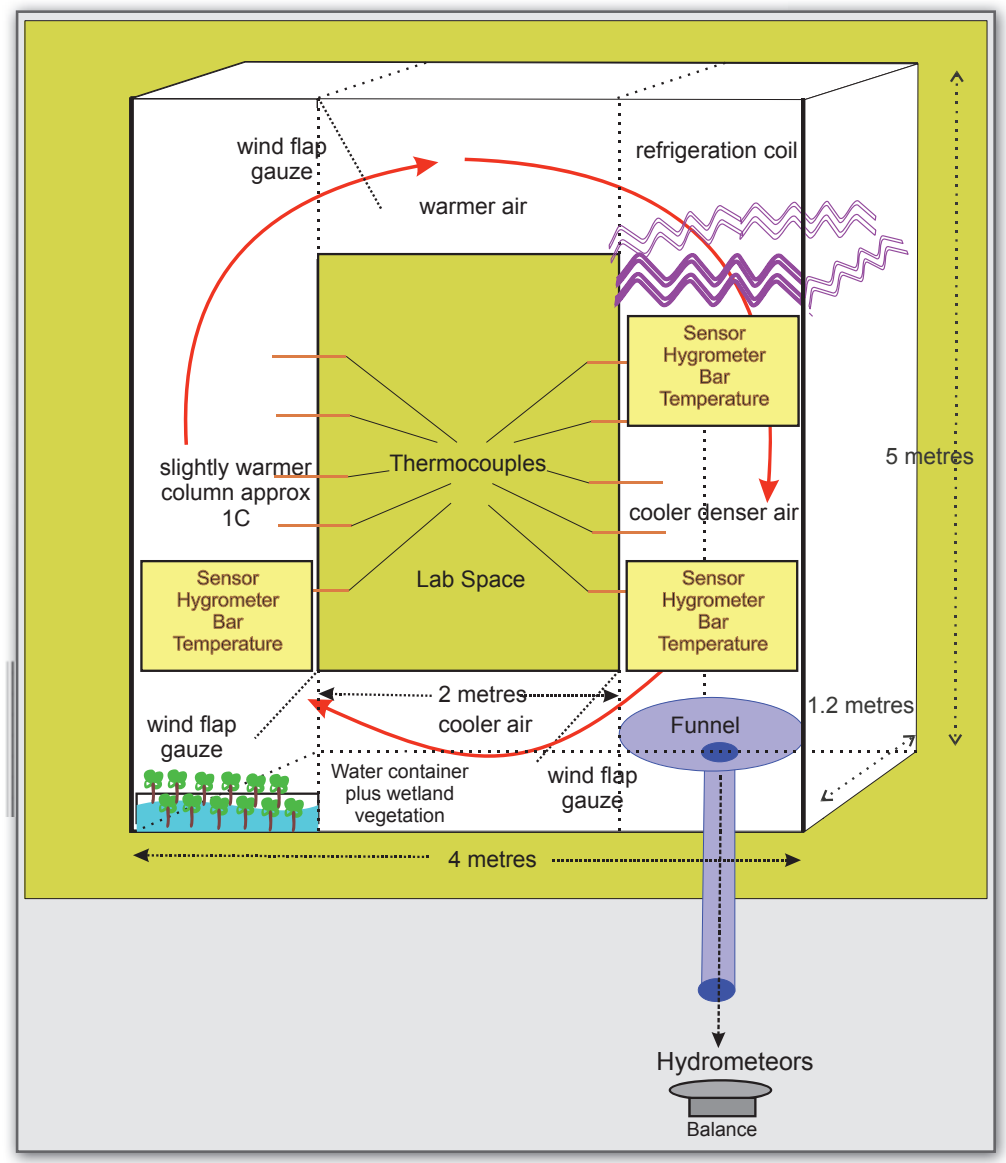

Source: Author. 
Without vegetation the condensation rate is 0.06 to 0.07 millimol. $\mathrm{m}^{-3} \cdot \mathrm{s}^{-1}$ on average compared with 0.11 when vegetation is present. Cooling, by some $2^{\circ} \mathrm{C}$, combined with a reduction in water vapour, by 6 grams $/ \mathrm{m}^{3}$ during the course of the experiment, leads to differential increases in air density. The latent heat released during condensation tends to warm the air in the immediate vicinity of the coolant coils and as such would tend to counter the clockwise air-circulation, the assumption being that the highly localized partial pressure reduction on condensation is the overriding force. The experimental data accords well with data from Costa Rica, where, for the past three years, daily meteorological data have been collected from two OTS sites, namely La Selva and Palo Verde, the former in particular displaying relatively high rates of evapotranspiration. Statistically high correlations are found between the calculated evaporative/condensation force $f_{\mathrm{E}}$, and corresponding surface wind movements. Those findings, combined with the experimental data, suggest that a high rate of condensation and the consequent partial pressure reduction at the scale of the lower troposphere leads to horizontal surface airflows of the order of $1 \mathrm{~m} \cdot \mathrm{s}^{-1}$.

In this experiment, with three condensing cycles (blocks), we show the tight correlation between the theoretical and actual windspeeds. The calculated kinetic windspeed (watts $=0.5$ area*air density*velocity cubed) is an ideal solution and takes no account of frictional and turbulent forces. Hence it is approximately double that of the actual windspeed. The trendlines, 5 per moving average are red for the anemometer and black for the calculated airflow.

Graph 7. Experiment with three condensing cycles

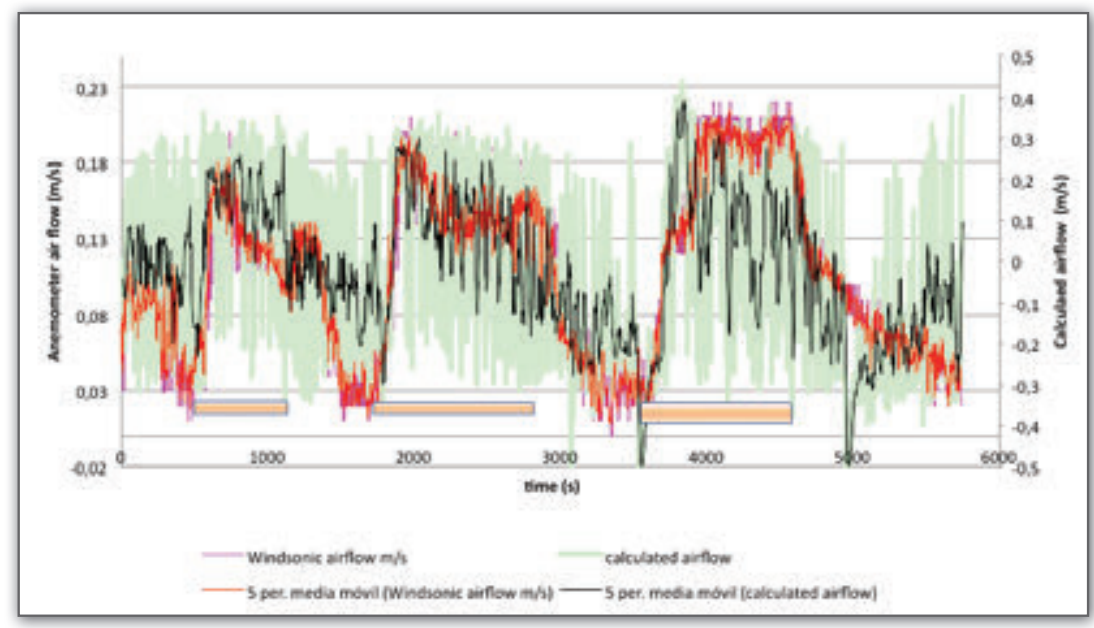

Source: Author. 
Three condensing cycles, again showing close correlation between the airflow as measured and that calculated from kinetic principles. The red indicates anemometer speed and black, the calculated airspeed.

\section{Description}

If we consider the Trade Winds, which pass in each hemisphere from the higher tropical latitudes, $\left(27^{\circ}\right)$ in the northern hemisphere from the Sahara, and in the southern hemisphere from the Kalahari, therefore in a north-easterly and south-easterly direction respectively, we find that the respective Trade Winds from the two hemispheres converge in the Inter-tropical Convergence Zone - ITCZ - over the Amazon Basin. From radio-soundings over different locations and using the equations as indicated in the flow chart (figure. 15), we can then determine that an evaporative/condensation force gradient (Makarieva \& Gorshkov, 2007) literally follows the equatorial trajectory of the winds, such that from the source of the Trade Winds in the desert regions of West Africa to the ITCZ and beyond to the Andes, the difference amounts to a force of as much as 8 hectopascals per kilometre, which - in meteorological terms - is a significant force when maintained over a large distance of several thousand kilometres. In the horizontal plane a barometric difference of a few hectopascals over a 100 kilometres or so may result in an acceleration of the air stream such as to result in storm force winds.

The locations are as follows, with data provided by the University of Wyoming. For each site (when available) the data was then downloaded and elaborated on a daily basis since January 2011 and including historic data from previous years, for instance for Leticia, Manaus and Tres Esquinas during the El Niño phenomenon of early 2010, as well as during 2005, the year of the great Amazonian drought (to be followed by a more extensive drought in 2010).

Thanks to free availability provided by the University of Wyoming, Radiosonde data has been obtained for the following sites: 
Table 2. Radiosonde data sites

\begin{tabular}{|c|c|c|c|}
\hline \multirow[t]{2}{*}{ SITE } & \multirow[t]{2}{*}{ PLACE } & \multicolumn{2}{|c|}{ COORDINATES } \\
\hline & & LATITUDE & LONGITUDE \\
\hline In Salah (60630) & $\begin{array}{l}\text { (Sahara Desert, } \\
\text { Algeria) }\end{array}$ & $27^{\circ} 12^{\prime} \mathrm{N}$ & $002^{\circ} 28^{\prime} \mathrm{E}$ \\
\hline $\begin{array}{l}\text { Guimar, Spain } \\
(60018)\end{array}$ & $\begin{array}{l}\text { (Tenerife, Canary } \\
\text { Islands }\end{array}$ & $28^{\circ} 18^{\prime} 0 ” \mathrm{~N}$ & $16^{\circ} 25^{\prime} 0 " \mathrm{~W}$ \\
\hline $\begin{array}{l}\text { Fernando de } \\
\text { Noronha Airport: } \\
\text { (SBFN) }\end{array}$ & $\begin{array}{l}\text { Western Atlantic, } \\
\text { Brazil }\end{array}$ & $3^{\circ} 51^{\prime} 16^{\prime \prime} \mathrm{S}$ & $32^{\circ} 25^{\prime} 23^{\prime \prime} \mathrm{W}$ \\
\hline Belem, (SBBE) & Brazil & $1^{\circ} 27^{\prime} 0 " \mathrm{~S}$ & $48^{\circ} 29^{\prime} 0 " \mathrm{~W}$ \\
\hline Manaus (SBMN) & Brazil & $3^{\circ} 6{ }^{\prime} 47^{\prime \prime} \mathrm{S}$ & $60^{\circ} 1^{\prime} 31^{\prime \prime} \mathrm{W}$ \\
\hline $\begin{array}{l}\text { Porto Velho } \\
\text { (SBPV) }\end{array}$ & Brazi & $8^{\circ} 46^{\prime} 0 " \mathrm{~S}$ & $63^{\circ} 54^{\prime} 0^{\prime \prime} \mathrm{W}$ \\
\hline Leticia (SKLT) & Colombia & $4^{\circ} 12^{\prime} 55^{\prime \prime} \mathrm{S}$ & $69^{\circ} 56^{\prime} 26^{\prime \prime} \mathrm{W}$ \\
\hline Bogota (BOG) & Colombia & $04^{\circ} 38^{\prime} \mathrm{N}$ & $74^{\circ} 05^{\prime} \mathrm{W}$ \\
\hline & & LATITUDE & LONGITUDE \\
\hline $\begin{array}{l}\text { Tres Esquinas } \\
\text { (TQ) }\end{array}$ & $\begin{array}{l}\text { Caqueta, } \\
\text { Colombia }\end{array}$ & $1^{\circ} 50^{\prime} 51 \mathrm{~N}$ & $74^{\circ} 47^{\prime} 43 \mathrm{~W}$ \\
\hline St Helena (61901) & St Helena & $15^{\circ} 56 " \mathrm{~S}$ & $5^{\circ} 44^{\prime \prime} \mathrm{W}$ \\
\hline Boa Vista (SBBV) & Roraima, Brazil & $2^{\circ} 49^{\prime} 0 ” \mathrm{~N}$ & $60^{\circ} 40^{\prime} 0 " \mathrm{~W}$ \\
\hline Morona (MOR) & Ecuador & $3^{\circ} 73^{\prime} 0^{\prime \prime} \mathrm{S}$ & $73^{\circ} 25^{\prime} 0^{\prime \prime} \mathrm{W}$ \\
\hline Tindouf (DAOF) & Algeria & $27^{\circ} 40^{\prime} \mathrm{N}$ & $8^{\circ} 8^{\prime} \mathrm{W}$ \\
\hline
\end{tabular}

Source: Author.

During the course of the past two years, I have reviewed radio-sounding data from various sites based upon the trajectory of the Trade Winds between Africa and the Amazon Basin. As part of my study of the data I determine the partial pressure force $(\mathrm{hPa} / \mathrm{km})$ derived from the relative humidity and temperature for each site and at each level $\mathrm{z}$ in altitude. In those calculations I assume that water vapour acts as an ideal gas and that it condenses at a rate contingent on the environmental lapse rate (ELR) or $\Gamma$ as one proceeds upwards in altitude. In that way, for each of the locations (some 13 in all), stretching from the Sahara to Bogotá, the latter just $4^{\circ}$ North of the Equator, I calculate the partial pressure force at different $z$ altitudes in the troposphere. My results indicate that a significant partial pressure force gradient manifests itself as one follows the trajectory of the Trade Winds from Africa to the Amazon Basin and across to the equatorial Andes. 
How the Biotic Pump links the hydrological cycle

and the rainforest to climate

Graph 8. Monthly data derived from daily radiosoundings for the different locations

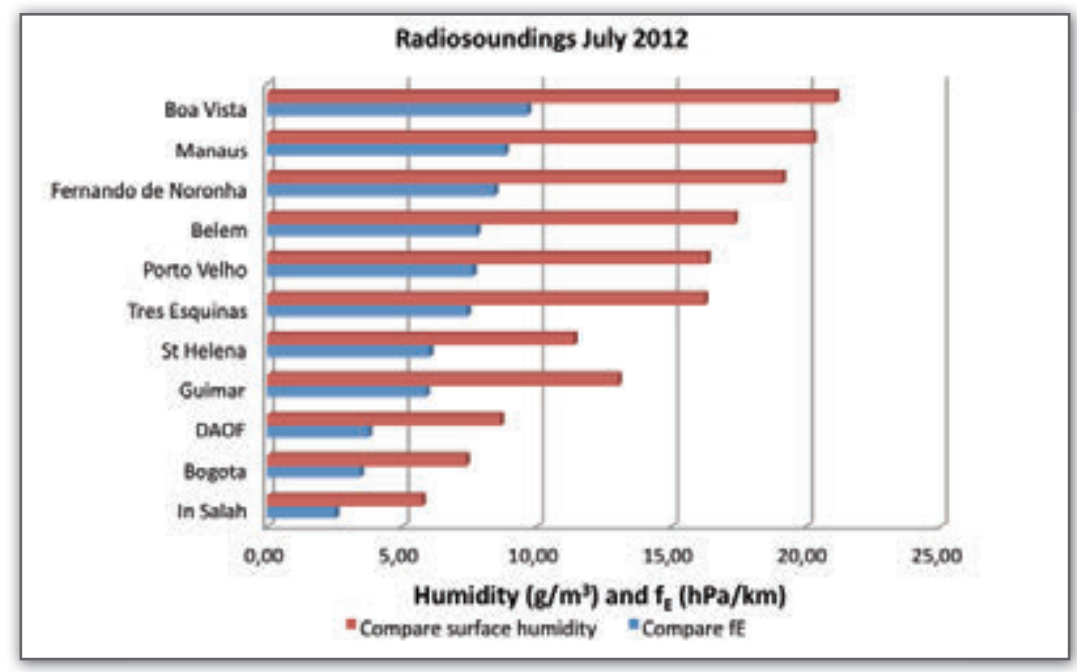

Source: Author.

The evaporative/condensation force $\mathrm{f}_{\mathrm{E}}(\mathrm{hPa} / \mathrm{km})$ is calculated using the equations as described in chapter 3 as is surface humidity. In effect, surface humidity (grams of water vapour per cubic metre of air follows a parallel trajectory as does $\mathrm{f}_{\mathrm{E}}$ (Makarieva \& Gorshkov, 2007).

Figure 11. Radio-sounding sites on South America

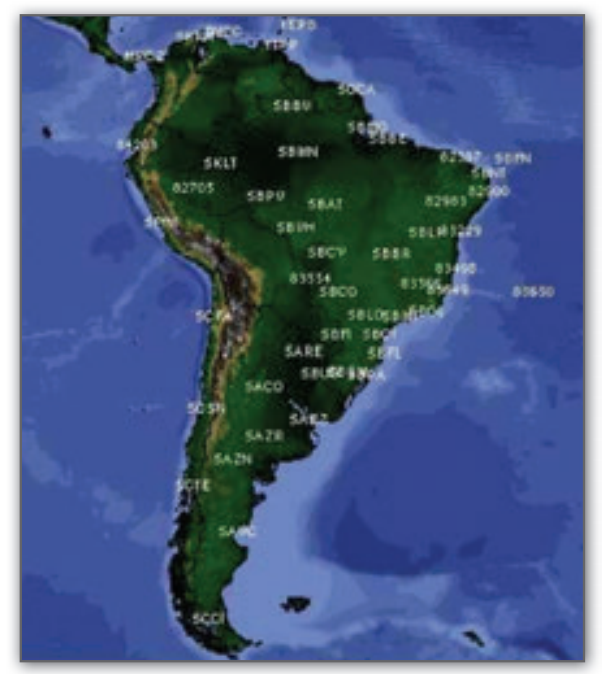

Source: University of Wyoming, s.f. 


\section{Peter Bunyard}

Figure 12. Radio-sounding sites on Africa

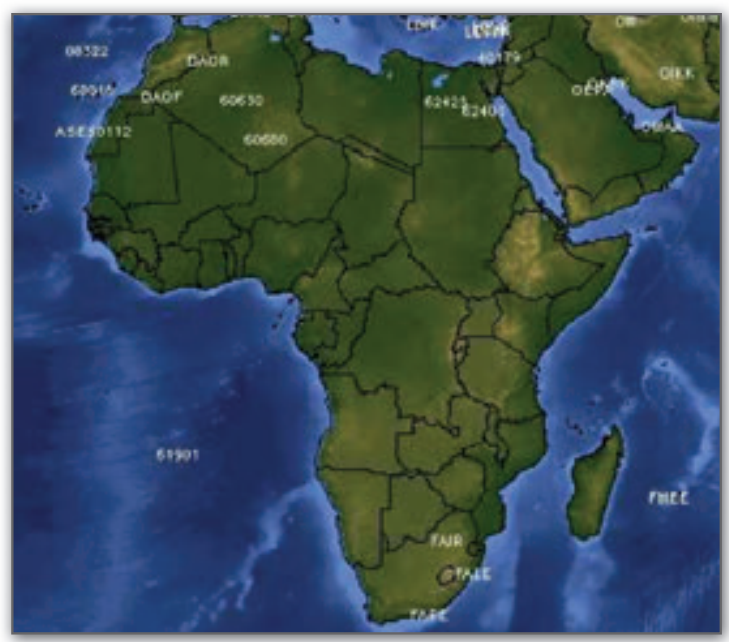

Source. University of Wyoming, s.f. 


\section{Chapter 3}

\section{RESULTS AND ANALYSIS}

The radio-soundings give us the opportunity to apply 1 standard physical equations of state to the data and thereby calculate the net upwards force, $\mathrm{f}_{\mathrm{E}}$, as a result of the condensation of water vapour. The partial pressure force, $\mathrm{f}_{\mathrm{E}},(\mathrm{hPa} / \mathrm{km})$ shows an exponential decline with altitude, as is to be expected given the temperature reduction as the air expands with reduced atmospheric pressure. Given the relative humidity, we use the equations of ClausiusGlapeyron for each altitude level, $z$, to calculate the amount of water vapour (Makarieva \& Gorshkov, 2007).

A well-forested locality, such as Leticia, Colombia, in the western Amazon, shows a partial water vapour curve against altitude which follows closely the ideal curve as represented in the equation developed by Makarieva and Gorshkov (2007). See graphs 10 and 11.

We can apply exactly the same equations from Makarieva and Gorshkov to ground-based meteorological data.

$$
\text { Hence: } \quad P_{\mathrm{H}_{2} \mathrm{O}_{z}}=P_{\mathrm{H}_{2} \mathrm{O}_{\mathrm{S}}} \exp \left\{-\int_{0}^{z} \frac{d z}{h_{\mathrm{H}_{2} \mathrm{O}}}\right\}
$$

with $\mathrm{PH}_{2} \mathrm{O}_{z}$ as the partial pressure of water vapour at altitude z; $\mathrm{PH}_{2} \mathrm{O}_{s}$ as the partial pressure of water at sea-level or zero altitude and where $-d T / d z=E L R(\Gamma$ or environmental lapse rate). 
The theoretical height of water vapour in the atmosphere is given by:

$$
h_{\mathrm{H}_{2} \mathrm{O}}=\frac{T^{2}}{\left\{\frac{-d T}{d z}\right\} T_{\mathrm{H}_{2} \mathrm{O}}}
$$

And, the theoretical temperature when all water has vaporised is given by:

$$
T_{\mathrm{H}_{2} \mathrm{O}} \equiv \frac{Q_{\mathrm{H}_{2} \mathrm{O}}}{R} \cong 5301 \mathrm{~K}
$$

From the actual ELR, $\Gamma$, we can show that:

$$
h_{\mathrm{H}_{2} \mathrm{O}}=\frac{T^{2}}{\left\{\frac{-d T}{d z}\right\} T_{\mathrm{H}_{2} \mathrm{O}}}=2.41 \mathrm{~km}
$$

When the $\mathrm{T}$ is 288 and $\Gamma$ is $6.5 \mathrm{~K} / \mathrm{km}$ and

$$
T_{\mathrm{H}_{2} \mathrm{O}} \cong 5301 \mathrm{~K}
$$

And to determine the partial pressure of water vapour at each z, we can apply the standard Clausius-Clapeyron equation:

$$
\ln \frac{P_{2}}{P_{1}}=\frac{Q\left(T_{2}-T_{1}\right)}{R T_{2} T_{1}}
$$

Or

$$
\log P_{2}-\frac{Q\left(T_{2}-T_{1}\right)}{R T_{2} T_{1} * 2.303}=\log P_{1}
$$

Where $Q$, the Latent heat of Evaporation $=43 \mathrm{~kJ} \mathrm{~mol}^{-1}, \& \Gamma(\mathrm{ELR})=$ $-d T / d z$ and $R$, the ideal gas constant is $8.3 \mathrm{~J} \mathrm{~K}^{-1}$.

$$
\frac{-d T}{d z}=\Gamma_{H_{2} O} \quad=\frac{T}{H}
$$


And

$$
T=T_{s} \exp \left\{-\frac{Z}{H}\right\}
$$

Under current conditions in the lower atmosphere the scalar height for water vapour, with $\mathrm{T}_{\mathrm{H} 2 \mathrm{O}}=5301 \mathrm{~K}, \mathrm{M}_{\mathrm{v}}=18.02 \mathrm{~g} \mathrm{~mol}^{-1}, \mathrm{~g}=9.8 \mathrm{~m} \mathrm{~s}^{-2}$, $\mathrm{R}=8.3 \mathrm{~J} \mathrm{~K}^{-1}$ :

$$
h_{v s} \equiv R T_{s} / g M_{v}=13.5 \mathrm{~km}
$$

In fact, radiosonde data for the tropics, as seen in the data for Boa Vista $30^{\text {th }}$ January 2013, indicates that the scalar length of water vapour from the ground upwards is approximately $13 \mathrm{~km}$. Empirical data therefore confirms the physical principles laid down by Makarieva and Gorshkov (2007).

Graph 9. Leticia, partial pressure water vapour against temperature

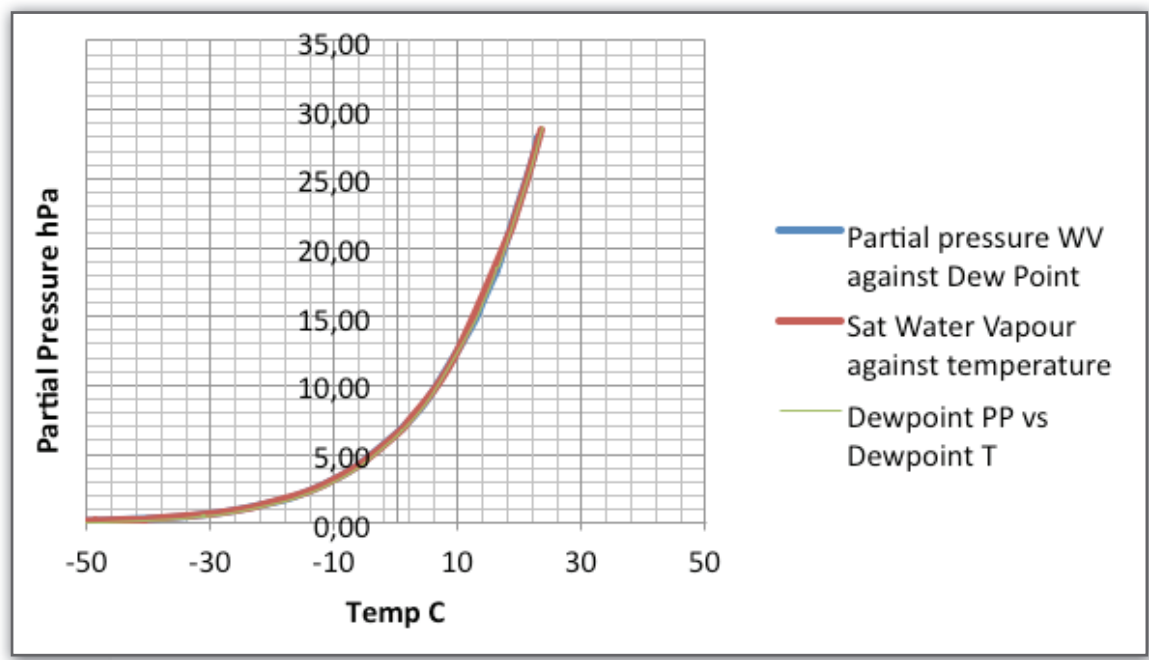

Source: Author. 
Graph 10. Leticia, partial pressures water vapour with altitude

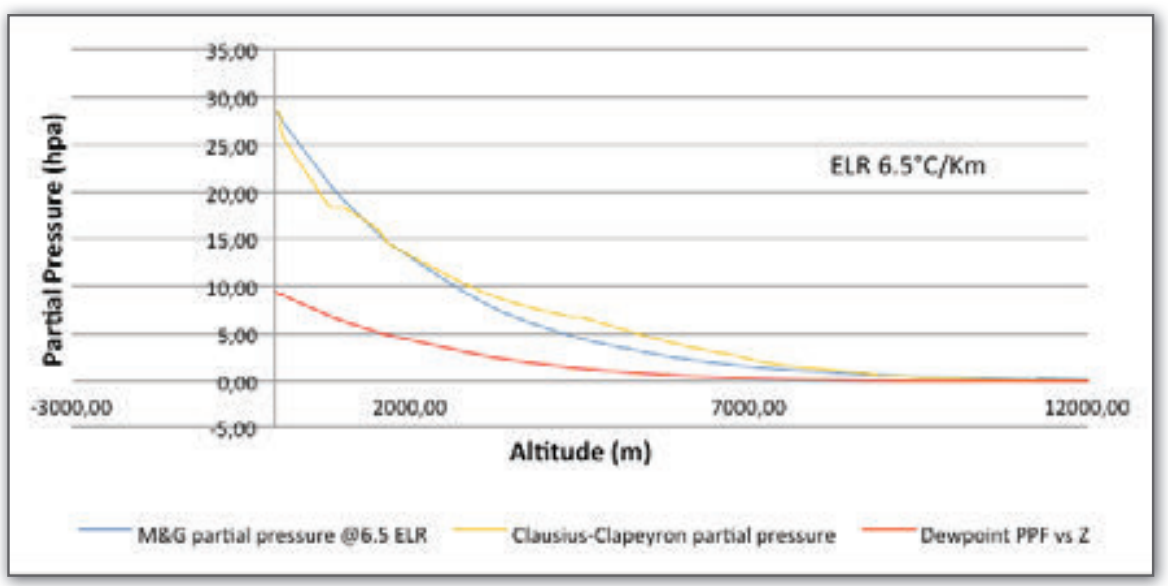

Note: Showing that the scalar height of the vapour is approximately $13 \mathrm{~km}$. Source: Author.

That scalar length for humid air should be compared with dry air, where $h_{d s}=8.4 \mathrm{~km}$. Meanwhile, were the troposphere to be composed solely of water vapour, then theoretically and on the basis of physical principles:

$$
H=\frac{R T_{\mathrm{H}_{2} \mathrm{O}}}{g M_{v}}=250 \mathrm{~km}
$$

Which would give an ELR, $\Gamma$, of 288/250 = $1.2 \mathrm{~K} / \mathrm{km}$, in comparison with $6.5 \mathrm{~K} / \mathrm{km}$ or $9.8 \mathrm{~K} / \mathrm{km}$ (moist to dry air). That difference explains in physical terms why water vapour is bound to condense with altitude in the lower to middle troposphere and, as such, is a factor in helping the Earth to retain its water, in sharp contrast to the Earth's flanking planets, Venus and Mars.

Meanwhile the net Evaporative-Condensation Force is derived from the upward acceleration of the parcel of air owing to the loss of water vapour from condensation minus the downward pull of the water vapour at any $\mathrm{z}$ in the column caused by gravity. Indeed, as can be seen from empirical calcula- 
tions, the ratio of the upward force to the downward pull is 5:1 in favour of the $\mathrm{f}_{\mathrm{E}}$ - the evaporative/condensation force (Bunyard, 2012). Thus,

$$
f_{E}=P_{H_{2} O} O\left(\frac{1}{h_{H_{2} O}}-\frac{1}{h_{v}}\right)
$$

For example, taking the radio-sounding data for Leticia on $9^{\text {th }}$ September 2013 and utilizing the calculated dewpoint $\mathrm{T}$ of $22.6^{\circ} \mathrm{C}$, we obtain a partial vapour pressure of $26.8 \mathrm{hPa}$ at 84 metres and barometric pressure of 1005 $\mathrm{hPa}$. At that $\mathrm{z}$ (altitude) the condensation level $\mathrm{h}_{\mathrm{H} 2 \mathrm{O}}$ is $2.52 \mathrm{~km}$, with a $\Gamma$ of $6.5 \mathrm{~K} / \mathrm{km}$ and $h_{v} 13.93 \mathrm{~km}$. Therefore the upward force is 10.52 and the downward force is $1.90 \mathrm{hPa} / \mathrm{km}$, leaving a net upward force of $8.62 \mathrm{hPa} / \mathrm{km}$ and a ratio between the two of 5.53 .

Graph 11. Theoretical curves of the evaporative force $f_{E}$

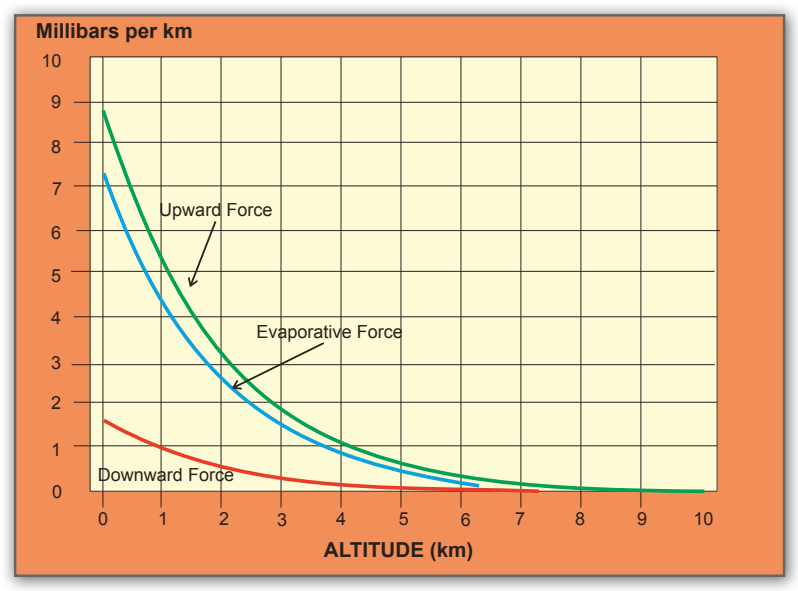

Source: Makarieva and Gorshkov, 2007.

(a) Saturated partial pressure of water vapour $P_{H 20}(z)$ and weight of the saturated water vapour in the atmospheric column above height $z$ at $\Gamma_{\mathrm{ob}}=6.5$ $\mathrm{Km}^{-1}$.

$$
W_{a}(z)=\int_{z}^{\infty} \frac{P_{H 2 O}\left(z^{\prime}\right)}{h_{v}(z)^{\prime}} d z^{\prime}
$$


Saturated partial pressure at tha surface is $P_{H 2 O}(0)=20$ mbar. (b) The upward-directed evaporative force $f_{E}$, equal to the difference between the upward-directed pressure gradient force $f_{\uparrow}$ of a unit volume of the saturated water vapour, $f_{E}=f_{\uparrow}-f_{\downarrow}$.

Graph 12. Partial Pressure Force. Leticia 9th September 2013

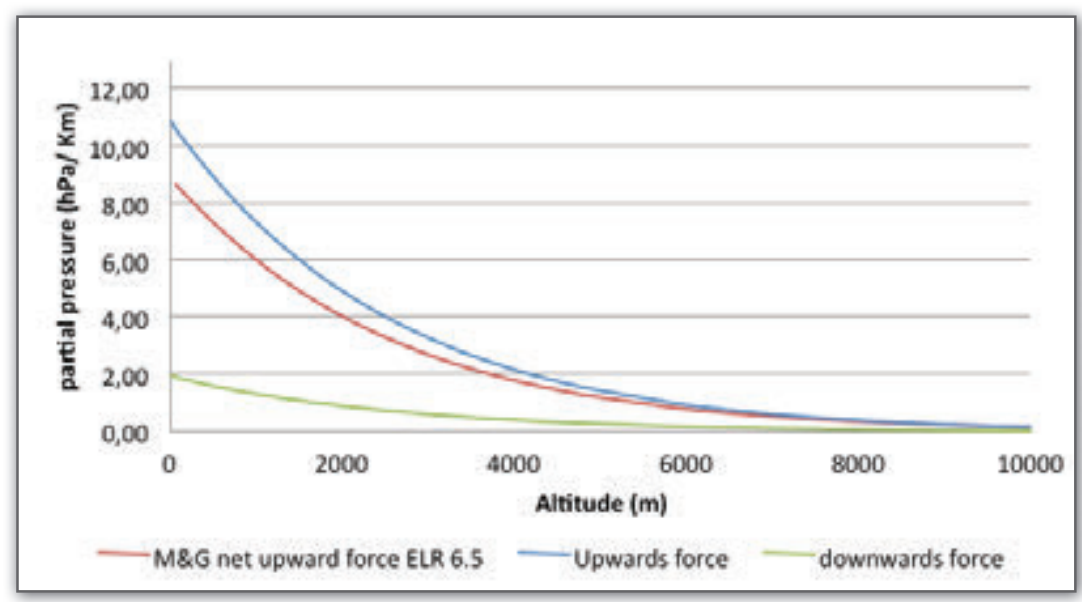

Source: Author.

The graph shows a good fit between the theoretical curve and the actual curve of $\mathrm{f}_{\mathrm{E}}$, the water vapour partial pressure force $\mathrm{hPa} / \mathrm{km}$. The upwards force (blue) depends on the rate of condensation and is the partial pressure of water vapour divided by the altitude at which clouds form. The downwards force (green) results from the column weight of water vapour in the lower atmosphere (troposphere). The net upwards force (red) is the former minus the latter.

Makarieva and Gorshkov (2007) propose that a gradient difference of a few hectopascals per kilometre is sufficient to draw the Trade Winds in a gentle and steady flow, over the surface water of the tropical Atlantic Ocean and across the Amazon Basin to the Andes in the air mass known as the Walker Circulation. Their proposition is that the processes of convection over the rainforest, resulting from the biotic pump, are essential to the maintenance of a sturdy Walker Circulation; hence the idea that Trade Winds 
are sucked by the accumulative physiological activity of more than 5 million square kilometres of rain forest. Two processes effectively come into play in maintaining the atmospheric rivers over the Amazon Basin: first, the recycling of rainfall by means of evapotranspiration, amounting to as much as 50 per cent of Amazon rainfall; second, the sucking in of surface air, bearing ocean-derived humidity by means of the high rate of condensation, which itself is fuelled by the forest evapotranspiration.

The corollary, the result of widespread deforestation, would be that the Trade Winds lose their momentum and dwindle away to the point that rainfall over the central and western portions of the Amazon, as well as over the eastern slopes of the Andes, dies away exponentially as one passes inland (Makarieva, Gorshkov, \& Li, 2013; Makarieva et al., 2014).

The exponential reduction in rainfall as one proceeds inland from the coast to the interior is represented by the following equation:

$$
\operatorname{Flux}_{x}=\operatorname{Flux}_{0} \exp ^{(-x / l)}
$$

Where $x$ is the distance inland and $l$ represents precipitation formation and includes moisture upwelling, condensation and precipitation. If precipitation is substituted for flux we get the equation,

$$
P_{X}=P_{0} \exp [-x / l]
$$

$\mathrm{Or}$

$$
\ln P_{x}=\ln P_{0}-x / l
$$

And the net result of wide scale deforestation over the Amazon Basin would be as follows: 
Graph 13. Deforestation impact over the biotic pump

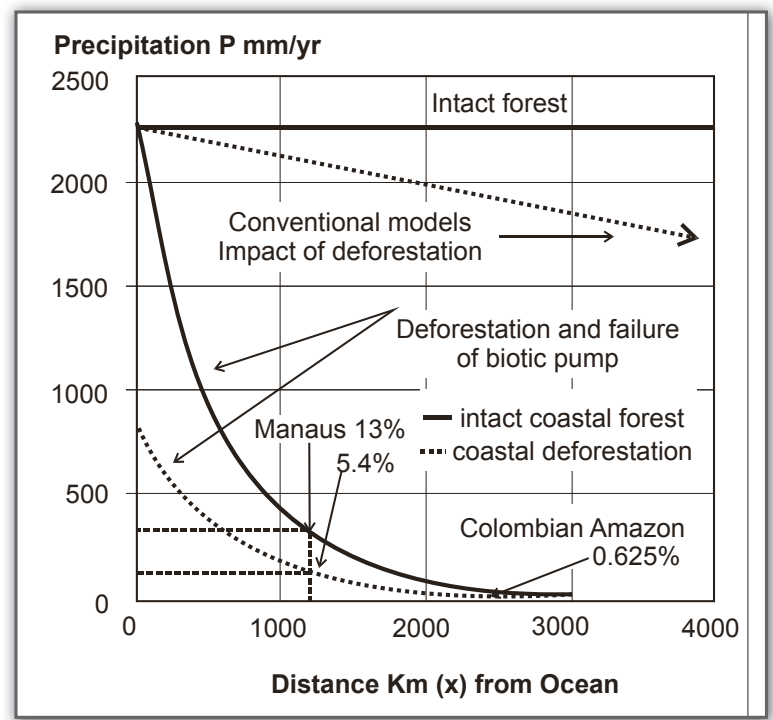

Note: They use a length of $600 \mathrm{~km}$ over which distance a molecule of water will evaporate and fall-out through precipitation. Source: Makarieva and Gorshkov, 2007.

If the biotic pump theory is shown to be consistent with reality, then, as far as the Amazon Basin is concerned, we can surmise that its vast expanse - in comparison with the Congo Basin in Africa - is a consequence of several prime factors:

1. The range of the Andes Mountains is to the West and hence at the outer limits of the tropical Hadley Cell air mass circulation with the majority of the landscape and topography, from the Atlantic Ocean inland, being relatively flat, such that Leticia, in the Colombian Amazon, therefore 2,500 kilometres from the ocean, is barely 45 metres above mean sea level. In effect, the prime obstacle to the free flow of the surface winds across much of the Basin - the Walker Circulation - will be the roughness of the tree stems and foliage up to some 35 metres or so.

2. By way of contrast, in equatorial Africa the mountain range, in the form of the Rift Valley, is to the East, thereby putting the western face of the mountain range in the rain shadow of easterly winds. 
Meanwhile, the Atlantic Ocean, in a direction counter to that which supplies the Amazon, also supplies the Congo Basin, and to a degree the two equatorial regions are in competition with each other, with the Amazon Basin, winning out, perhaps in no small measure because of its greater coverage with closed canopy forest than is sustained in the Congo. Certainly, as with the Colombian Chocó, the Congo rainforest may suck air from the easterly Trade Winds such that they flow abruptly towards the West, thereby bringing rain to equatorial Africa.

3. Another critical factor in favour of the Amazon is that the Sun moves in relation to a stationary Earth in an East to West direction during the course of each day. If we consider that it takes the Sun between 2 and 3 hours to pass from the eastern extremity of Brazil to the Andes, then that trajectory will influence the timing of transpiration such that it will pass, like a metachronal wave, from East to West. My initial findings, derived from meteorological data for La Selva, Sarapiqui, Heredia, Costa Rica, indicate that the high point in the evaporative force is during the early part of the morning, before above-canopy surface temperatures exceed $30^{\circ} \mathrm{C}$ and later in the afternoon, again when temperatures are falling. As a result we can consider that the apparent solar trajectory will cause a ripple of activity to coincide with a moving suction force such that the eastern reaches of the humid tropical rainforest will provide a flush of water vapour for those regions further to the West (graph 15). Meanwhile, we can assume that a similar process will take place over the Congo, but this time, the flush of surface humidity will move in a counter direction to the surface winds. In general, it would seem that the precipitation pattern over equatorial Africa is more akin to that which happens over the Chocó in western Colombia, with the winds sucked in against the general flow of the Trade Winds and therefore delivering. the highest precipitation over the western mountain ranges. Therefore, in contrast to the Amazon Basin, where the absolute surface humidity increases towards the western reaches, away from the Atlantic Ocean, the rainforests with the highest surface humidity in the Congo, are encountered in the West, close to the Atlantic Ocean. 
4. The high rate of condensation which occurs over the eastern flank of the Andes, as the air stream rises, will then, effectively, close the process. In confirmation, I find that more than 50 per cent of the precipitable water in the air column, as determined over the western Amazon, Tres Esquinas in the Colombian Caqueta, for example, will be drained out of the air mass by the time it reaches over the upper moorlands - the páramos - of Colombia's eastern cordillera (table 3). That being so, the cloud forests of the tropical Andes as well as the native vegetation of the páramos - frailejones (Espeletia) and sphagnum moss, for example - will help maintain an active east to west circulation over the Atlantic Ocean and across the Amazon Basin. Such characteristics help determine the significant difference between Amazonia and the Congo.

Graph 14. La Selva, February 2014. Average temperature and average $f_{E}$

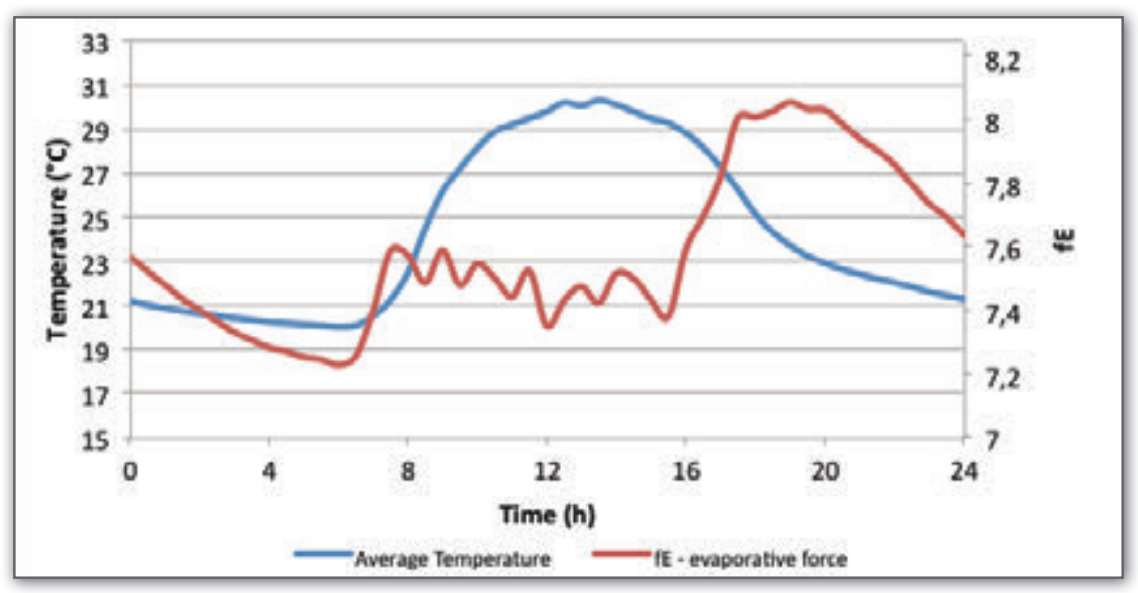

Source: Author.

As the temperature rises during the day, the evaporative/condensation force, $\mathrm{f}_{\mathrm{E}}$ first increases, holds steady with fluctuations and, at around 4:00pm begins to rise, reaching a peak at around 6:00pm, after which it declines. 
How the Biotic Pump links the hydrological cycle

and the rainforest to climate

Table 3. Data from radio-soundings for locations from Africa to Colombia

\begin{tabular}{|l|c|c|c|c|c|c|c|}
\hline $\begin{array}{c}\text { August } \\
\text { average 2012 }\end{array}$ & $\begin{array}{c}\text { Tres } \\
\text { Esquinas }\end{array}$ & Leticia & Manaus & Bogotá & $\begin{array}{c}\text { Fernando } \\
\text { de } \\
\text { Noronha }\end{array}$ & Tenerife & $\begin{array}{c}\text { El } \\
\text { Salah }\end{array}$ \\
\hline $\mathrm{f}_{\mathrm{E}} \cdot \mathrm{hPa} / \mathrm{km}$ & 7.00 & 9.10 & 8.21 & 3.88 & 8.07 & 6.83 & 2.89 \\
\hline $\begin{array}{l}\text { Precipitable } \\
\text { water mm }\end{array}$ & 45.65 & 55.25 & 40.73 & 20.02 & 33.70 & 25.42 & 17.49 \\
\hline $\begin{array}{l}\text { Surface } \\
\text { humidity g/ }\end{array}$ & 15.03 & 20.10 & 18.42 & 8.57 & 18.33 & 15.19 & 6.50 \\
\hline $\mathrm{m}^{3}$ & & & & & & &
\end{tabular}

Source: Author.

From table 3 and 4, which gives averages from radio-soundings of certain locations for the months of August and January 2012, we see that the precipitable water content in millimetres $\left(\mathrm{kg} / \mathrm{m}^{2}\right)$ drops substantially once the air stream has passed to Bogotá at 2,650 $\mathrm{m}$ altitude. The surface humidity has also dropped substantially, a consequence of the drop in temperature with altitude such that, even at similar relative humidities, the air can hold considerably less water vapour in absolute terms. The following bar chart shows the gradient in the evaporative-condensation force and surface humidity for different locations from the Sahara to the Amazon Basin and up the piedmont to Bogotá for August 2012.

Graph 15. Calculations of $\mathrm{f}_{\mathrm{E}}$ and surface humidity from radio-soundings, August 2012

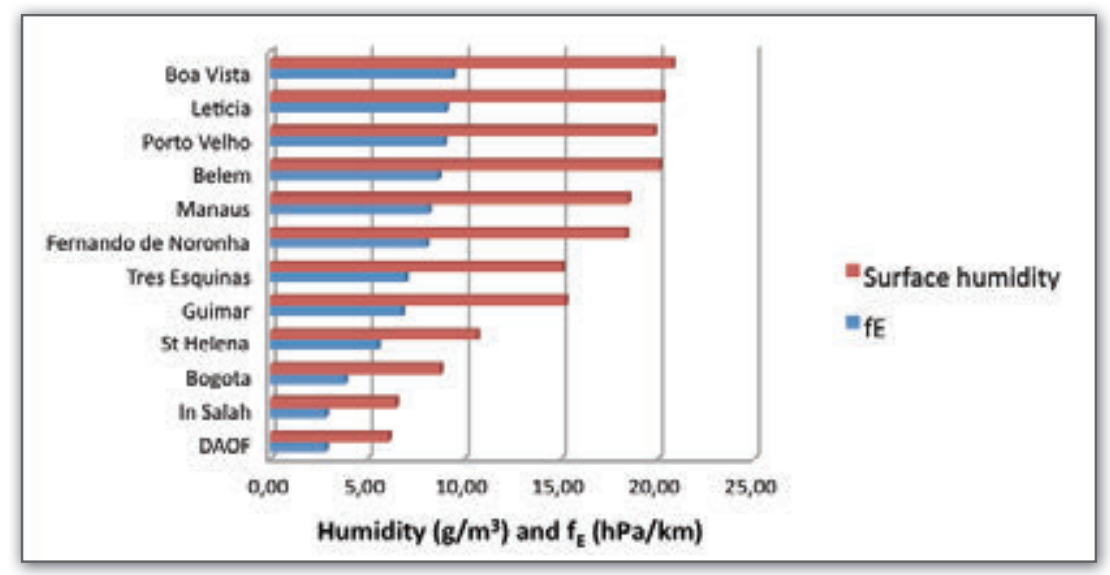

Source: Author. 
Table 4. Radiosoundings of various locations

\begin{tabular}{|c|c|c|c|c|c|c|c|}
\hline $\begin{array}{c}\text { January } \\
\text { average } \\
2012\end{array}$ & $\begin{array}{c}\text { Tres } \\
\text { Esquinas }\end{array}$ & Leticia & Manaus & Bogotá & $\begin{array}{c}\text { Fernando } \\
\text { de } \\
\text { Noronha }\end{array}$ & Tenerife & $\begin{array}{c}\text { El } \\
\text { Salah }\end{array}$ \\
\hline $\mathrm{f}_{\mathrm{E}} \cdot \mathrm{hPa} / \mathrm{km}$ & 7.94 & 9.21 & 9.13 & 3.79 & 8.37 & 4.10 & 2.60 \\
\hline $\begin{array}{l}\text { Precipitable } \\
\text { water mm }\end{array}$ & 50.98 & 60.21 & 57.53 & 18.21 & 39.68 & 15.20 & 8.34 \\
\hline $\begin{array}{l}\text { Surface } \\
\text { humidity } \\
\mathrm{g} / \mathrm{m}^{3}\end{array}$ & 17.01 & 20.36 & 20.34 & 9.10 & 19.06 & 8.79 & 5.20 \\
\hline
\end{tabular}

Source: Author.

Graph 16. Radio-soundings for January 2012. Comparative $\mathrm{f}_{\mathrm{E}}$ and surface humidity

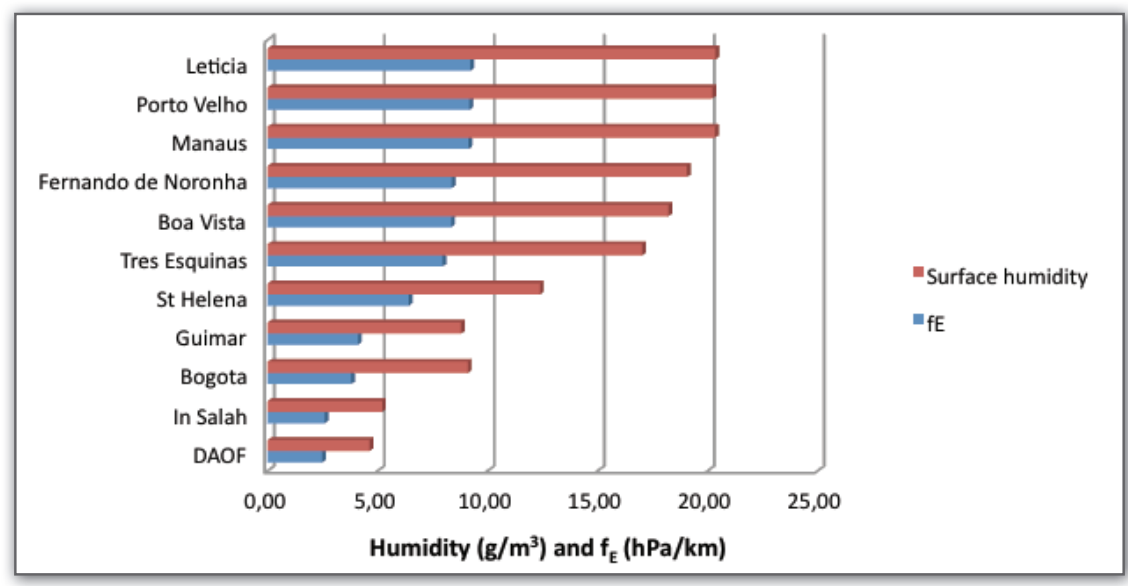

Note: The graph shows the gradient in $\mathrm{f}_{\mathrm{E}}$ and surface humidity as one passes further west, with the exception of Tres Esquinas. Source: Author.

To illustrate the validity of the biotic pump theory, Makarieva and Gorshkov reviewed precipitation patterns over large river basins in distinct regions of the world. They showed that river basins with a high closedcanopy forest cover, such as exemplified by the Amazon and Congo River basins in the equatorial tropics and by the Yenesey River Basin in Siberia, demonstrate the principle that a high precipitation level is maintained right across the basin (graph 16). In contrast, river basins which lack forest demonstrate an exponential decline in precipitation with increasing distance from the ocean (Makarieva \& Gorshkov, 2007; Makarieva, Gorshkov, \& Li, 2013). See graph 17. 
How the Biotic Pump links the hydrological cycle

and the rainforest to climate

Graph 17. Dependence of precipitation on distance $\mathrm{X}(\mathrm{Km})$

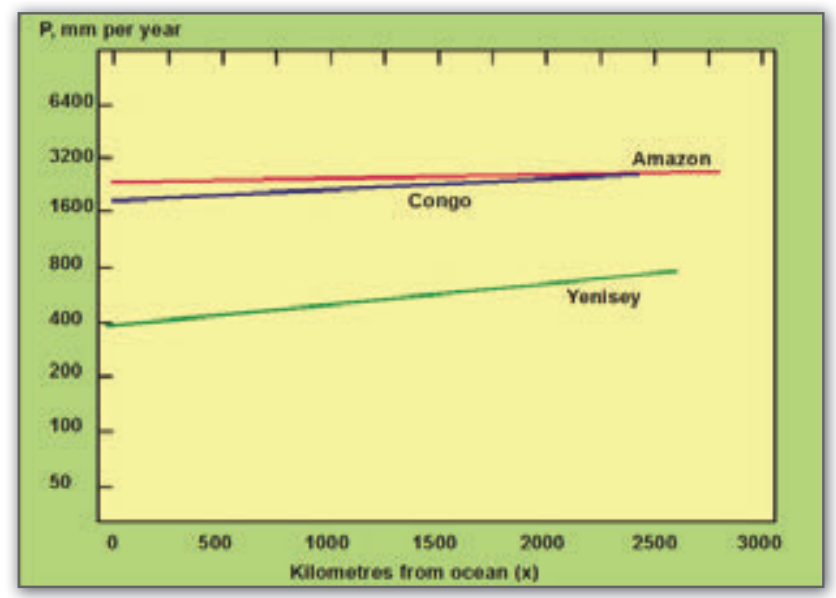

Source: Makarieva and Gorshkov, 2007.

Makarieva and Gorshkov maintain that the biotic pump theory explains why continental river basins which have a large extent of closed-canopy rainforest maintain the level of precipitation for thousands of kilometres.

Graph 18. Precipitation over non-forested territories

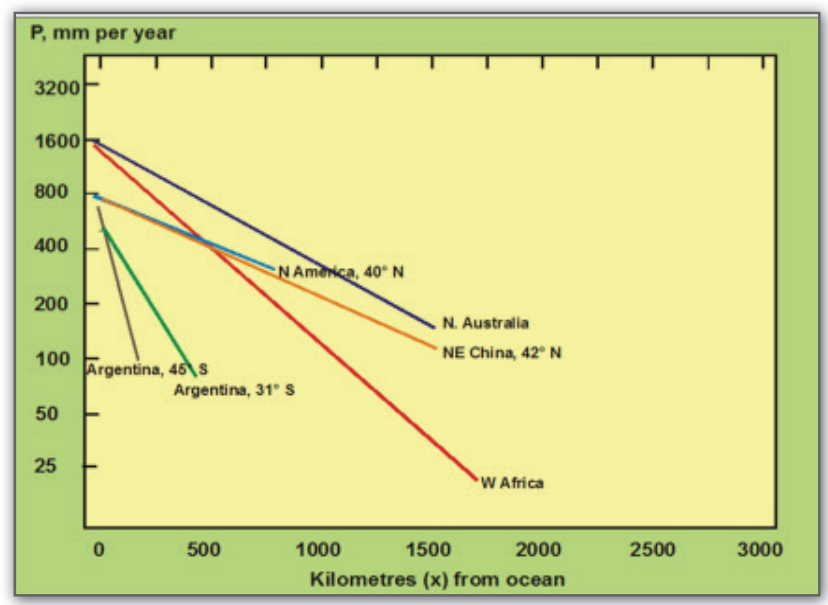

Source: Makarieva and Gorshkov, 2007. 
Exponential decline in precipitation inland over river basins without forest cover.

Figure 13. Condensing vapour over forested slope in contrast to that cleared for pasture

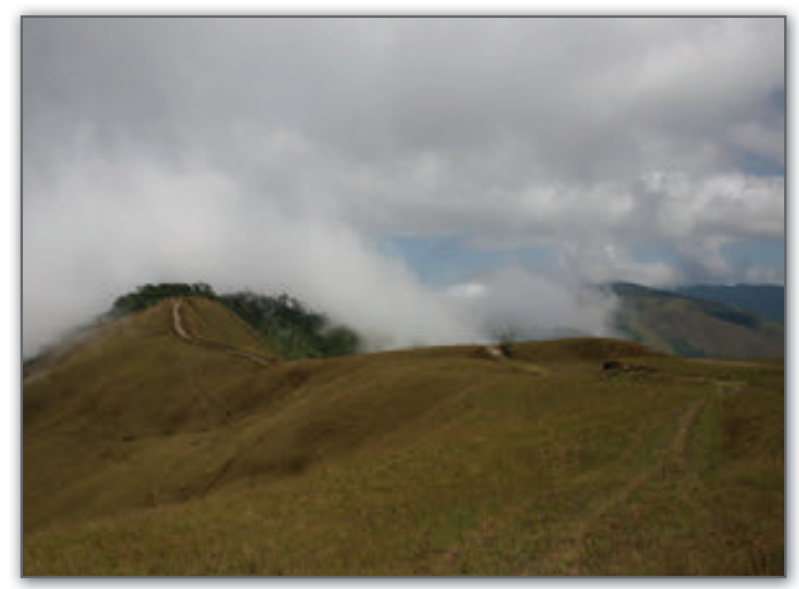

Source: Courtesy of the Finnish Ambassador to Colombia, Mikko Pyhälä.

Figure 14. The Colombian Putumayo, deforested for cattle

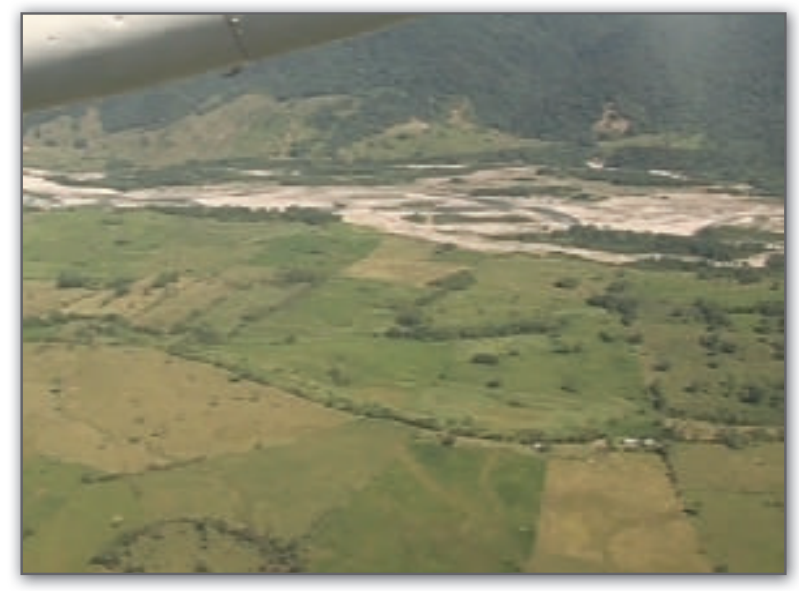

Source: Author, November 2005. 
Since one kilogram-force per square metre $\left(\mathrm{kgf} / \mathrm{m}^{2}\right)=0.0980665$ hectopascals $(\mathrm{hPa})$, from the radio-sounding data, we can convert the specific humidity directly into a kilogram force, taking into account the altitude change between two adjacent $z$ (in many instances approximately $2 \mathrm{hPa}$ ). Thus, by finding the average specific humidity between two adjacent $z$, we obtain a $\mathrm{kg}$ force $(\mathrm{kgf})$ of 0.34 . By doing that successively for the column of air to the point when there is little or no water vapour we can get a column of numbers which added together should approximate closely the precipitable water as given in the downloaded data. (see attached flow chart, figure 15). For instance, taking the data for Leticia, I calculate the specific humidity difference $\left(r_{1}+r_{2}\right) / 2$, between two adjacent altitudes, $z$; then I multiply by the difference in hectopascals between adjacent $z$ and multiply by 10.197 to convert $\mathrm{hPa}$ of atmospheric pressure to $\mathrm{kg} / \mathrm{m}^{2}$. By adding up such successive calculations for the atmospheric profile from the radio-sounding data, I obtain the total precipitable quantity of water vapour in the air column.

For that day in Leticia, I obtain $55.76 \mathrm{~mm}$ of precipitable water compared with $56.05 \mathrm{~mm}$ as taken from the downloaded data. The difference of $0.29 \mathrm{~mm}$ of precipitable water amounts to a difference of 0.5 per cent. In general the difference between the downloaded data of precipitable water compared to calculations based on measuring $h_{v}$, the scalar length of water vapour in the troposphere amount to between 0.2 to $0.5 \mathrm{~mm}$, verifying the validity of the physical procedures.

Those equations are encapsulated in the following flow diagram, developed by the author from hydrological equations pertaining to the physics of the biotic pump (figure 15): 


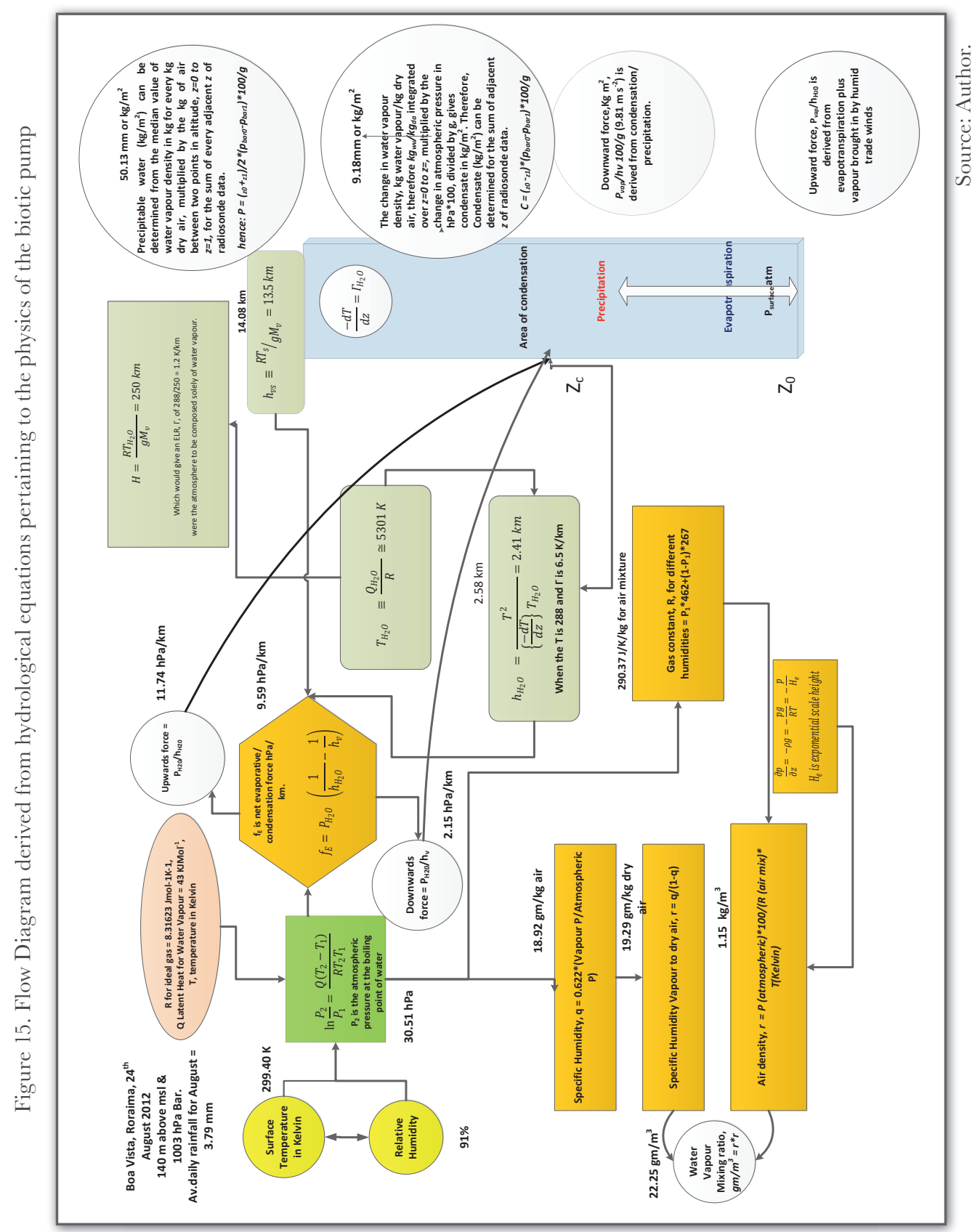


Using the data from a radiosonde reading for Leticia, Amazonas, we can take some of the steps indicated in the flow chart to show the physics employed. The first radio-sounding reading is at $84 \mathrm{~m}$ above sea level, the temperature is $23.8^{\circ} \mathrm{C}$, the relative humidity is given as 95 per cent, and the precipitable water $54.47 \mathrm{~mm}$. That data provides us with the means to calculate the partial pressure of water vapour, using the Clausius- Clapeyron equation:

$$
\log P_{2}-\frac{Q\left(T_{2}-T_{1}\right)}{R T_{2} T_{1} * 2.303}=\log P_{1}
$$

Where $Q$, Latent heat of Evaporation $=43 \mathrm{~kJ} \mathrm{~mol}^{-1}$ and $R$, the ideal gas constant is $8.3 \mathrm{~J} \mathrm{~K}^{-1}$. We can take $P_{2}$ as the pressure of boiling water at sea level, therefore $1013 \mathrm{hPa}$ and Kelvin, 373. The actual partial pressure of water vapour is given by multiplying the result by the $R H$, the relative humidity and we obtain $27.38 \mathrm{hPa}$. Taking the Environmental Lapse Rate $(\mathrm{ELR})$ as $6.5^{\circ} \mathrm{C}$ reduction in temperature for the first $\mathrm{km}$ in altitude, we can then use the following equation to calculate the condensation level:

$$
h_{\mathrm{H}_{2} \mathrm{O}}=\frac{T^{2}}{\left\{\frac{-d T}{d z}\right\} T_{\mathrm{H}_{2} \mathrm{O}}}=2.53 \mathrm{~km}
$$

We obtain a value for $T_{\mathrm{H}_{2} \mathrm{O}}$ from 1 equation:

$$
T_{\mathrm{H}_{2} \mathrm{O}} \equiv \frac{Q_{\mathrm{H}_{2} \mathrm{O}}}{R} \cong 5301 \mathrm{~K}
$$

And by using the equation:

$$
h_{v s} \equiv R T_{s} / g M_{v}=13.96 \mathrm{~km}
$$

Where $\mathrm{g}$ is the gravitational force and is the molecular weight of water, we obtain the value for the scalar height $M_{v}$, of water vapour in the lower atmosphere. Using the results of the equations 1.3 and 1.8, and applying them to the equation:

$$
f_{E}=P_{H_{2} O} \quad\left(\frac{1}{h_{H_{2} O}}-\frac{1}{h_{v}}\right)
$$


We find that the evaporative/condensation force at $\mathrm{z}_{1}$ is $8.8 \mathrm{hPa} / \mathrm{km}$. Through the use of standard equations we can calculate the specific humidity of air at each $\mathrm{z}$ and determine the air density, having first calculated the ideal gas constant, $\mathrm{R}$ for air, taking into account the partial pressure of water vapour. For instance at $\mathrm{z}_{1}$ and using:

$$
R=\left(462 * p_{w v}\right)+\left(1-p_{w v}\right) * 267
$$

We obtain an $R$ value of 290.03, which gives us an air density of 1.165 $\mathrm{kg} / \mathrm{m}^{3}$. Finally, carrying out the calculations as described above we obtain the quantity of precipitable water in the air column $-54.38 \mathrm{~mm}$.

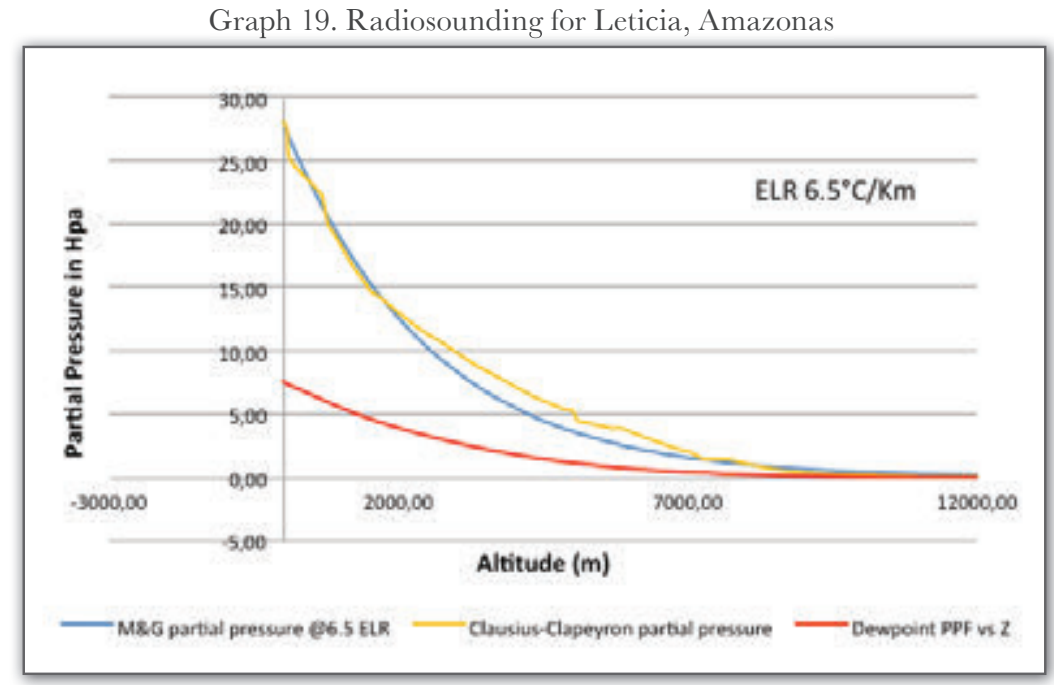

Note: This graph shows the results of basic calculations carried out according to the flow chart in figure 15. Source: Author.

\section{Amazon Basin}

Finally, I encounter significant differences between two western Amazon locations in the Colombian Amazon (graphs 21-25). Tres Esquinas in the Caquetá region, has been subject to extensive deforestation; while, Leticia in Amazonas has largely retained its forests, as well as being located beside the Amazon River. Such differences, in particular as they show up in a significant reduction in the density of water vapour found in the column of air close to the surface, become conspicuous during the drought-inducing conditions of an El Niño episode, as occurred in the first few months of 2010. Both locations have similar quantities of precipitable water in the air column, in- 
dicating that the forest-poor Tres Esquinas is benefitting from the forested regions further to the North and East for supplying the atmosphere will a full complement of water vapour as present in the atmospheric river. But whereas the forested areas maintain a high rate of evapotranspiration, the deforested Tres Esquinas is unable to do so during the dry season on account of a significant reduction in PAW - Plant Available Water. In conclusion, the forested regions are able to continue their high rate of evapotranspiration and hence are better able to enhance cloud formation with consequent precipitation under stressful conditions. The physiology of the rainforest with its deep roots and high vascularization is well-adapted to varying climatic conditions, while simultaneously maintaining an equitable climate (Nepstad et al., 1994). Climate and vegetation are therefore embedded in each other, as is recognised in the Biotic Pump theory of Anastassia Makarieva and Victor Gorshkov.

Graph 20. Radiosounding calculations based on surface conditions as given in altitude $z_{1}$

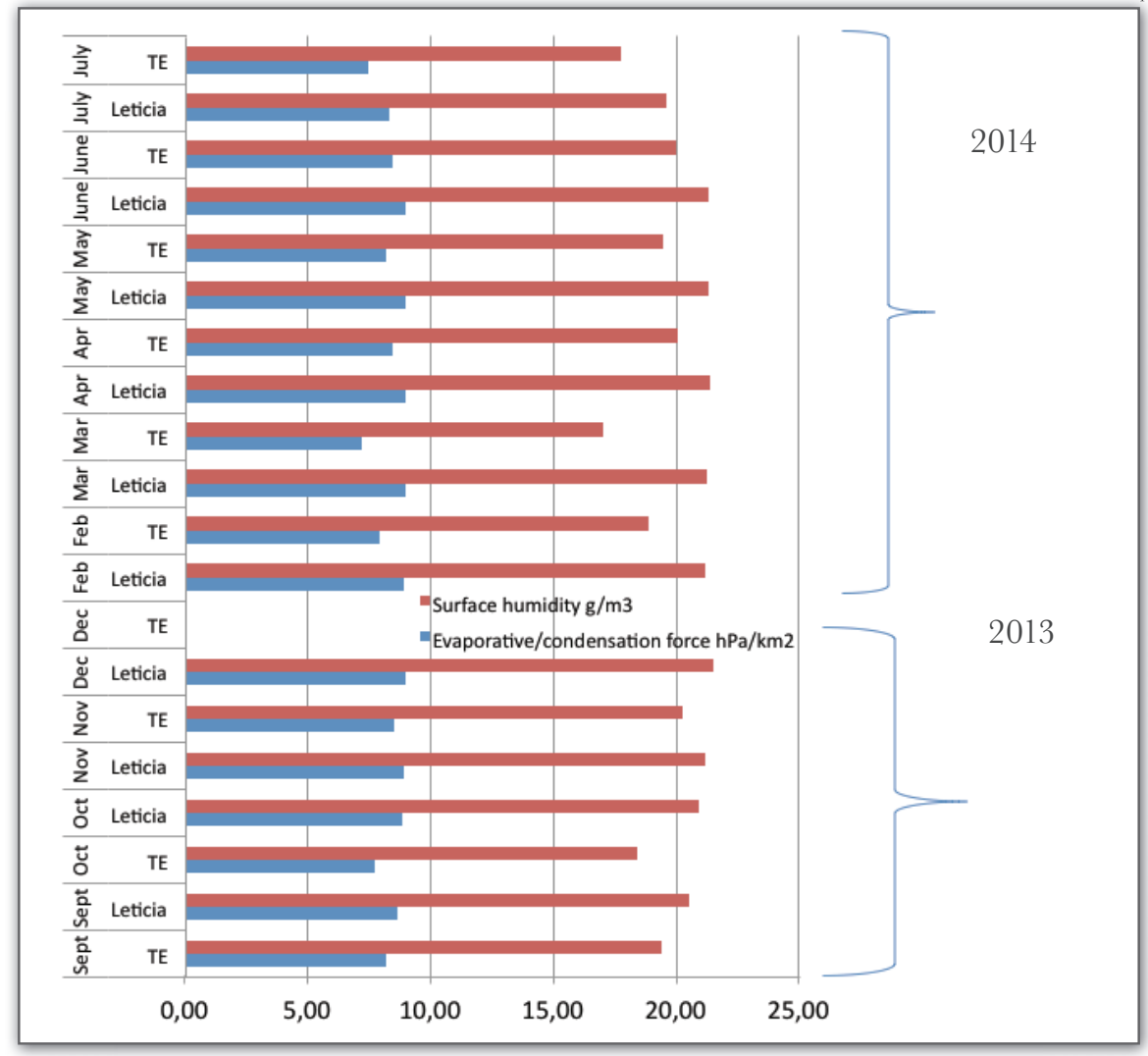

Source: Author. 
Monthly averages during 2013 and 2014 for Leticia and Tres Esquinas (TE). are compared for the evaporative/condensation force $\left(\mathrm{hPa} / \mathrm{km}^{2}\right)$ and for absolute surface humidity $\left(\mathrm{g} / \mathrm{m}^{3}\right)$. TE, deforested constantly shows poorer characteristics than Leticia, even during their distinct dry and wet seasons.

In that regard, I have found considerable monthly variability in the variance of surface humidity for Tres Esquinas in comparison with the relatively tight variances found for Manaus and Leticia. I would suggest that the degree of variability of the variance of surface humidity, as determined from averaging daily data for each month, is an indicator of the changing relationship between the surface environment and the hydrological cycle. The variance can therefore indicate a potential vulnerability to drought conditions in what must be a positive feedback between natural cycles of drought, as during an episode of El Niño, and the failing ability of anthropogenically-imposed vegetation to pump water vapour into the lower atmosphere through evapotranspiration owing to lack of access to groundwater sources.

That finding for Tres Esquinas conforms to an analysis carried out by Germán Poveda and his colleagues on Plant Available Water (PAW) during the dry spells imposed by El Niño events in the coffee growing region, in the Colombian province of Antioquia. They state:

Under sunlit coffee, soil moisture exhibited much more pronounced deficits than under shade coffee and forest, which indicates that the former is more prone to water stress. Thus, El Nino-related dry spells might be mitigated via land cover and land use, which is also a relevant conclusion bearing on the possible effects of climate change. (Poveda, Álvarez, \& Rueda, 2011; Poveda, Jaramillo, Quiceno, \& Mantilla, 2001). 
How the Biotic Pump links the hydrological cycle

and the rainforest to climate

Graph 21. Monthly data from February 2010 to April 2011 and the same for the early part of 2011

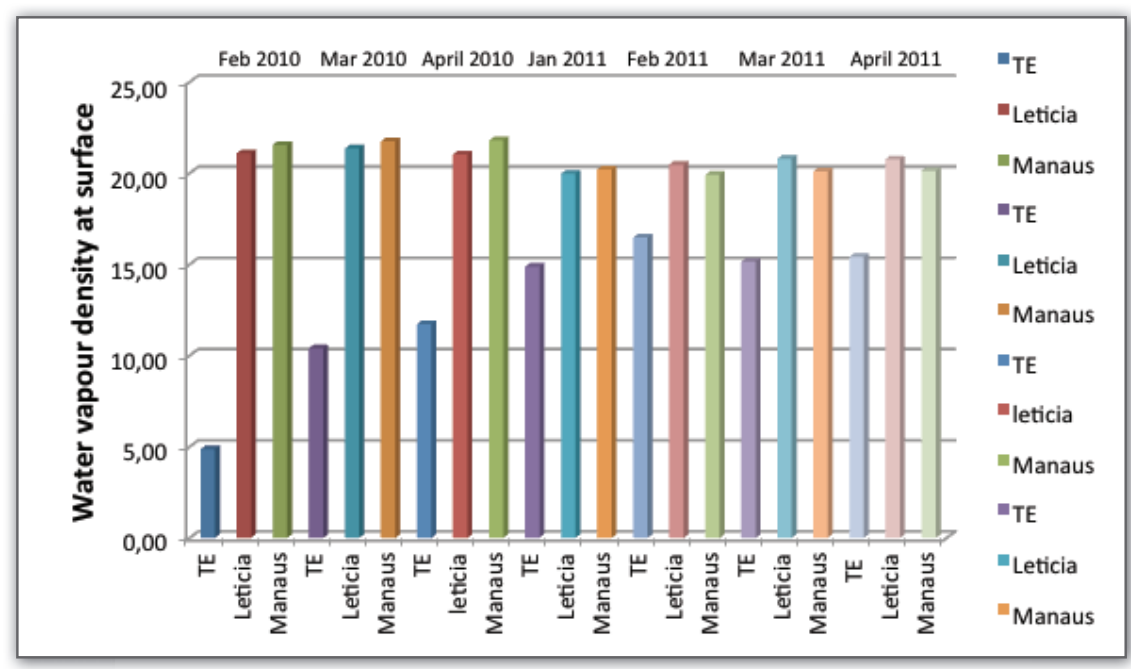

Note: A strong episode of El Niño featured during the first part of 2010. Source: Author.

Graph 22. The variance of surface water vapour density on a monthly basis 2011-2012

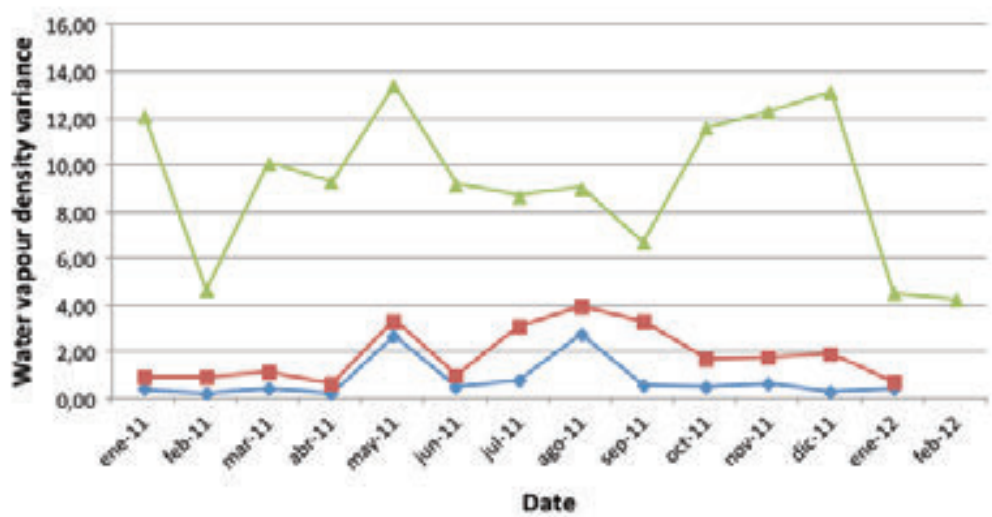

- Leticla Variance $2011-$ Manaus Variance $2011-$ Tres Equinas Variance 2011

Source: Author. 
We find wide variations in the variance for Tres Esquinas (deforested) and tighter results for Leticia and Manaus, where the two curves seem to follow each other closely.

Graph 23. The variance of surface humidity on a monthly basis 2011-2012

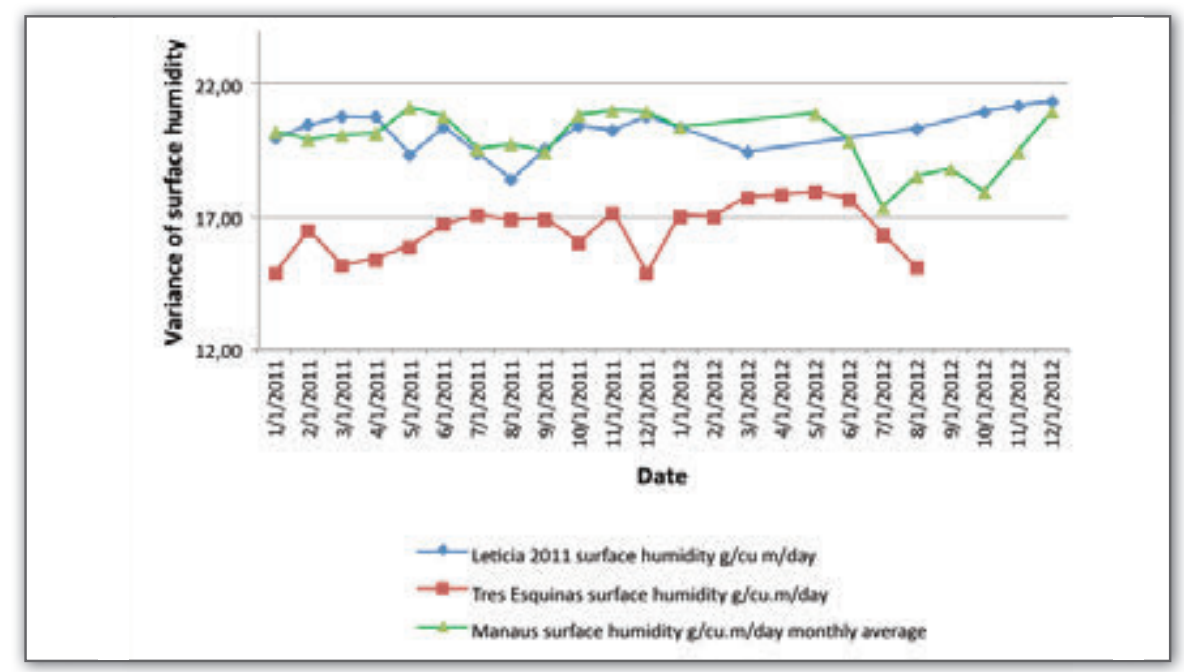

Source: Author.

Graph 24. Variance in surface humidity (2011-2012)

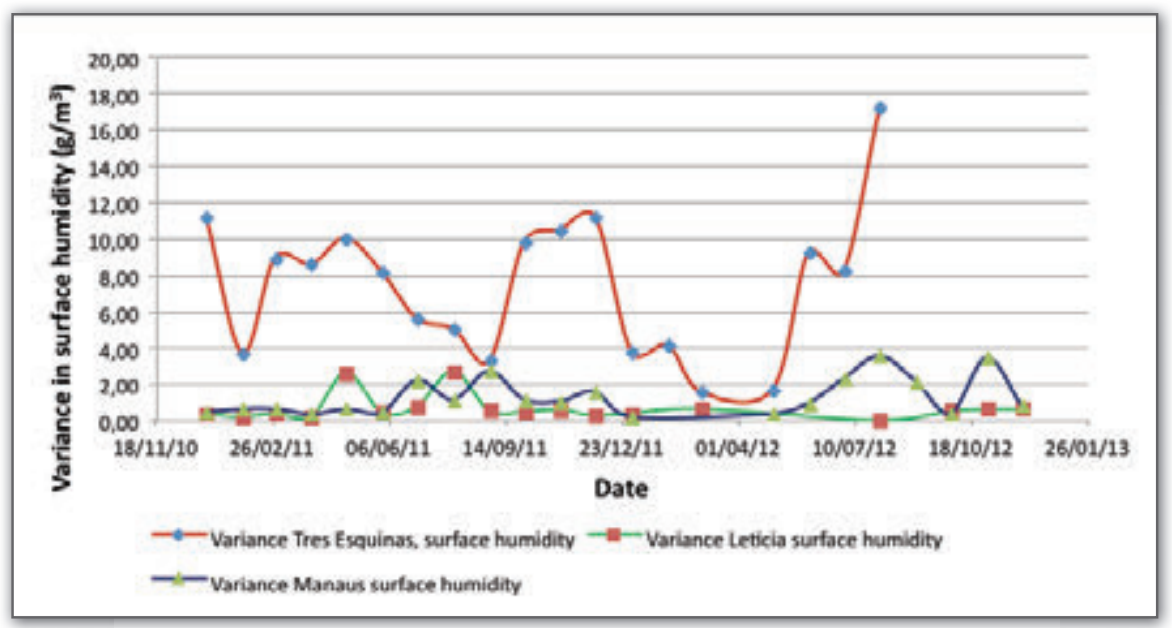

Source: Author. 
It becomes clear that the closed-canopy rainforest, with its deep roots, can maintain sustainable hydrological conditions. As Makarieva and Gorshkov explain, the below-canopy hydrological conditions, in effect bringing about a temperature inversion relative to the above-canopy temperature, help maintain a moist soil and near-saturation humidity. Those are critical factors, they claim, in the potential of the rainforest to draw in moist air with the prevailing winds. The rainforest has therefore evolved a nigh perfect structure and physiology for maintaining the transport of water vapour over large continental distances, with evaporation over the ocean feeding in net losses from precipitation and run-off. The corollary is that, without contiguous rainforest providing the fuel in terms of a high, sustained rate of evapotranspiration over the expanse of a river basin, precipitation inland will decline exponentially, on account of reduced condensation, such that Leticia, some 2,500 km from the mouth of the river, would receive less than 1 per cent of current precipitation. That catastrophic reduction in rainfall would be a consequence of a much diminished biotic pump, unable to bring about the necessary pressure changes such as are needed to suck in humid air from the ocean.

\section{Costa Rica}

In their biotic pump theory, Makarieva and her colleagues postulate that the high rate of evapotranspiration maintained, in the case of tropical humid rainforests, throughout the year, will lead to a net upwards force resulting from water vapour partial pressure changes. Those changes have a twofold element: a) the partial pressure of water vapour b) condensation brought about by a combination of an ELR (Environmental Lapse Rate), which reduces temperature with altitude, and the release from vegetation of cloud condensation nuclei (CGNs). The net result of the vegetative pumping of water vapour via evapotranspiration into the surface atmosphere, followed by substantial condensation leads to acceleration upwards, hence in the vertical plane, of the lower air mass. Air, as indicated in the Biotic Pump theory, to replace that upwards motion, will be sucked in from the horizontal plane. In effect, condensation reduces atmospheric surface pressure, and evapotranspiration therefore augments it. Graph 25 shows the results of an experiment to look at the impact of pressure changes brought about through condensation of water vapour on airflow. We see clearly how the airflow 
increases when the partial pressure of water vapour reduces because of condensation and vice versa how the airflow reduces as the humidity rises.

Graph 25. Impact of pressure changes brought about through condensation of water vapour on airflow

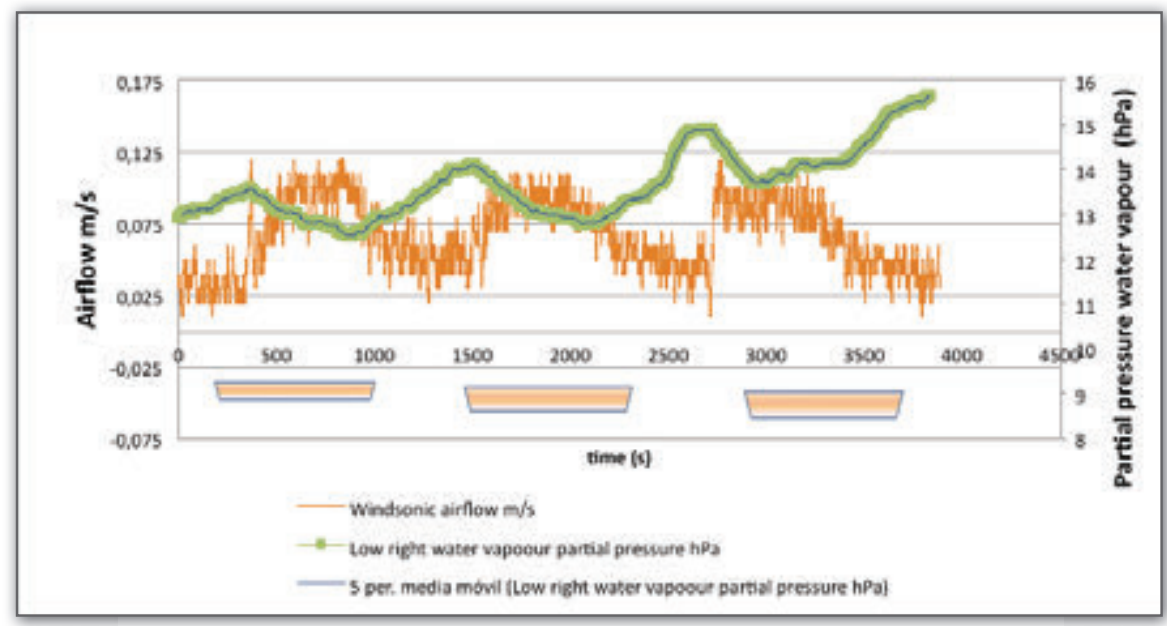

Source: Author.

The effect of condensation on the partial pressure of water vapour $(\mathrm{hPa})$ showing how, between condensing cycles, the humidity rises and hence the pressure increases, while during condensation the pressure falls. The airflow reduces as the partial pressure increases and vice versa increases when the partial pressure declines because of condensation.

Following the example of Makarieva, Gorshkov and colleagues (Makarieva, Gorshkov, \& Li, 2013), we can estimate the upward air velocity, albeit crudely. Global evaporation over the Earth's surface amounts to an average of $1000 \mathrm{~kg}$ of water vapour for every square metre per year. That works out at some 55,000 gram-molecules per square metre per year and, using an average surface temperature of $15^{\circ} \mathrm{C}$ and the classical ClausiusClapeyron equation to give us the partial pressure of water vapour under those conditions (saturated) we obtain the specific humidity and air density such that we can calculate the saturation water vapour concentration at the surface of 0.71 gram-mol per cubic metre (flow sheet figure 15). That being so, the upward velocity of the air from evaporation is: 


$$
\omega_{\bar{E}}=\frac{\bar{E}}{N_{H_{2} \mathrm{O}}}=2.47 \mathrm{~mm} / \mathrm{s} .
$$

We can also apply the same basic calculations to the Amazon Basin. If we take the average evapotranspiration at $4 \mathrm{~mm}$ daily at an average day time surface temperature of $25^{\circ} \mathrm{C}$, we obtain a of $2.05 \mathrm{~mm}$ per second. Since power is related to force multiplied by velocity, we can calculate the average global power engendered as a result of global evaporation and equally the average power engendered from Amazonian evapotranspiration. Thus, the global power amounts to $0.074 \mathrm{~kg}-\mathrm{m} / \mathrm{s}$ over each square metre and the power of ET over the Amazon Basin to $0.11 \mathrm{~kg} \mathrm{~m} / \mathrm{s}$ over each square metre. Those numbers are derived from calculating the evaporative-condensation force in $\mathrm{hPa} / \mathrm{km}$ and converting to $\mathrm{kg} / \mathrm{m}^{2}$. The net evaporation/condensation vertical power over each square metre of the same latitude tropical Atlantic as Amazonia is approximately one half that of Amazonia and that of the oceanic latitude of the Sahara another half less again, as measured from radio-sounding data.

\section{The evaporative-condensation force and winds}

Whereas radio-soundings provide us with the raw data to calculate water vapour densities and the evaporative/condensation force for each site and day, when readings are available, they do not give us the tools to correlate changes in wind velocity with changes in the partial pressure force derived from evaporation and evapotranspiration, the latter associated with vegetation rather than open bodies of water. Through providing meteorological data at half-hour intervals over 24 hours, OTS biological stations (Organization of Tropical Studies) sited in Costa Rica, give us the opportunity to test for such correlations. The data can then be summed for each month. As a result, we obtain interesting correlations which support the notion that wind-speed changes and the partial pressure of water vapour at the surface may indeed be associated (graphs 26 and 27). Using Pearson and Spearman we can correlate such associations quantitatively (table 5). 
Graph 26. La Selva OTG biological station, May 20th, 2012

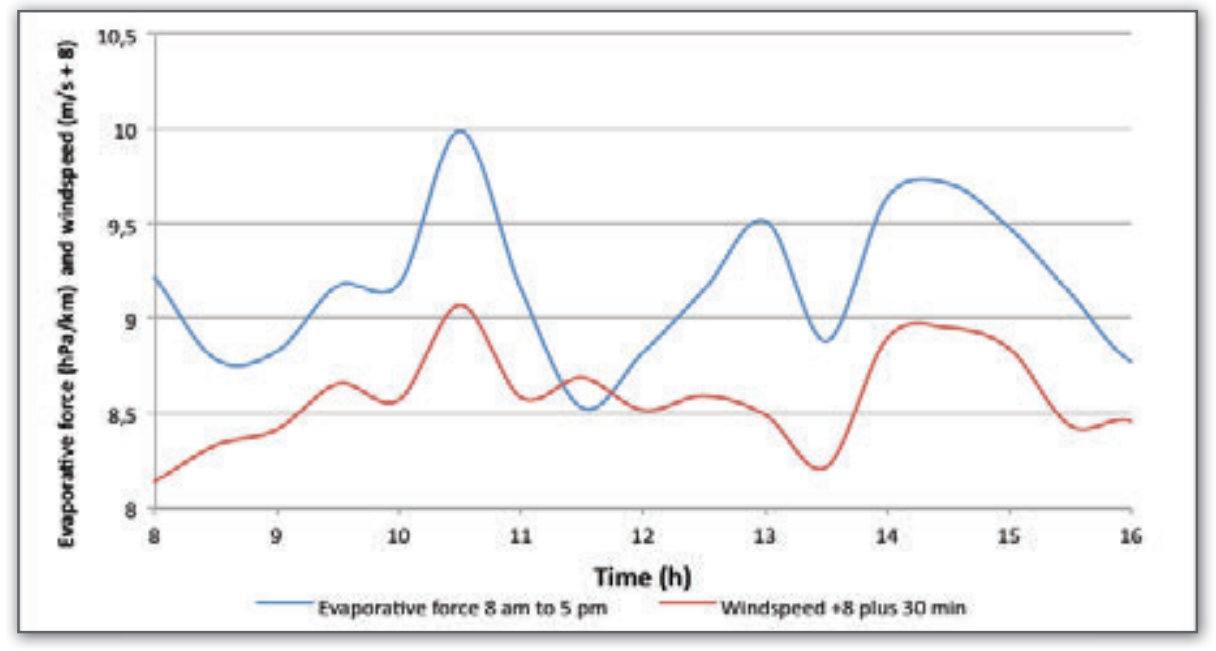

Note: Shows a strong correlation between the evaporative/condensation force $\mathrm{fE}$ and windspeed, with a 30 minute lag in the latter. Source: Author.

Graph 27. La Selva, 15th October 2012

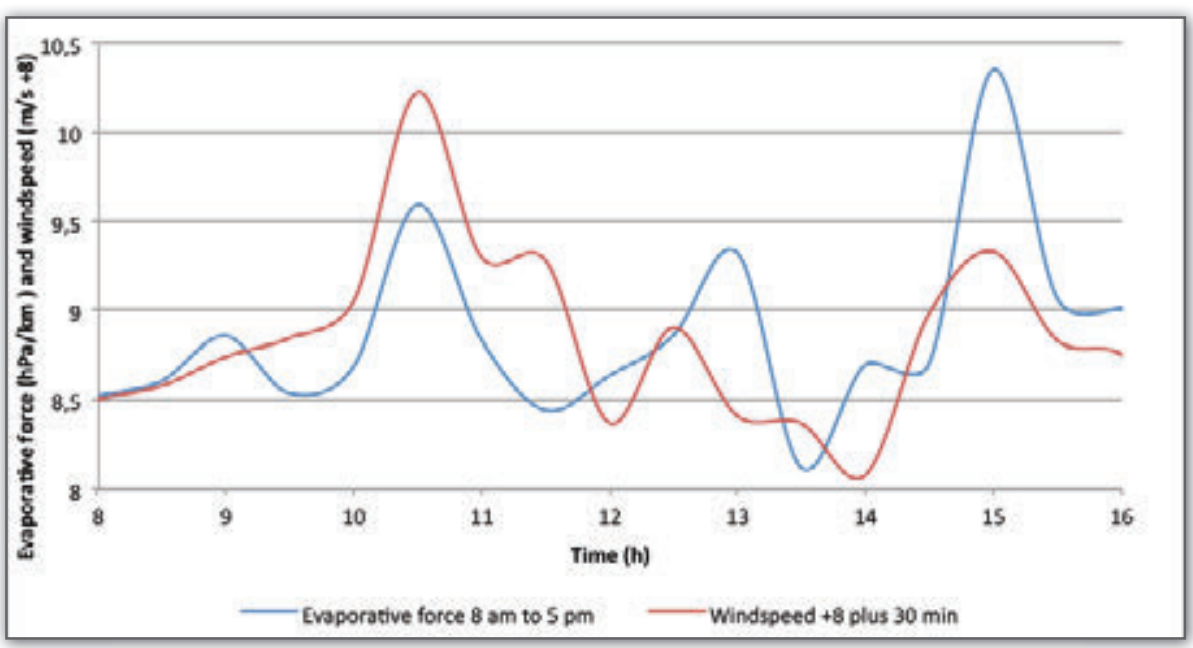

Source: Author. 
How the Biotic Pump links the hydrological cycle

and the rainforest to climate

Table 5. Correlations between $\mathrm{f}_{\mathrm{E}}$ and windspeed, La Selva, 25th December 2011

\begin{tabular}{|l|c|c|c|}
\hline \multicolumn{1}{|c|}{ Time 10am -2pm } & Golumn 1 & Column 2 & Column 3 \\
\hline slope of fE & 1 & & \\
\hline slope of wind & 0.919431 & 1 & 1 \\
\hline slope of wind $+30 \mathrm{~m}$ & -0.80534 & -0.63923189 & \\
\hline & & & \\
\hline \multicolumn{1}{|c|}{ Time 2pm-6pm } & Golumn 1 & Column 2 & Column 3 \\
\hline slope of fE & 1 & & \\
\hline slope of wind & 0.883049 & 1 & \\
\hline slope of wind $+30 \mathrm{~m}$ & -0.64508 & -0.52256536 & 1 \\
\hline
\end{tabular}

The Organization for Tropical Studies, as a non-profit consortium of some 63 universities from the United States, Australia and Latin America, owns and operates three biological stations in Costa Rica:

1. La Selva, in Serapiquí, which consists of lowland humid tropical forest on the Caribbean east side of the mountain range which straddles Costa Rica from south to north and extends into the Braulio Carrillo National Park. La Selva is recognized internationally as one of the premier facilities for rain forest research;

2. Palo Verde Biological Station lies in the heart of Palo Verde National Park in the North-Western Pacific lowlands and is known for its deciduous dry forest, freshwater marsh and extensive wetlands. The relative humidity is low in general compared to that of La Selva;

3. Las Cruces Biological Station and Wilson Botanical Garden on Costa Rica's southern Pacific slopes, is noted for its extensive collection of palms, bromeliads and endangered plants. Las Cruces is part of the Amistad Biosphere Reserve.

As pointed out, each of these three sites provides constant meteorological data, subdivided into half-hour intervals during the 24 hours of each day. The data can be assessed directly from the OTS website. In June 2011 I was invited by Professor Mary Glenn of the Anthropology Faculty of the State University of Humboldt, Arcata, California, to spend time with her students 
at the La Selva, OTG Biological Station. There, Diego Dierick (Ph.D.), who was in charge of one of the flux towers, alerted me to the strong diurnal barometric tidal wave which was in evidence. I therefore embarked on a line of research in which I adapted the spreadsheet that I had developed for the radiosonde data so as to incorporate daily meteorological data from La Selva. Using the Excel spreadsheet to analyse the 49 rows for 24 hours, I was and am able to calculate the partial pressure of water vapour for each row, using the respective relative humidity and temperature.

To test the biotic pump theory with empirical data, I decided to look at the rate of change of various variables, including those of windspeed, evaporative force $f_{E}$, barometric pressure, temperature, air density and specific humidity. I used two methods and have shown that they coincide absolutely as well as reflecting the variations and changes in the crude data. I therefore measured the changing slope for each point during the 24 hours and measured how each point relates to changes in those points either side of it. The results for a typical day can be seen below, confirming my methodology (graphs 28 and 29).

Graph 28. Rate of change of evaporative force $f_{E}$

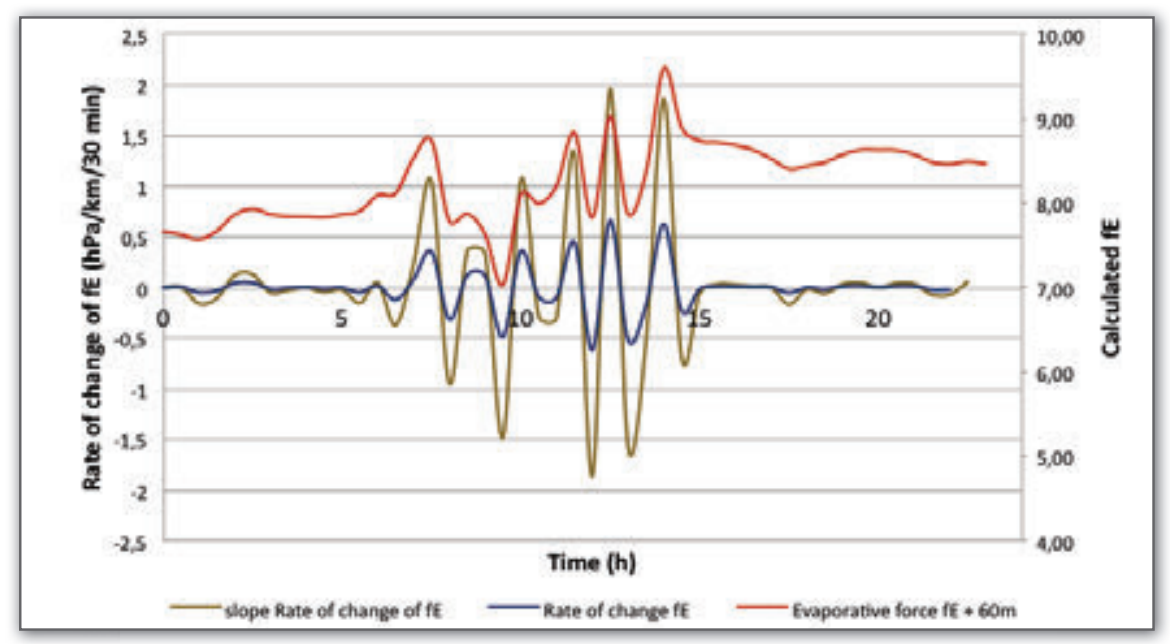

Source: Author. 
Graph 29. Rate of change of wind

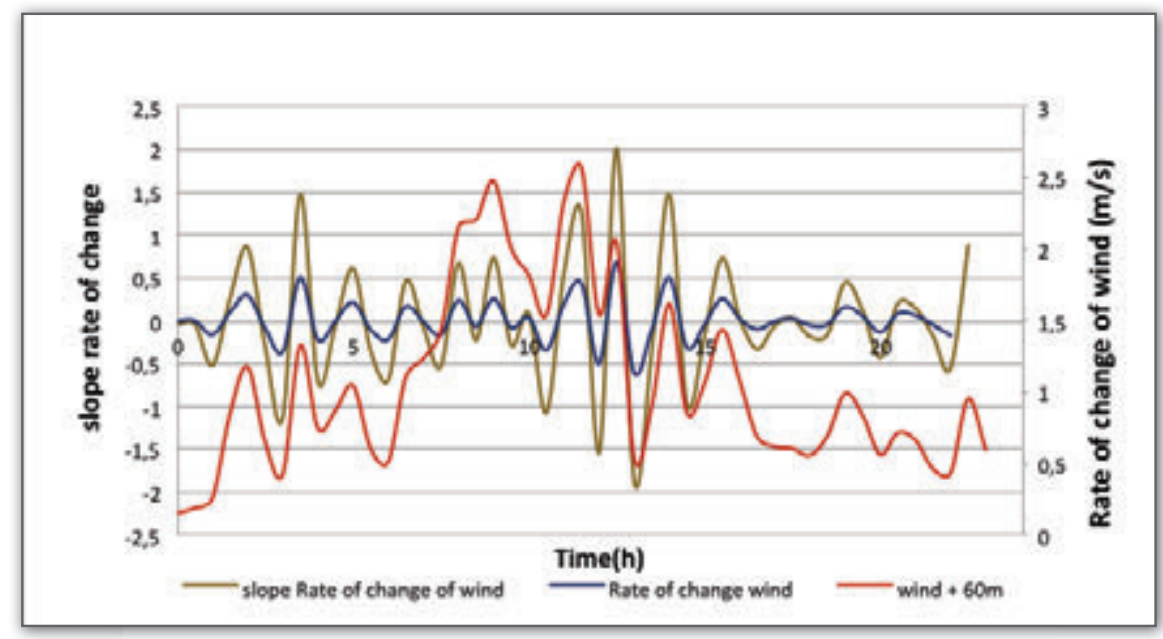

Note: Rate of change of wind in $\mathrm{m} / \mathrm{s}$ over a 30 minute period. The two methods for evaluating rate of change of wind speed coincide with the absolute data. Source: Author.

The purpose of all such calculations is to determine and register the changes and rates of change, whether positive or negative, over small slices of time for barometric pressure, for temperature, for air pressure changes, for air density and for wind speed, and then to determine whether any such changes correlate with variations over similar time scales of the partial pressure force of water vapour. An obvious way to measure the changes is through determining how the slope of consecutive data points varies in relation to that of the previous and successive points. Then, using Excel's built-in correlation analysis (Pearson \& Spearman) we can determine correlations, when they are strongly in evidence, for different days and sites, La Selva, January 18 2013 and Palo Verde, September 4 ${ }^{\text {th }}, 2011$.

In the graph for January $18^{\text {th }}, 2013$ (graph 30), we see apparent correlations during the daylight hours between the derived partial pressure force and wind speed, all of which coincides with a 'blip' in the barometric pressure. What becomes clear from the entire record of data, is that once the temperature starts increasing, (on account of a rapid increase in insolation) the partial pressure of water vapour in the surface atmosphere takes a sudden dip. That dip is generally followed by various peaks and troughs in the vapour partial pressure until relative humidity once again begins to rise. 
Graph 30. La Selva, January 18th, 2013

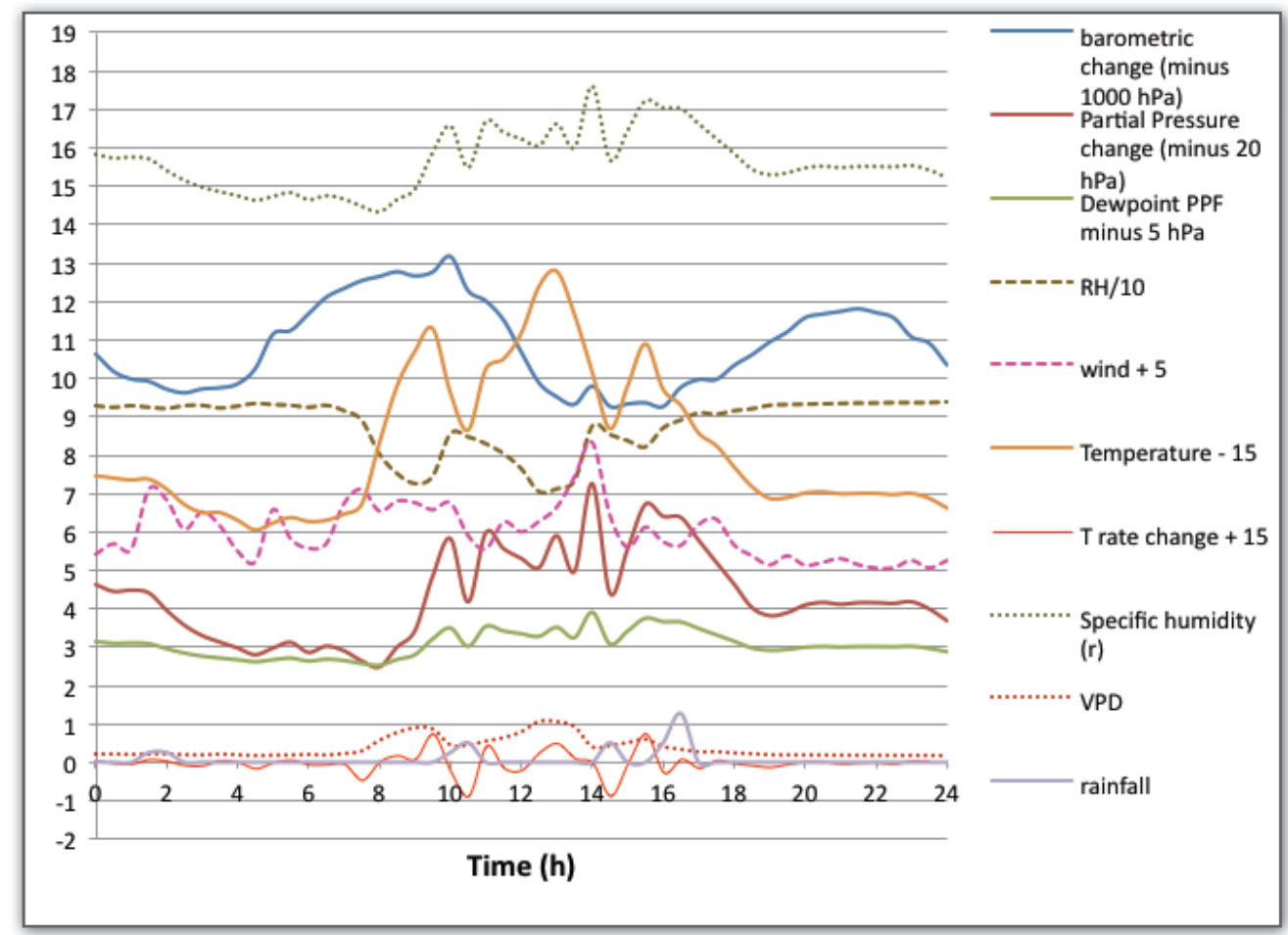

Source: Author.

This graph shows 24 hours of meteorological data, showing correlations between wind and changes in the partial pressure of water vapour. $\mathrm{X}$-axis is in hours (24) and the Y-axis are units contingent on the specific data, i.e. wind +5 ; RH/10; Dewpoint partial pressure WV - 5; etc. 
Graph 31. Palo Verde 4th September 2011

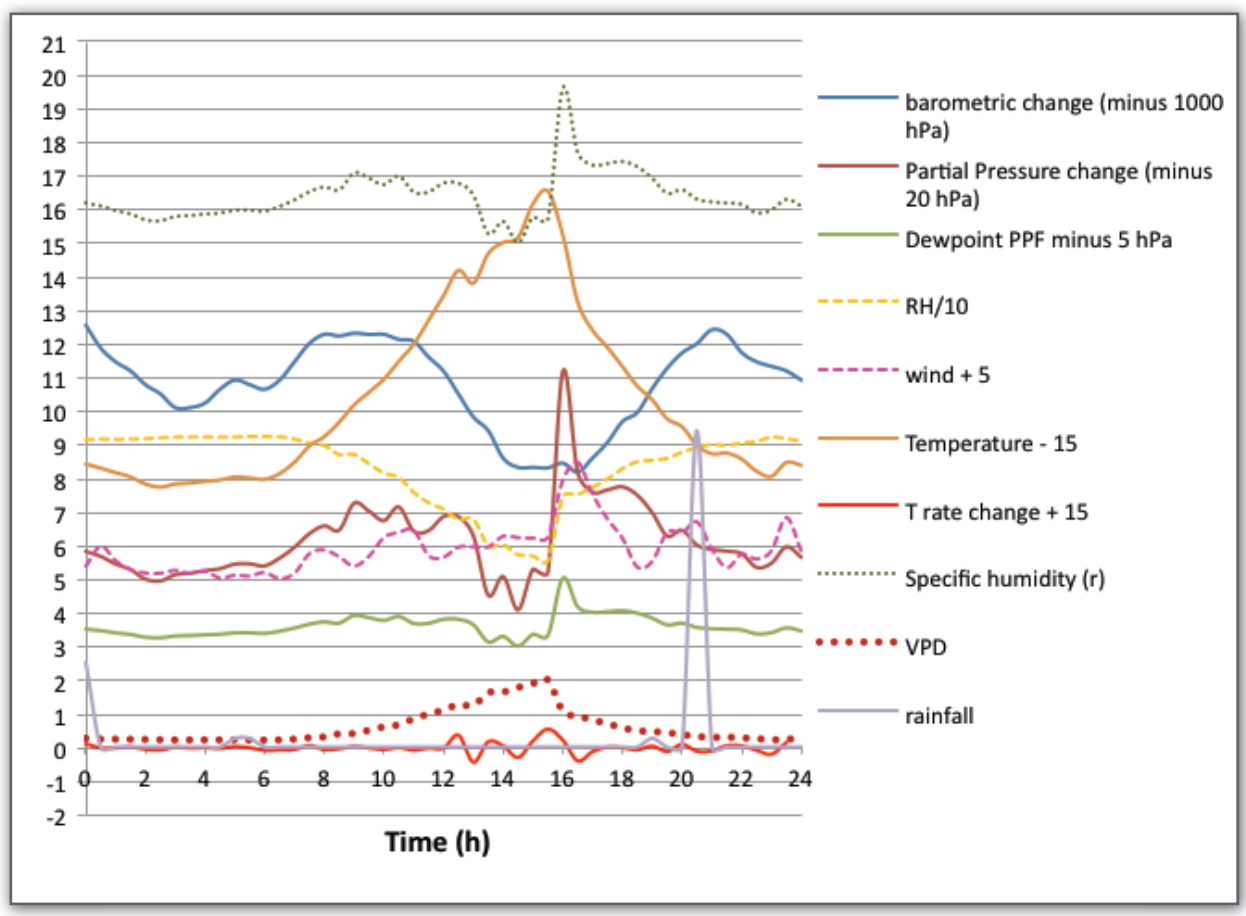

Note: This graph shows the correlations between windspeed and changes in the partial pressure of water vapour. Source: Author.

Given the same amount of water vapour in the surface atmosphere, obviously the relative humidity will increase as the temperature falls. However, the peaks in the partial pressure of water vapour, which occur simultaneously as the increase in relative humidity, coincide, as expected, with an actual increase in specific humidity. Thus, the specific humidity shows a rise between 8:00 am and 2:00 pm from some 14 grams of water vapour per kilogram of dry air to 18 grams. When we look at the correlation between the partial pressure force and the mean wind speed over 12 hours between 6:00 am and 6:00 pm for Palo Verde on $4^{\text {th }}$ September, 2011, we get the high value of 0.789. We get similar correlations with La Selva. A good example can be seen in the data for La Selva, 25 ${ }^{\text {th }}$ December 2011 (graph 32).

As with the radiosonde data, and using the formulas (see above) presented by Makarieva and her colleagues, we can calculate the scale height of water vapour in the air column $h_{v}$, as well as the prime condensation point, $h_{(H 2 O)}$. 
Having obtained those values we can continue with the calculation of the net upward force of the partial pressure of water in $\mathrm{hPa} / \mathrm{km}$. As before, it is a matter of applying basic physics to calculate the air density and the specific humidity in terms of grams of water vapour per kilogram of air and per cubic metre.

Graph 32. Rate of change of $f_{\mathrm{E}}$ versus windspeed, La Selva 25th December 2011

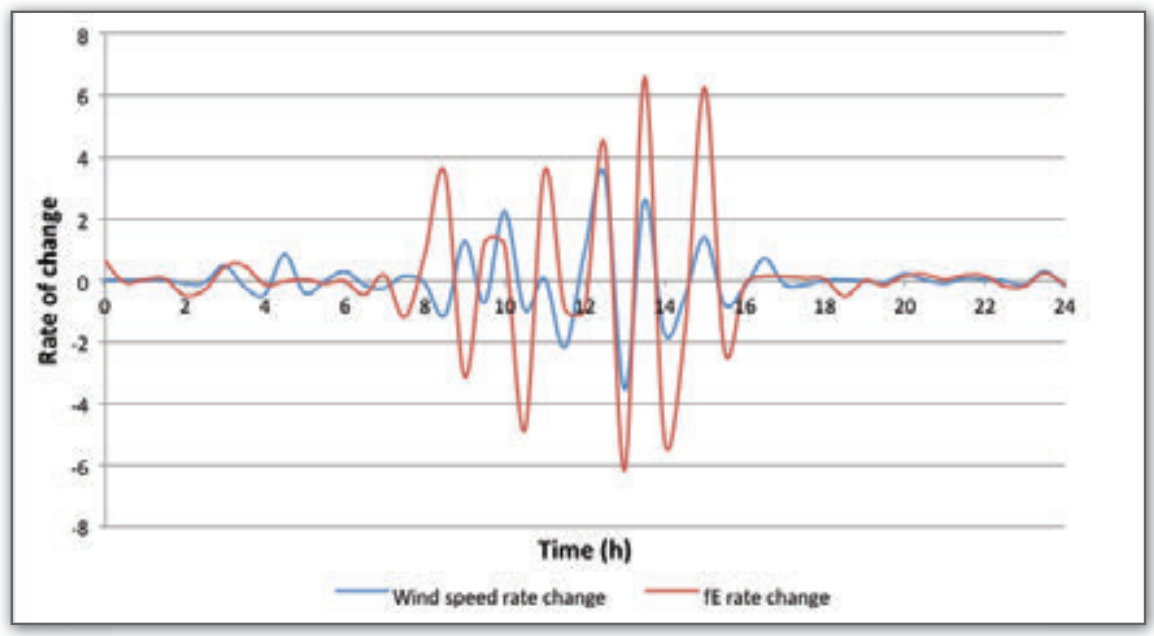

The windspeed rate of change in $\mathrm{m} / \mathrm{s}$ with a delay of 30 minutes and the rate of change of the evaporative/condensation force $\mathrm{f}_{\mathrm{E}}$. Source: Author.

Graph 33. La Selva 21st October 2012

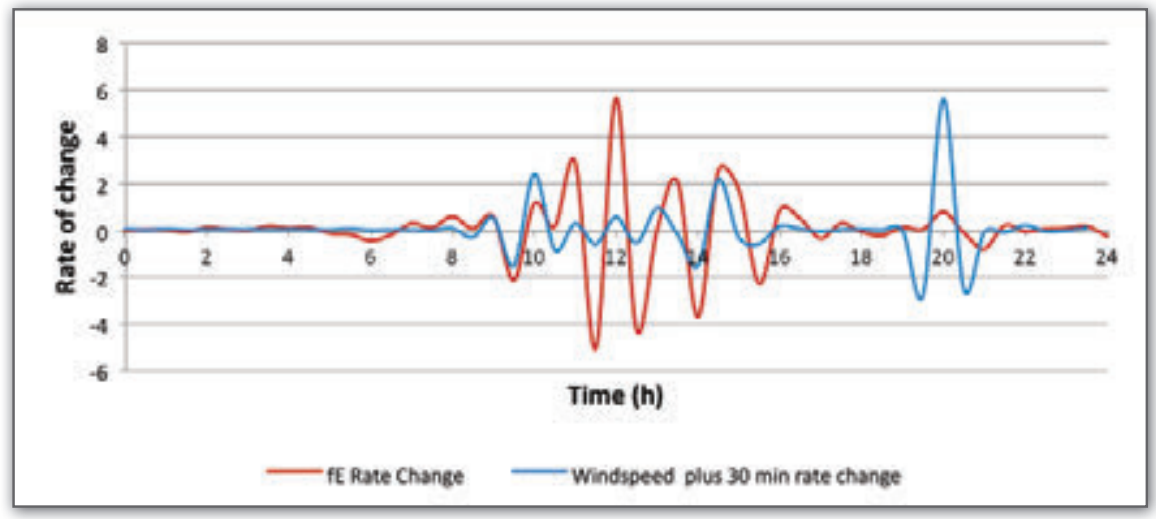

Note: The windspeed rate of change in $\mathrm{m} / \mathrm{s}$ with a delay of 30 minutes and the rate of change of the evaporative/condensation force $\mathrm{f}_{\mathrm{E}}$ in $\mathrm{hPa} / \mathrm{km}$. Source: Author. 
Graph 34. La Selva December 8th, 2013

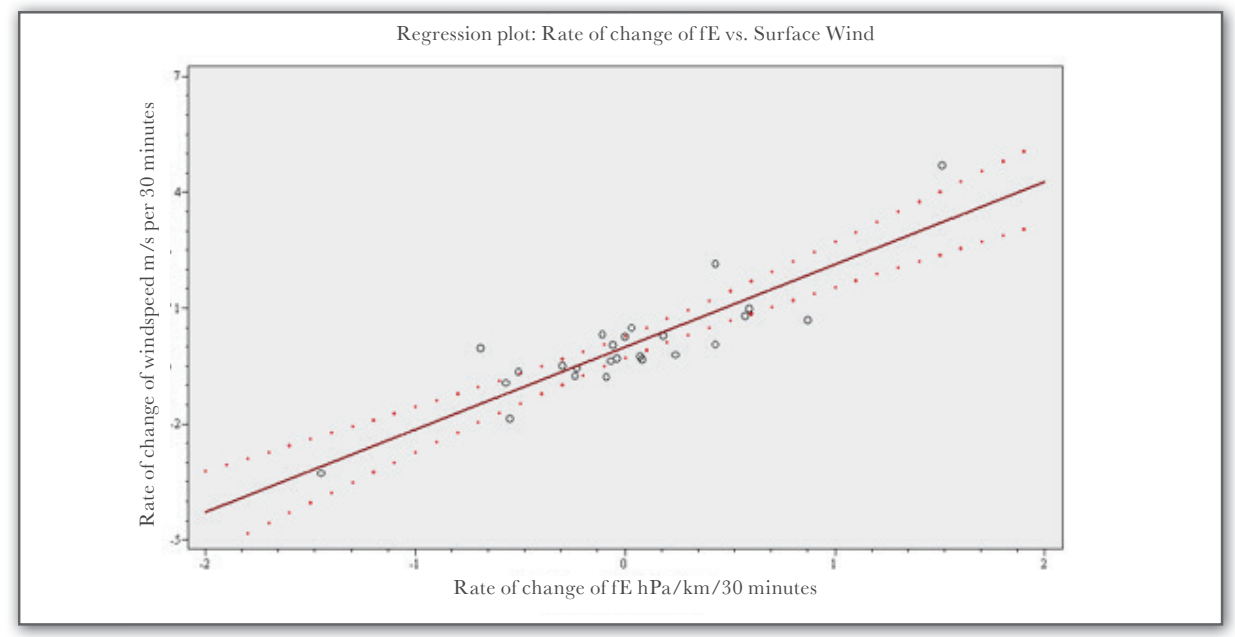

Note: Regression curve of rate of change of windspeed vs Evaporative Force $\mathrm{f}_{\mathrm{E}}$. Source: Author.

What is causing the increase in the velocity of the local wind(s)? Could it be the result of a reduction or possibly increase in temperature? Or could it be the result of the increase in the partial pressure force followed by a sharp period of condensation which acts, piston-like in the vertical plane and therefore draws in air in the surface horizontal plane? We must take into account the physics of the partial pressure force which depend essentially on the condensation of water vapour at approximately $2.5-4.5 \mathrm{~km}$ above the Earth's surface (as calculated in deriving $h_{(H 2 O)}$, thereby generating a partial vacuum. If, indeed, the increase in wind velocity were to be clearly and significantly correlated with the partial pressure change, then that would corroborate, if not prove, the Russian thesis of an evaporative/condensation, biotic force. 
Graph 35. Regression plot of $f_{E}$ vs windspeed rate of change

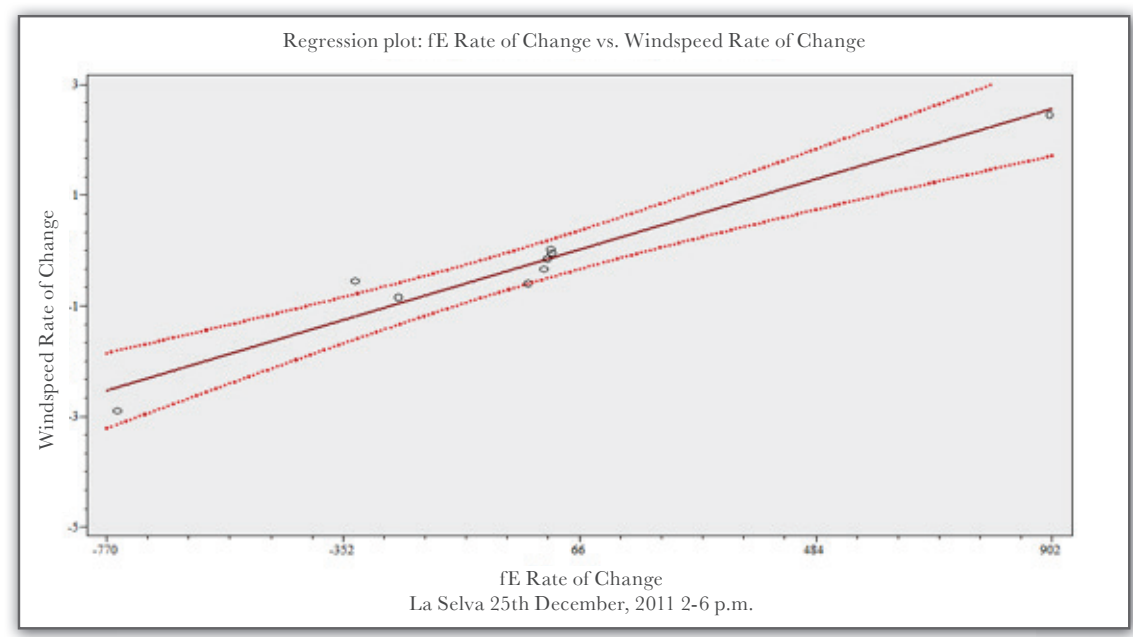

Source: Author.

Graph 36. Strong and weaker accumulated correlations for La Selva, March 2012

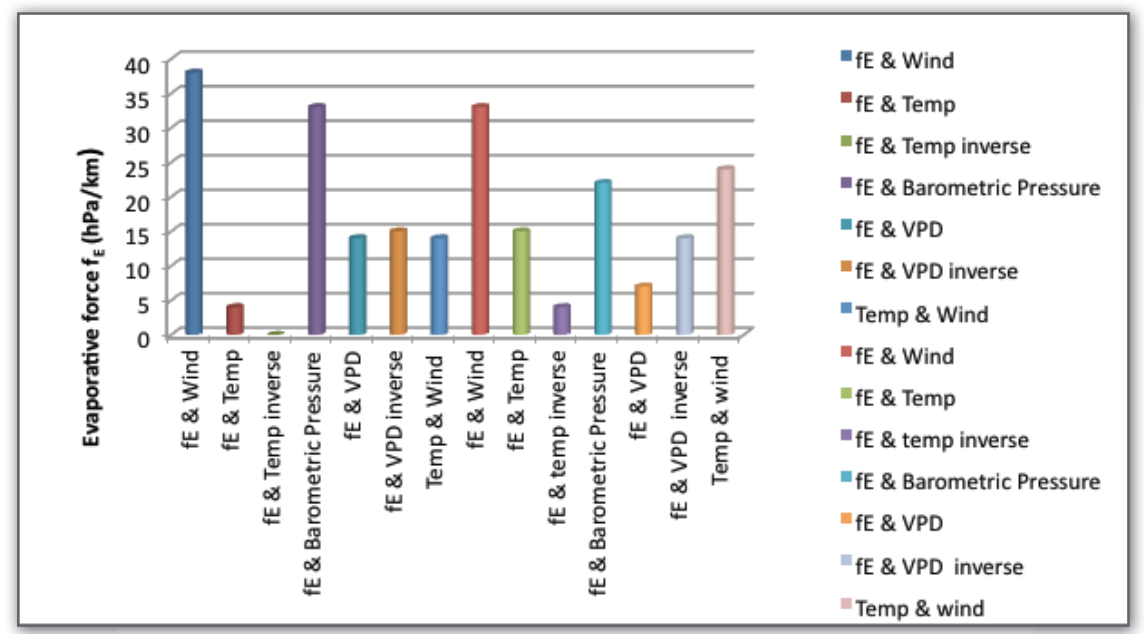

Source: Author.

Strong correlations 0.75 to 1.00 , on left and weaker correlations 0.5 to 0.74 on right. The correlations is between the evaporative force $f_{E}$, temperature, wind-speed, barometric pressure and the Vapour Pressure Deficit, 
VPD during daylight hours, 6am to 6pm. The highest correlations in each of the two categories, weak and strong, are for the relationship between wind and $f_{E}$.

\section{Diurnal Barometric Pressure Wave}

One noticeable feature of the low latitude tropics is the barometric tidal wave, which is seen at first glance as a double semi-diurnal sinusoidal wave. As the graphs below show there is clearly some relationship between the barometric tidal pressure wave and both relative humidity (adjusted to fit on the same graph) and equally air density. Air density, in fact, can be calculated from the raw Costa Rica data through the application of the equations of state for ideal gases.

What is causing such a distinct pressure wave? Certainly, the apparent movement of the Sun across the Earth during respective daylight hours is a prime factor as a result of heating the outer atmosphere - notably the thermosphere. Given how thin the atmospheric skin of air is in relation to the Earth's diameter, that heating transfers rapidly down to the surface and thereby expands the air and alters the resulting barometric pressure. Furthermore the presence of ozone in the stratosphere and water vapour in the troposphere, both of which are greenhouse gases, contributes to heat being retained at the surface and hence to further changes to surface barometric pressure. But is that a full explanation of the distinct form of the pressure wave, which takes the form that it does at the humid continental tropics, as distinct to a much flatter pressure wave at high latitudes?

Interestingly, barometric data for Northern Finland over 50 years, taken from a region with boreal forest, indicates that uniquely during September the diurnal barometric curve takes on the characteristics of the humid equatorial tropics. That finding fits in with the notion that the biotic pump functions during the late summer months in the boreal regions of the northern hemisphere, but not during the long winter, when the sun is barely seen to shine.

Table 6. Localization of Jokioinen

Jokioinen:

Latitude: $60^{\circ} 48^{\prime} 50.44^{\prime \prime}$

Longitude: $23^{\circ} 29^{\prime} 51.40^{\prime \prime}$

Source: Author. 
With the physicist, Dr. Plamen Netchev, and Carlos Peña of the Sergio Arboleda University in Bogota, Colombia, we have therefore used a statistical approach, involving the Fourier Series, to simulate the barometric wave and derive specific coefficients which relate to pressure. We have obtained the following mathematical expression to fit the data (Bunyard, Netchev, Peña, \& Redondo, 2012):

$$
\text { Bar pressure } p=p_{0}+\left(p_{1}-p_{2} \cos \left(\frac{\pi t}{12}\right)\right) * \sin \left(\frac{\pi t}{12}\right)
$$

For instance applying that expression with the respective values for $P_{0}, P_{1}$ and $P_{2}$ and being $1008 \mathrm{hPa}$ (1006 for May to June), 0.64 and 3.08 we obtain graphs 37 and 38, as seen below.

Graph 37. La Selva barometric waves, averaged for different months in 2012, with simulated waves

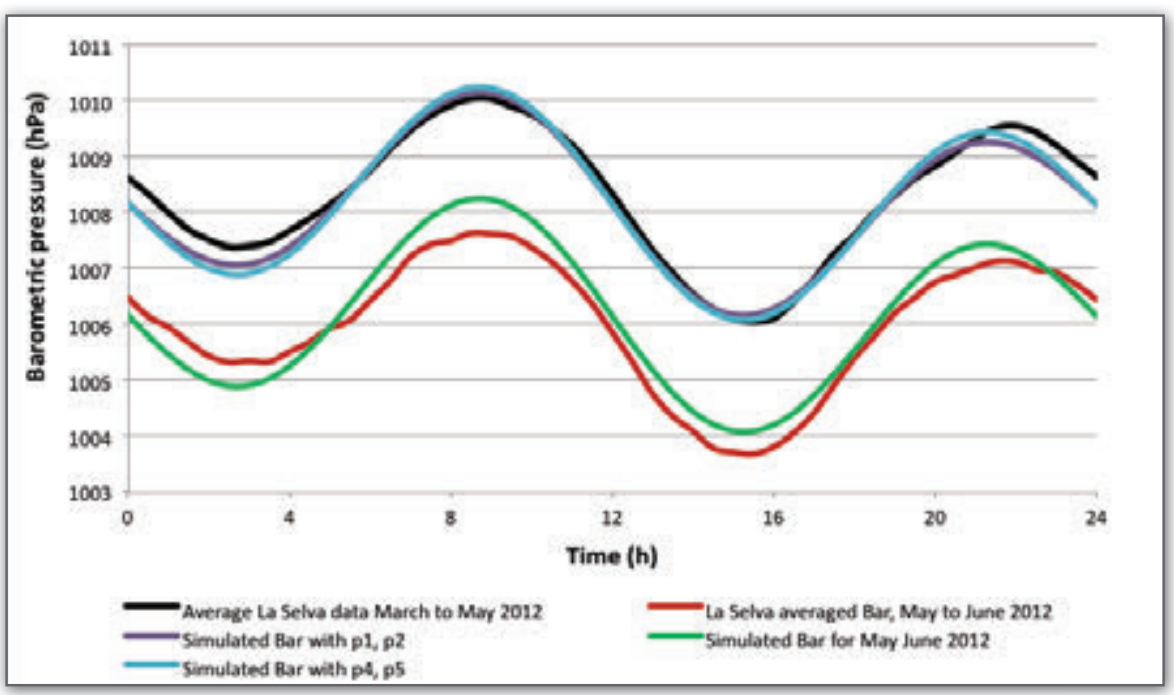

Source: Author. 
How the Biotic Pump links the hydrological cycle

and the rainforest to climate

Graph 38. Palo Verde March to April, 2012, averaged barometric diurnal wave against simulated curve

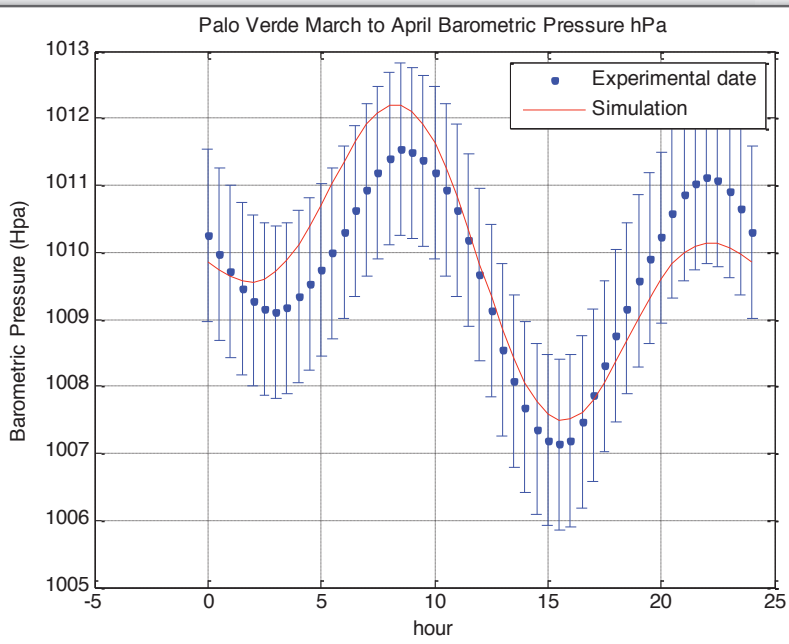

Source: Author.

Graph 39. Barometric average data for the 10 years, for Jokioinen in Northern Finland

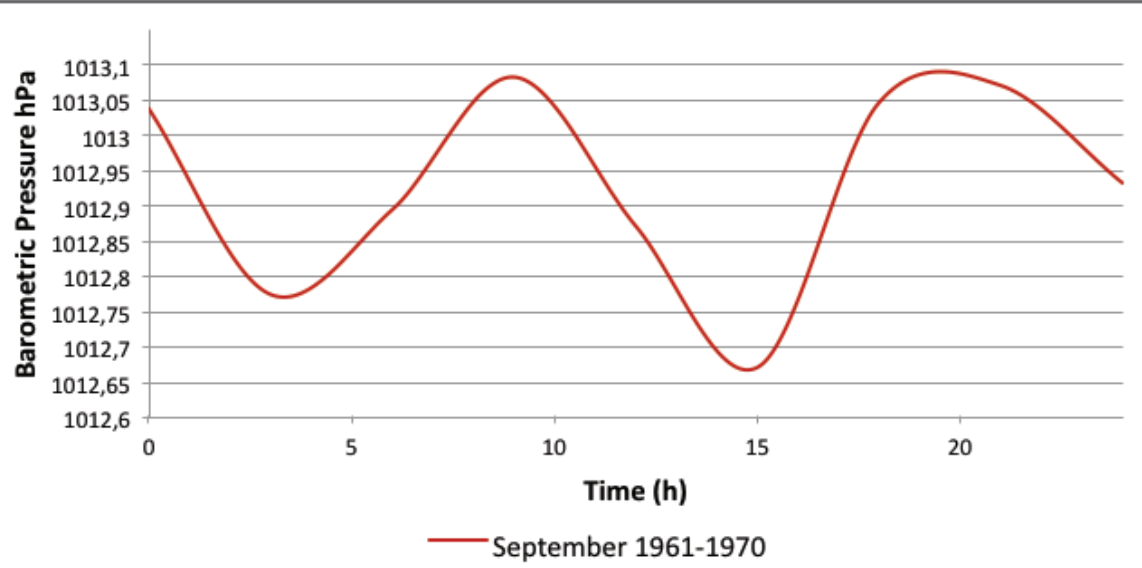

Source: Author. 
This graph indicates remarkable similarities with the barometric diurnal wave of the equatorial tropics. Only in September is such a marked similarity in evidence, indicating a probable connection with enhanced evapotranspiration.

Graph 40. Jokioinen for June 1961-1970

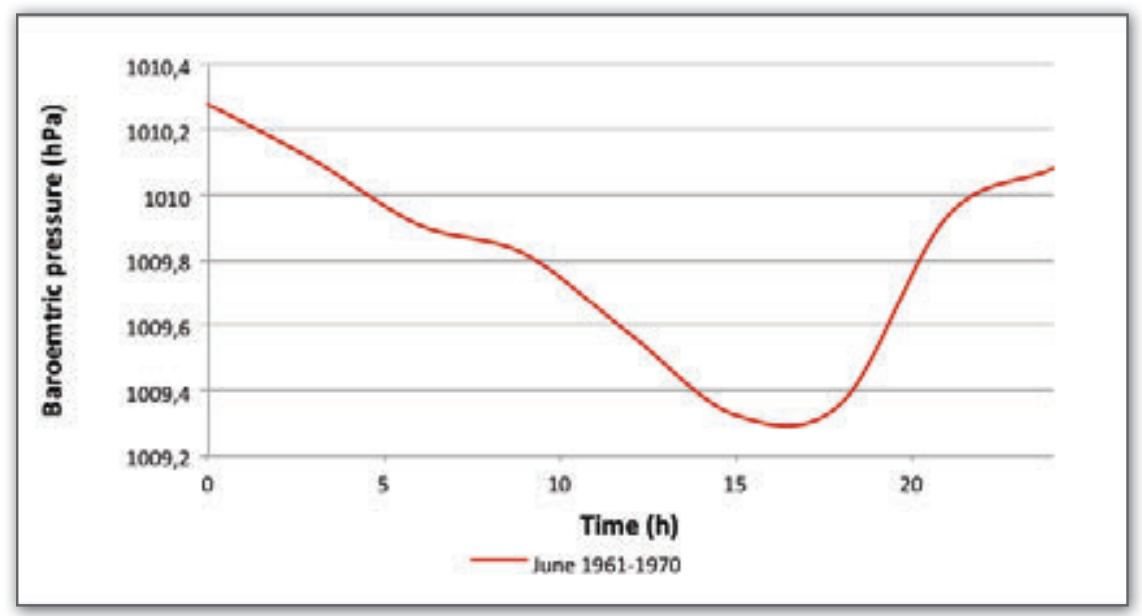

Source: Author based on information of Met-Office, s.f.

As can be seen from the above graph for La Selva (graph 37), covering two 45 day periods, we obtain relatively good concordance with the averaged barometric pressure. In particular, Dr Nechev has discerned that it is incorrect to assume, as some have suggested, that the second semidiurnal wave is a harmonic resonance of the first. When we pull out the cosine expression from the first of the two equations, we obtain a significant relationship with relative humidity and air density. It becomes clear that initially the relationship between the peak in the cosine expression and that of either relative humidity or air density is delayed, but, as the day progresses, the time difference between the curves shortens.

Consequently, we propose that $P_{1}$ relates to the solar input during the daylight hours and those of darkness, while $P_{2}$ relates to the biotic pump and the processes of evapotranspiration and condensation, hence the delays to the cosine fraction of the semi-diurnal wave. Meanwhile, $P_{0}$ is the barometric pressure at time zero (Bunyard et al., 2012). 
Graph 41. The relationship between the cosine component of the barometric wave and relative humidity

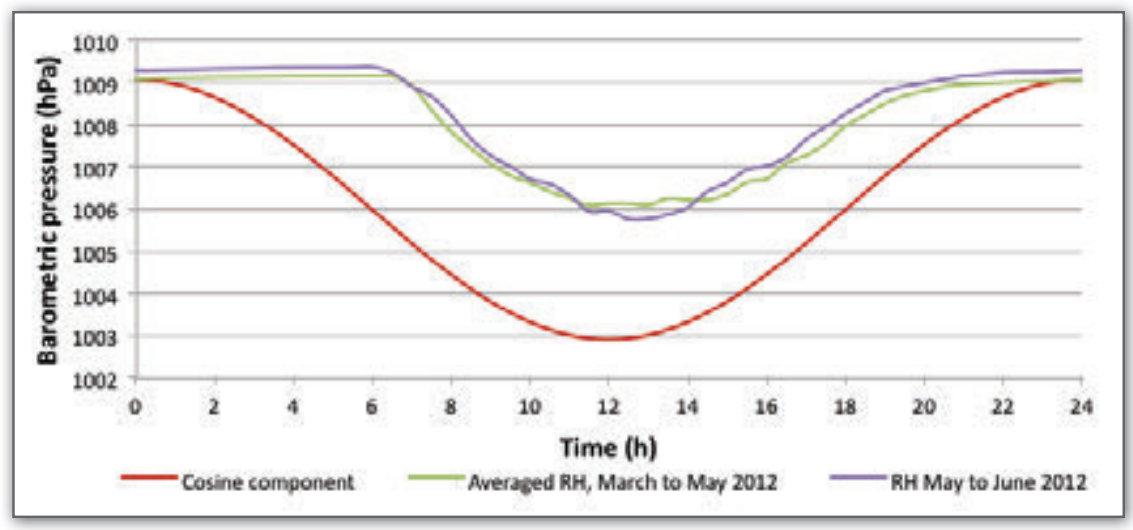

Source: Author.

If we are correct in our assumption that the biotic pump manifests itself as part of the barometric tidal wave, we will have made some contribution to the Makarieva/Gorshkov theory that the biotic pump must be included in climate models in order to give more realistic predictions as to the future consequences of deforesting large swathes of the Amazon Basin, or other forests for that matter.

Nonetheless, we must take into account that the empirical data does not indicate clearly and categorically that changes in the wind speed at the surface are absolutely associated with changes in the upward-directed evaporative/condensation force. Temperature plays its part, especially in providing the driver for evapotranspiration, as calculated through the application of ideal gas laws and the Clausius-Clapeyron equations. Yet, in various graphs for La Selva, for example graphs 33 and 34 and consistent during the course of the year, we see that variations in wind speed can be correlated with variations in the evaporative/condensation force, $\mathrm{f}_{\mathrm{E}}$. Indeed, as shown earlier, the strongest and most persistent correlations associated with changes in wind speed are with $\mathrm{f}_{\mathrm{E}}$ rather than temperature (graph 36).

We also find a relationship between the daily measurement of condensation over the Pacific Ocean and the cosine curve, indicating that the atmospheric water path follows a relationship akin to that of relative humidity over the tropical rainforest (graphs 41-44). This finding certainly lends weight to 
our thesis that the barometric wave relates in good measure to daily variations in humidity and condensation.

Graph 42. Liquid water path determined over 24 hours

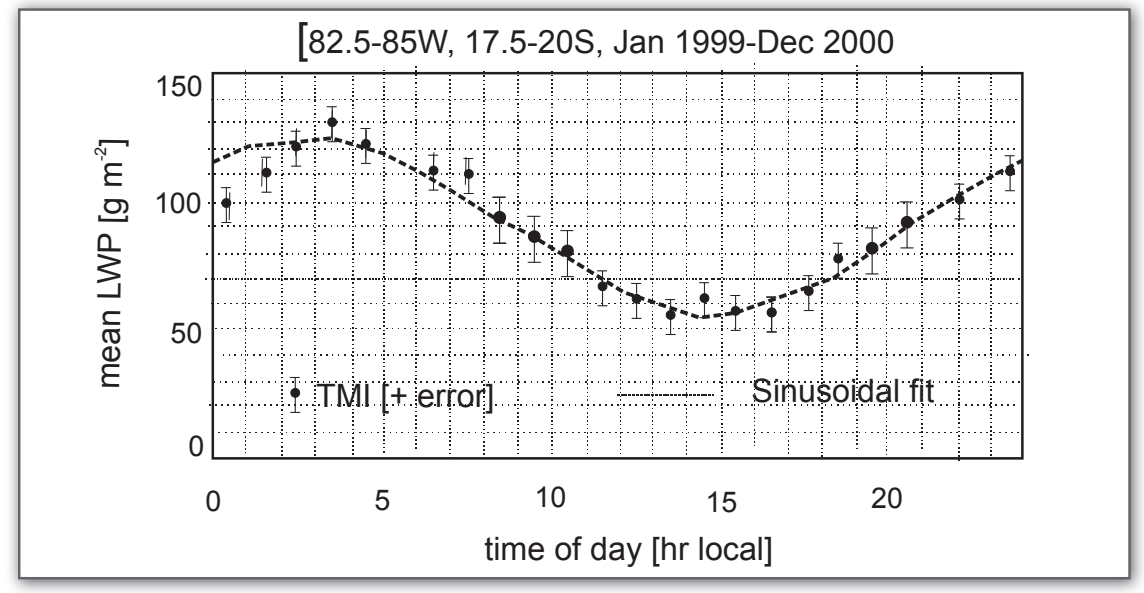

Source: Wood, Bretherton and Hartmann, 2002.

Atmospheric water path as determined over 24 hours in the Pacific reveals similarities with the cosine component derived from the barometric wave for La Selva, implying that the diurnal wave is strongly influenced by hydrology.

Graph 43. Cosine component of bar wave

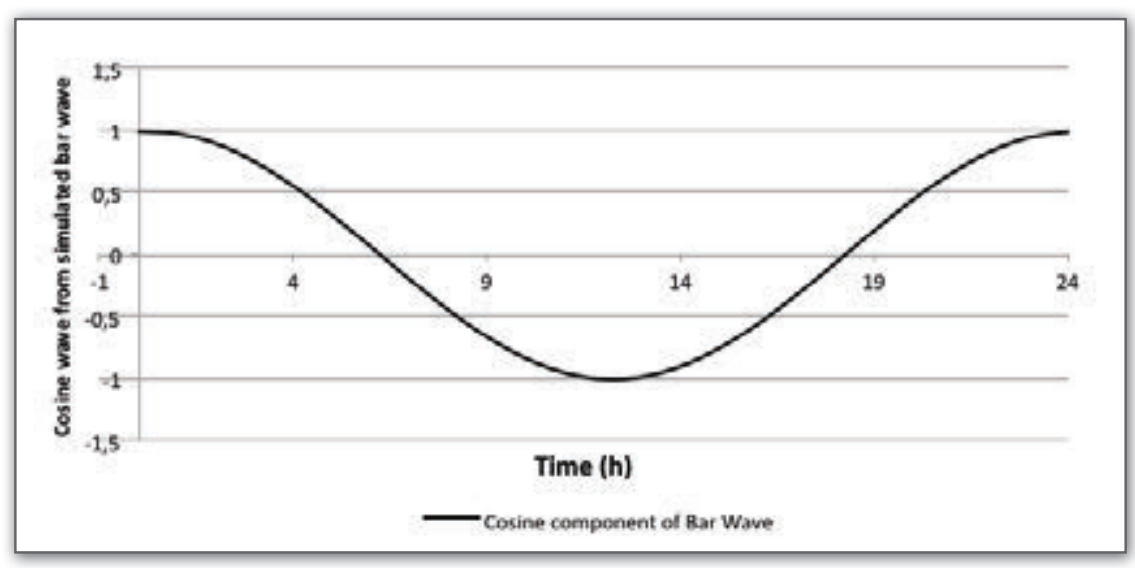

Source: Author. 
How the Biotic Pump links the hydrological cycle

and the rainforest to climate

Graph 44. Liquid water path over Pacific

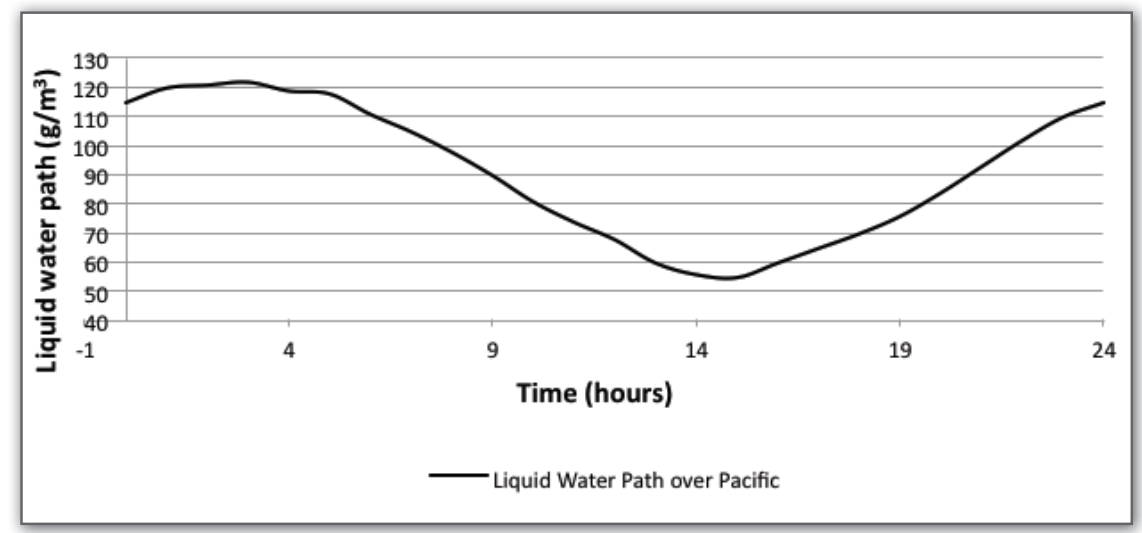

Source: Author. 



\section{Ghapter 4}

\section{DISGUSSION}

Qunlight is clearly the driver of all the processes

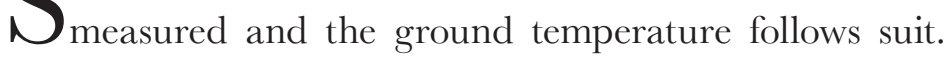
The degree of insolation received at the surface will depend on cloud cover and thickness, such that during rainy spells the insolation at the surface may decline by as much as 300 watts per square metre, as seen for La Selva, Costa Rica. The higher the temperature the more we would expect water vapour, as measured by specific humidity, to concentrate in the air column at ground level. The temperature increase during the daylight hours may be as much as $10^{\circ} \mathrm{C}$, from $23^{\circ} \mathrm{C}$ to $33^{\circ} \mathrm{C}$, at both the Costa Rica sites, La Selva and Palo Verde. However, humidity declines as the temperature rises above $30^{\circ} \mathrm{C}$, at least as encountered in data from La Selva, Costa Rica, (graph 45). That finding suggests that the rainforest shuts down its stomatal connection with the atmosphere once the temperature rises towards it meridiem daily climax. 
Graph 45. La Selva, Costa Rica

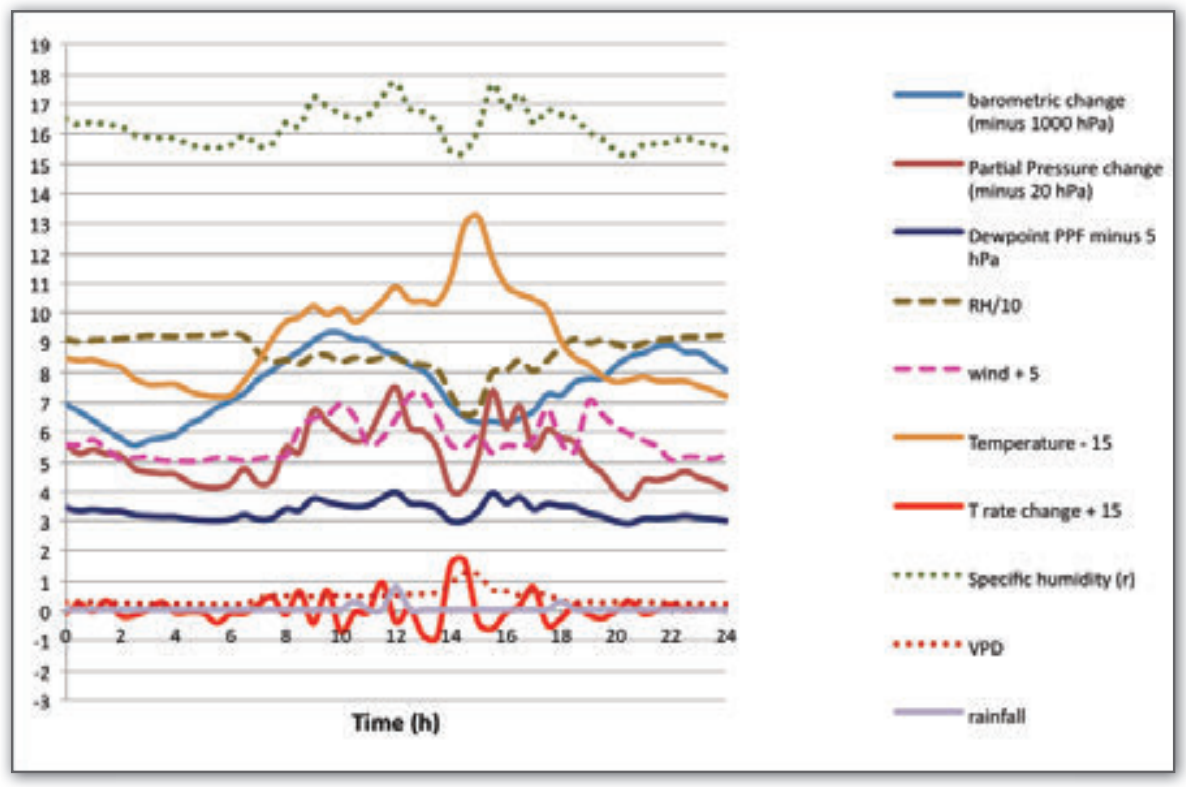

Note: As the temperature (brown) rises above $30 \mathrm{C}$, so the relative humidity, specific humidity and partial pressure of water vapour all decline, picking up again once the temperature falls later in the afternoon. Source: Author.

From registering the relative humidity changes during the period of rising surface temperatures, we observe that the relative humidity does not keep pace with the temperature and in general declines from 95 per cent or more during the cooler night time to 50 per cent or so during the heat of the day. By calculating the partial pressure of water vapour and the specific humidity we find that the values tend to dip suddenly with swift increases in temperature and rise to peaks as the temperature falls later in the day (graph 45). Meanwhile, as we have determined with the barometric pressure wave, the sharp dip in air density and the relative humidity of water vapour during the mid-morning to late afternoon, following a cosine trajectory, indicates that the pattern of change is maintained during the course of months and years. That trajectory also fits well with the biotic pump theory inasmuch as the barometric pressure declines as the partial pressure of water vapour reduces and builds up as the partial pressure increases. The theory anticipates that condensation, which reduces the partial pressure of water vapour, will cause the barometric pressure to fall by several millibars. 
Graph 46. Diurnal barometric tidal wave (hPa) for La Selva, Costa Rica

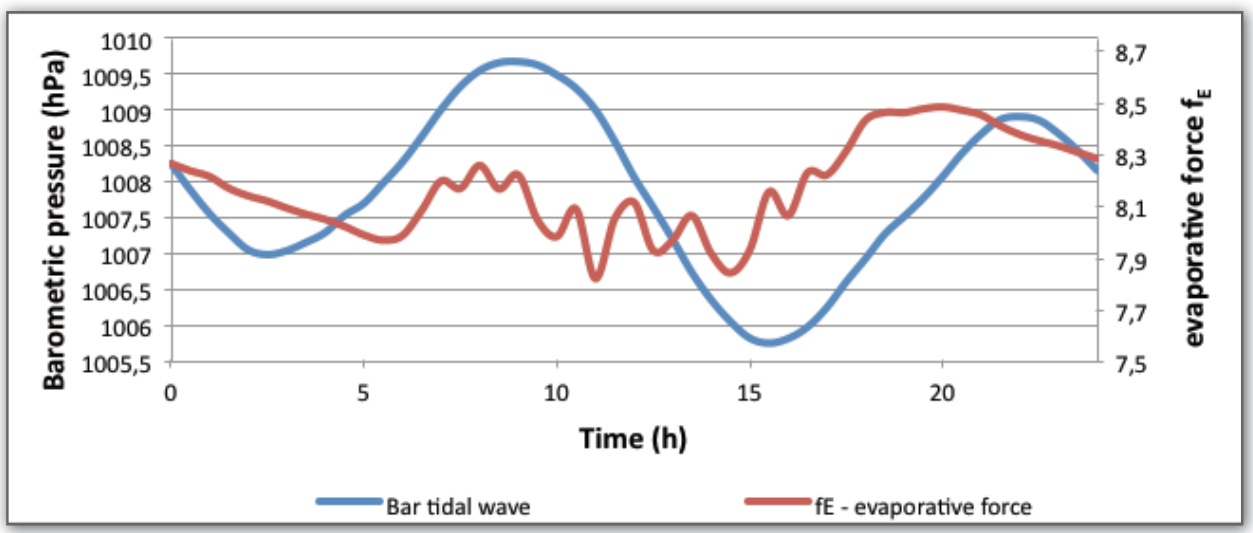

Source: Author. Note: Averaged over 24 hours and the evaporative/condensation force, $(\mathrm{hPa} / \mathrm{km})$, showing some corresponding relationship.

Since there are no large bodies of water in the immediate vicinity of the meteorological stations, it would seem that atmospheric humidity at ground level would be mainly provided for by evapotranspiration from the vegetation. That being the case, the abrupt changes in the partial pressure of water vapour in the air column just above ground level would be the result of stomatal opening and closing. With the rapid temperature increase the relative humidity will inevitably fall - hence a sharp increase in the Vapour Pressure Deficit (VPD) up to $2 \mathrm{kPa}$ and more - such as potentially to increase the drawing out and evaporation from the vegetation's vascular system. Yet, the suction generated by the drawing out of water will increase the chance that air will enter the vascular system, either in the water conduit formed by the dead tissues of the xylem or in the actual leaf vascular system. To avoid the cavitation caused by air interfering with the water column, the plant may protect itself by shutting down the stomata.

Current wisdom suggests that as the relative humidity falls, then the water vapour pressure differential between the inside of the leaf and the outside air will increase, such as to enhance transpiration. Peak increases in the water vapour partial pressure seem to be followed by an equivalent peak in the relative humidity. Which is chicken and which is egg here? Is that perceptible upward jump in relative humidity a consequence of enhanced 
water vapour pressure in the atmosphere, brought about through enhanced evapotranspiration? Or is the upward blip simply a consequence of a fall in the temperature? In fact, in evaluating the changes in the specific humidity we can show, as we would expect, that the curve follows precisely that associated with the partial pressure of water vapour curve and its derived partial pressure force. In that respect, the upward jump in relative humidity is seen to be associated with a rise in the specific humidity (graph 45).

Research into the relationship between temperature and evapotranspiration for various crops, such as beans, wheat and soya, suggests that an increase in surface temperature associated with a reduction in relative humidity causes the crop to respond through the forming of a large water vapour differential, according to Fick's diffusion law. In general, the crop takes up from the soil and transpires some $500 \mathrm{~kg}$ of water for each kilogram of new dry matter formed. Whatever the prime mover, our interest is in the relationship between temperature changes and stomatal regulation of transpiration.

To summarise: leaf internal temperatures during periods of daylight tend to be higher than those of ambient air on account of the leaf having a lower albedo and therefore a higher absorption of sunlight. That higher leaf temperature will lead to a higher vapour differential and therefore to an increased escape of water vapour from the leaf to the exterior, which can even occur when the ambient relative humidity is 100 per cent. Like sweating, the evaporation of water from inside the leaf requires latent heat of evaporation, some $44 \mathrm{KJ} / \mathrm{mol}$, which will therefore result in cooler leaf temperatures. Indeed, plant physiologists recognise that cooler leaf temperatures in the heat of the day may be a necessary condition for better photosynthetic efficiency, given that at higher temperatures the Rubisco-related reaction with oxygen increases, thereby reducing the availability of the enzyme system for $\mathrm{CO}_{2}$ conversion as a necessary step in photosynthesis. The Rubisco-oxygen reaction is known as photo-respiration and it is characteristic of C-3 plants in particular. One would therefore expect the stomata to open fully as the ambient temperature increases, such as to increase the flow of water vapour and thereby to cool the leaf surface exposed to the Sun.

However, during drought conditions plants may become water-stressed particularly, as is the case with many crops, they have a short-rooting system. 
When water-stressed, plants respond by reducing water-loss through stomatal-closure which in turn will reduce net primary production and, moreover, will lead to higher leaf temperatures. If the water stress continues the leaf may become damaged and no longer capable of maintaining photosynthesis.

Much of the literature on water vapour exchanges between vegetation and the ambient air expresses the view that the loss of water via transpiration is a necessary evil of successful primary photosynthetic production. Undoubtedly such views on plant-to-air water exchanges have largely been formed by plant physiologists who have focussed on crop and cultivar production, in particular when considering the net economic advantages of irrigation (Cruiziat, 2006).

Yet, it has become increasingly clear to climatologists and hydrologists that evapotranspiration helps maintain humidity, especially below the closed canopy of a humid tropical rainforest, thereby helping to keep soils moist and compensating for run-off. Indeed, as mentioned before, rainfall over the Amazon Basin, particularly in the central and western reaches, depends on a high rate of evapotranspiration. One concern relates to the impact of global warming associated with a doubling of pre-industrial levels of $\mathrm{CO}_{2}$ - from 280 to 560 parts per million by volume - on the ecosystem functioning of the rainforest. Both higher ambient temperatures and higher $\mathrm{CO}_{2}$ atmospheric levels will bring about the increased closure of stomata such as to reduce the exchanges of water vapour even when the ambient relative humidity falls. That loss of evapotranspiration potential could have a marked impact on the recycling of water vapour over the Amazon Basin such as to reduce rainfall significantly in the more western reaches (Betts, Sanderson, \& Woodward, 2008; Betts et al., 2002).

Furthermore, if the evaporative biotic pump mechanism functions as dictated by physics, a marked reduction in the water vapour partial pressure at the surface will lead to a lower if not a vanishing partial pressure gradient between the Amazon Basin and the tropical Atlantic Ocean such as to reduce the flow of the trade winds across the Basin. That reduced flow, associated with declining rainfall could bring about a sharp reduction in what are now the rich tropical rainforests to the west of the Basin and to the piedmont forests and cloud forests, which also play a fundamental role in precipitation patterns. 
D. Eamus and S. T. Shanahan have studied the relationship of the water vapour pressure deficit (VPD in $\mathrm{kPa}$ ) and stomatal closure under different conditions, taking into account cuticle transpiration as a significant component of overall evaporation (ET) from the leaf surface.

They observed:

The three phases of stomatal responses to VPD. For well watered leaves, as VPD increased from approximately $0.5 \mathrm{kPa}$ to approximately $5 \mathrm{kPa}$, ET (evapotranspiration) increased for small to moderate increases in VPD (from 0.5 to $2.5 \mathrm{kPa}$ ), remained approximately constant for moderate values of VPD (about 2.5-3.5 $\mathrm{kPa}$ ) and then ET decreased for larger values of VPD. Thus, stomata did not regulate ET with increasing VPD when VPD was low to moderate, but stomata did limit ET when VPD was moderate to large (Eamus \& Shanahan, 2002, p. 4).

And:

At low values of $[\mathrm{VP}] \mathrm{D}, \mathrm{E}[\mathrm{T}]$ increases with increasing [VP]D because the supply of water to the guard cell is sufficient to maintain guard cell volume and hence turgor, despite increasing losses of water from the guard cell through peristomatal transpiration and loss into the sub-stomatal cavity. Because turgor is maintained, stomatal aperture is maintained and hence transpiration increases with increasing [VP]D. At this stage, peristomatal transpiration is a very small fraction of total transpiration. However, above a certain value of $[\mathrm{VP}] \mathrm{D}$, the supply of water to the guard cell becomes insufficient to maintain guard cell volume. It is both peristomatal transpiration and water loss into the sub-stomatal cavity that causes the decline in guard cell volume and hence decreased aperture and hence lower transpiration. This loss of water from the guard cell therefore feeds back on guard cell volume, and aperture, such as to cause declining aperture at a rate sufficient to cause declining $\mathrm{E}[\mathrm{T}]$ (pp. 5-6).

Our results from three OTC meteorological sites in Costa Rica, namely Palo Verde, La Selva and las Cruces, of the Vapour Pressure Deficit (VPD) 
during the 24 hours show definite changes, with the major deficit occurring during daylight hours when the temperature rises. For Las Cruces, which is at 1200 metres above sea level and which harbours well-conserved premontane wet tropical forest, the day-time temperature does not generally exceed $26^{\circ} \mathrm{C}$. The VPD remains below $1 \mathrm{kPa}$ and, distinct from the other two sites, the partial water vapour pressure tends to rise as temperature rises and any dips during the daylight hours are considerably smaller than the plunging dips of partial pressure and specific humidity associated with temperature rises of $>30^{\circ} \mathrm{C}$ which occur at La Selva and Palo Verde (graphs 47 and 48).

Graph 47. Las Cruces, 2nd May, 2012

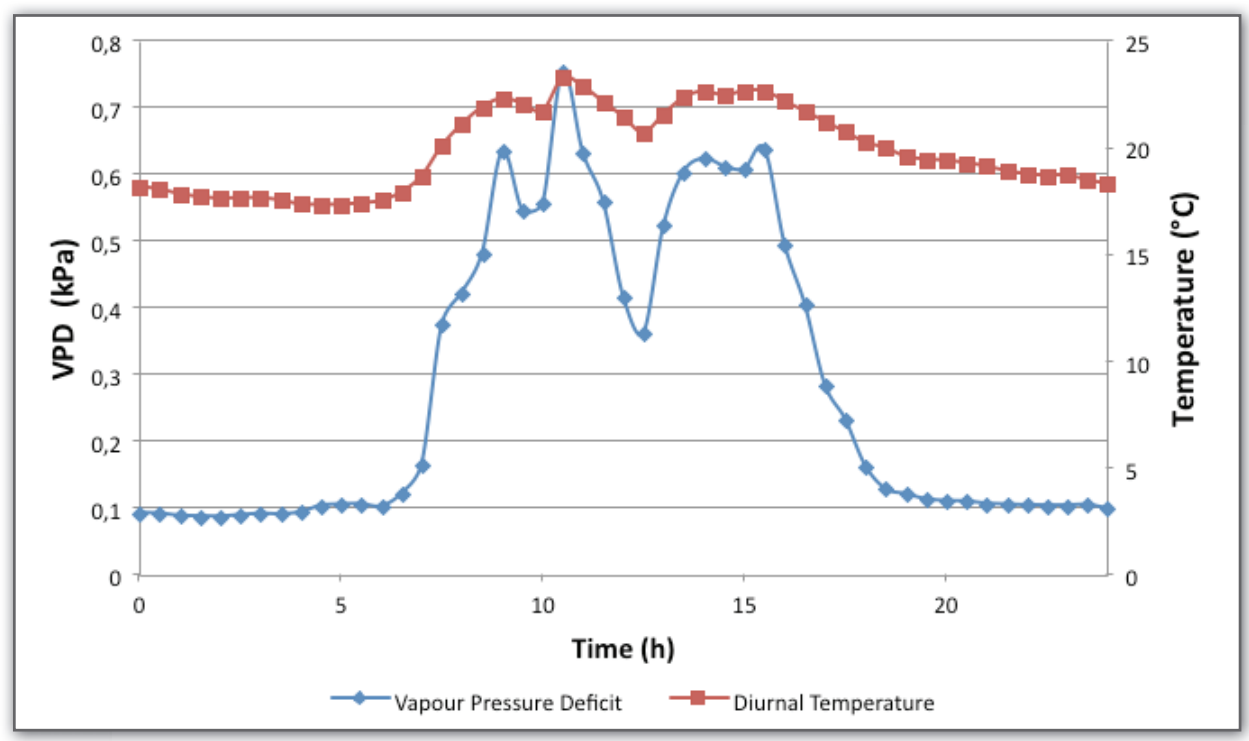

Note: It shows a direct relationship between the Vapour pressure deficit and diurnal temperature. Source: Author. 


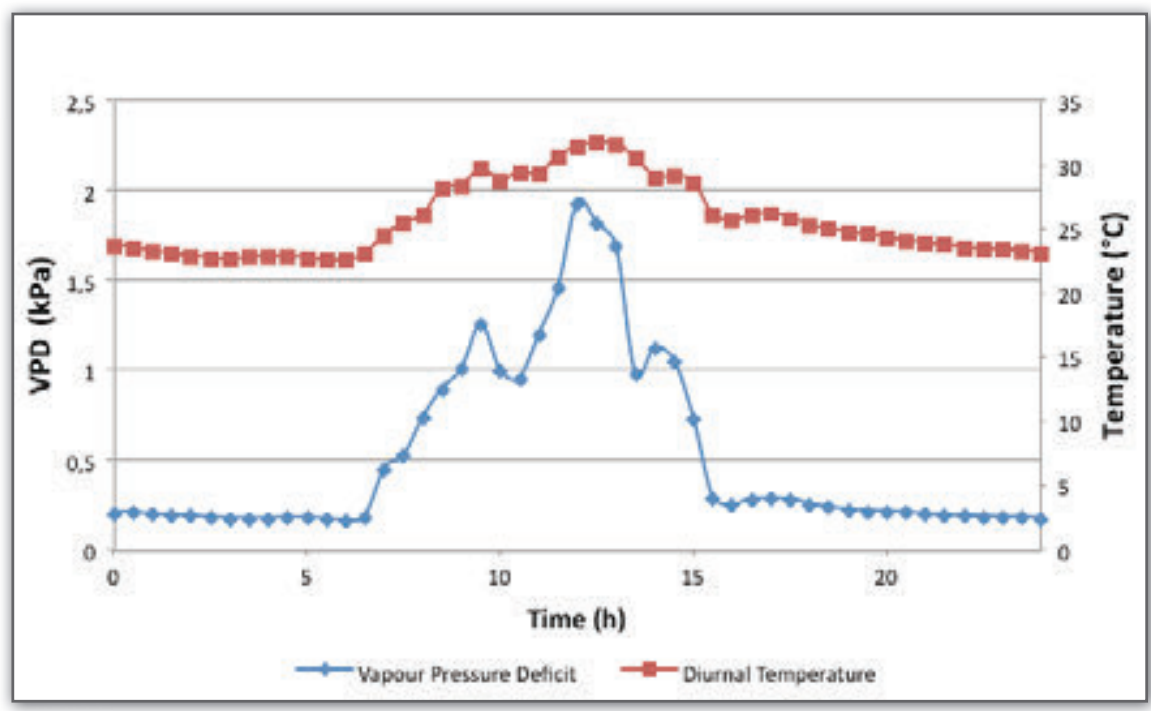

Source: Author.

\section{Experimental results: the ultimate proof?}

Finally, I refer back to the physical experiment as depicted in figures 9 10. Preliminary results indicate that condensation leads to airflow in a clockwise direction. I use webcams to follow the movement of light gauzes and video recordings indicate that the movement begins some 30 seconds after the cooling compressor is switched on. That movement is verified quantitatively through the use of sensitive anemometers. Together with Dr. Martin Hodnett, now retired from the UK Centre for Ecology and Hydrology, we are in the process of upgrading the instrumentation and already are obtaining outstanding results.

The preliminary results we have obtained consistently indicate a close correlation between the rate of condensation of water vapour, as induced through the use of refrigeration coils, and the airflow, which shows a marked directionality during different phases in the experimentation. The partial pressure change during 5 second intervals can be readily calculated from humidity, temperature and pressure changes. Likewise we can calculate air density changes and from those data we can calculate the expected wind 
velocity, using the kinetic energy equation whereby the power in Watts = $0.5 *$ air density $\rho$, * Area (square metres) * velocity cubed, $\mathrm{V}^{3}$. Since $1 \mathrm{~Pa}$ $($ Pascal $)$ per cubic metre $=1$ Newton $=1$ Joule.metre and 1 Joule.second $=$ 1 Watt, then $1 \mathrm{~Pa}$ change in partial pressure per second, per square metre $=1$ Watt. Therefore, with $p$ being pressure in pascals, $V$ velocity in $\mathrm{m} / \mathrm{s}$ and the air density,

$$
V^{3}=\frac{2 \Delta p}{\rho}
$$

When we carry out such calculations we obtain a remarkable correspondence between the airflow induced through condensation and the calculated kinetic airflow. Naturally, the partial pressures of water vapour as well as air density depend on local conditions of temperature, humidity and barometric pressure according to the equations of state for ideal gases. Therefore,

$$
\frac{p}{R T}=\rho
$$

Where $p$ is pressure in $\mathrm{Pa}, R$ is the ideal gas constant, calculated for changes in the proportion of water vapour to dry air, and $T$ is the temperature in Kelvin.

Hence, it is not surprising that changes in temperature follow the trajectory of the airflow, since it underpins the change in the partial pressure of water vapour which in turn will affect air density. Nevertheless, the best fit is between the calculated airflow and the empirically derived airflow.

The 100 per cent repetitive results from the experiment showing a tight correlation between the calculated and actual airflow suggest strongly that the physics underlying the biotic pump theory must be correct and therefore an active principle that should be accounted for in relation to the larger atmosphere outside the experimental structure. The set of experiments therefore adds substance to the findings of significant correlations between the partial pressure force of water vapour and surface airflow, again with a strong directionality, for la Selva in Costa Rica. 
Graph 49. Rate of change in calculated airflow vs anemometer airflow

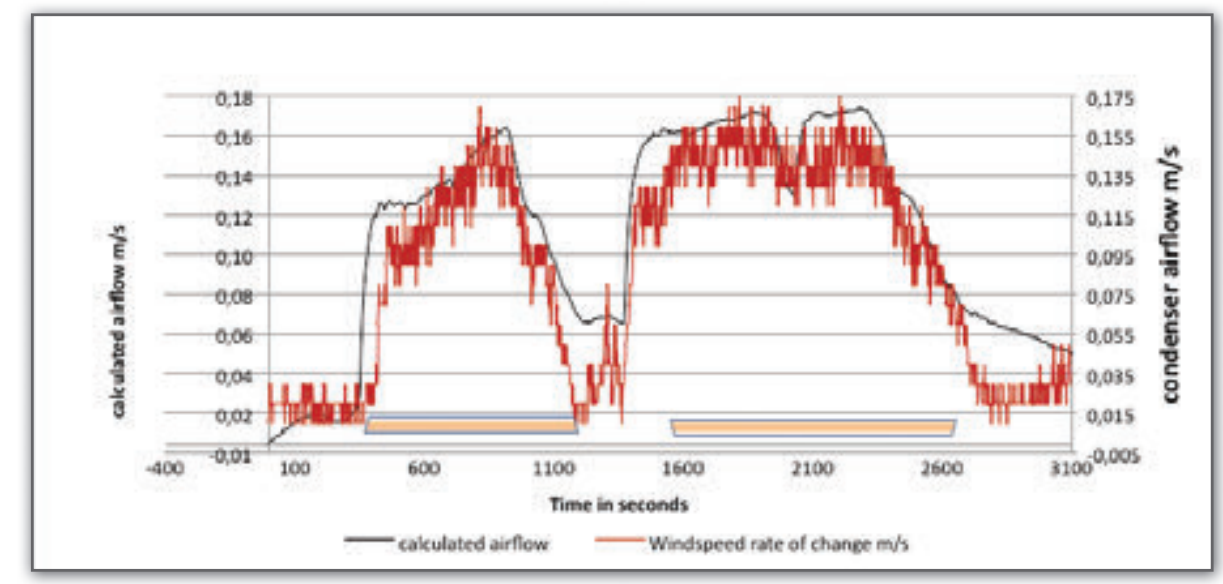

Source: Author.

Graph 50. Condesation rate airflow

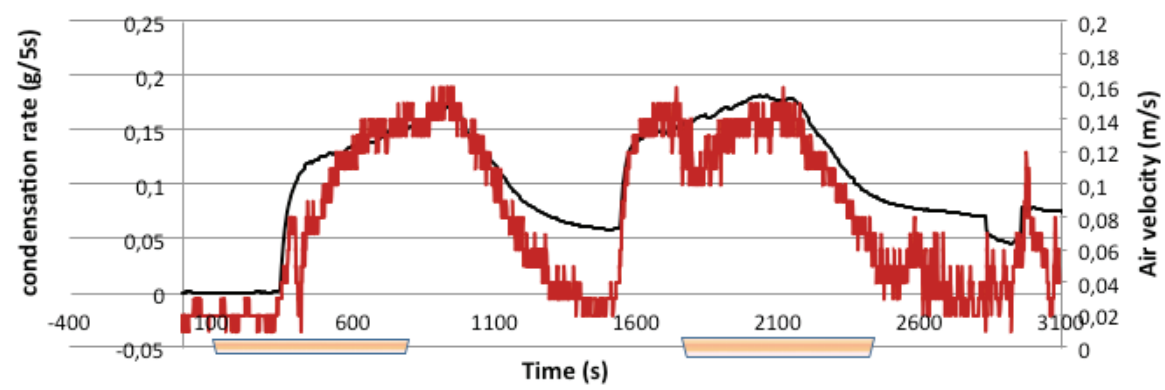

- calculated airflow $\quad$ Windspeed rate of change $\mathrm{m} / \mathrm{s}$

Source: Author. 
Graph 51. Experiment

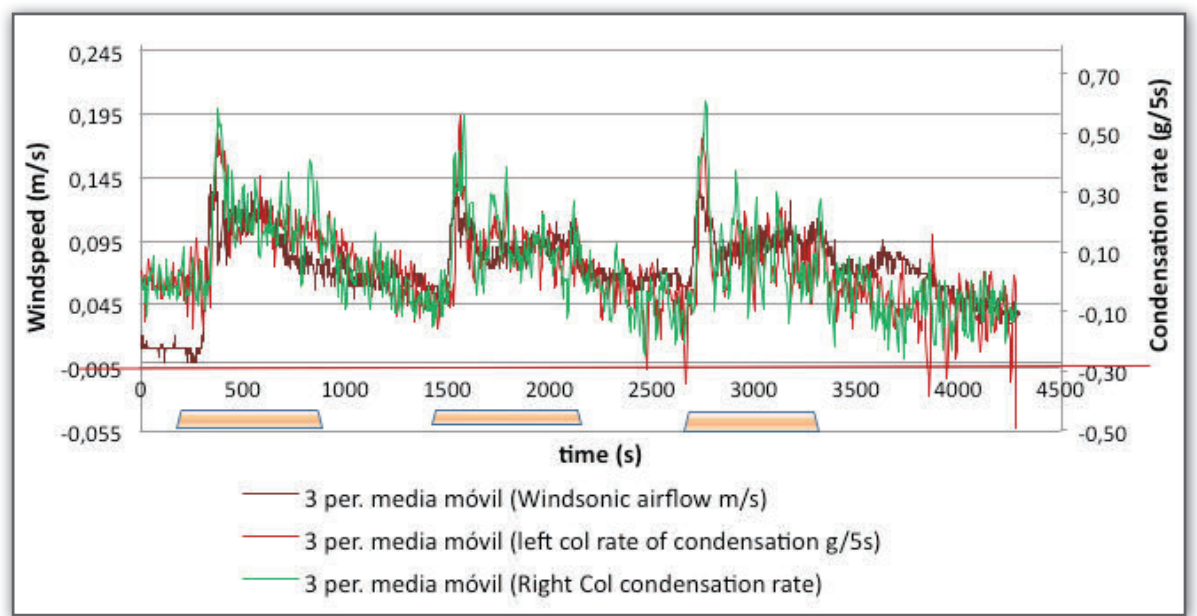

Source: Author.

In the graph the windspeed (left axis) as measured with the 2-D anemometer $\mathrm{m} / \mathrm{s}$, the condensation rate (right axis), with left column green and right column red. Close correspondence is seen between airflow and condensation. The suction caused by the change of pressure brought about through water vapour condensation results in a sharp increase in airflow. The black line represents the measured airflow, using a moving average of 3 , similarly, the green line represents the rate of condensation in grams per second of the right column (where the condensation coils are located, and the red line represents the left column).

These experimental results, as shown in graphs 50 to 57, indicate a close correlation between airflow plus its directionality, hence clockwise flow, and the rate of condensation as brought about through the cooling coils. That correlation is mirrored by the tight fit between the measured airflow and the calculated airflow. Moreover, even when the temperature is higher and the air density lower in the right column compared to the left column, the flow caused by condensation still imposes itself with air moving clockwise and therefore from left to right in the upper connecting tunnel. That movement is clearly seen in the inclination of the gauze sited at the top of the left column. 
Graph 52. Airflow versus partial pressure change

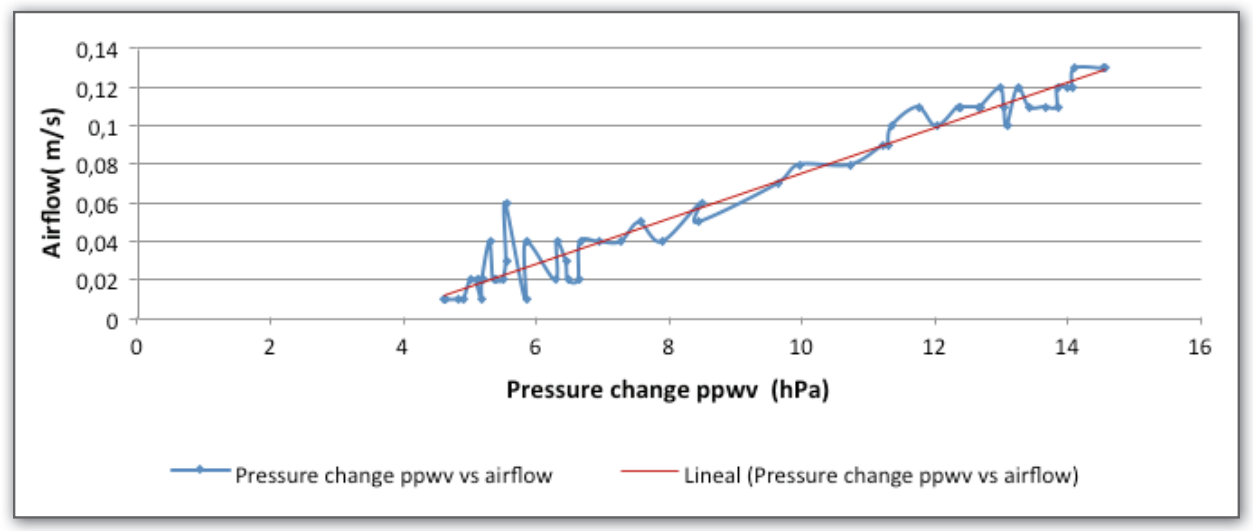

Note: Experimental results. Source: Author.

Graph 53. Airflow and partial pressure change

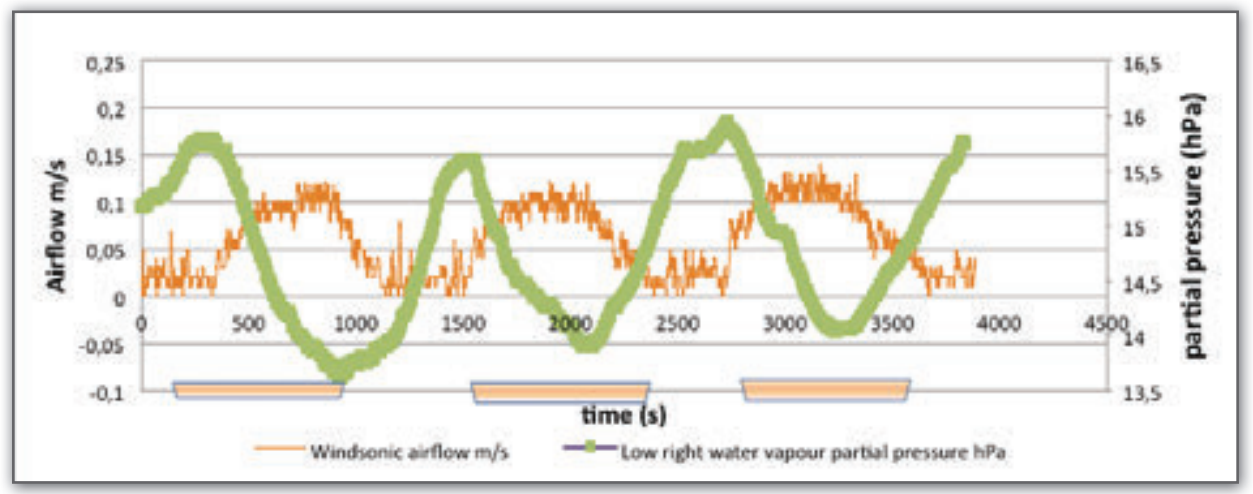

Note: We see an inverse relationship and as the partial pressure water vapour (ppwv) reduces because of condensation so the airflow increases and vice versa. Source: Author. 
How the Biotic Pump links the hydrological cycle

and the rainforest to climate

Graph 54. Calculated airflow at condenser versus airflow in right and left columns

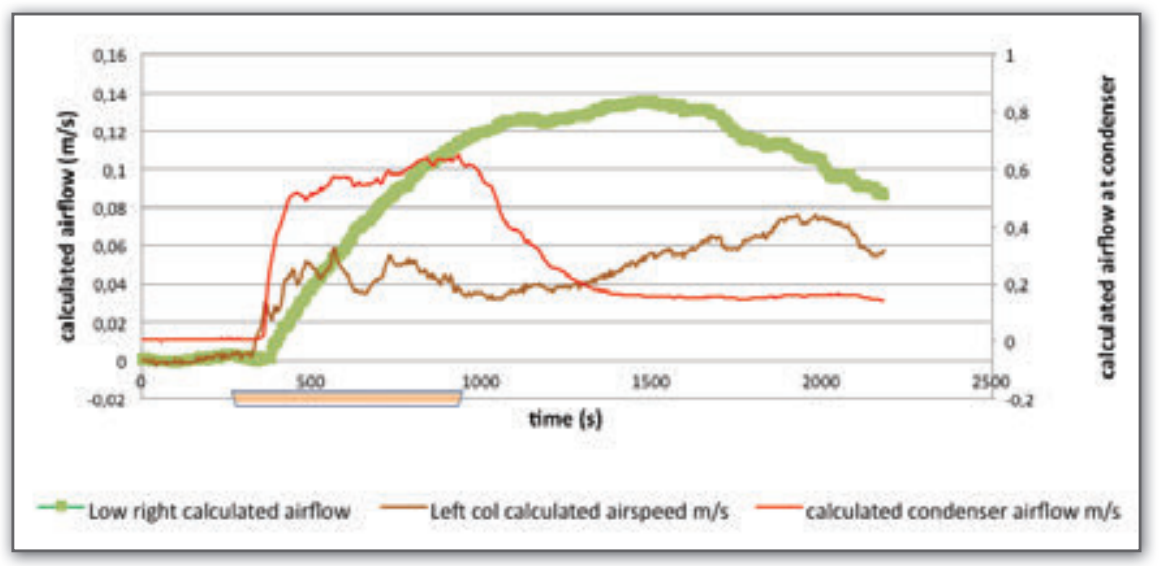

Source: Author.

Graph 55. Counterflow in action when the condenser is switchedoff

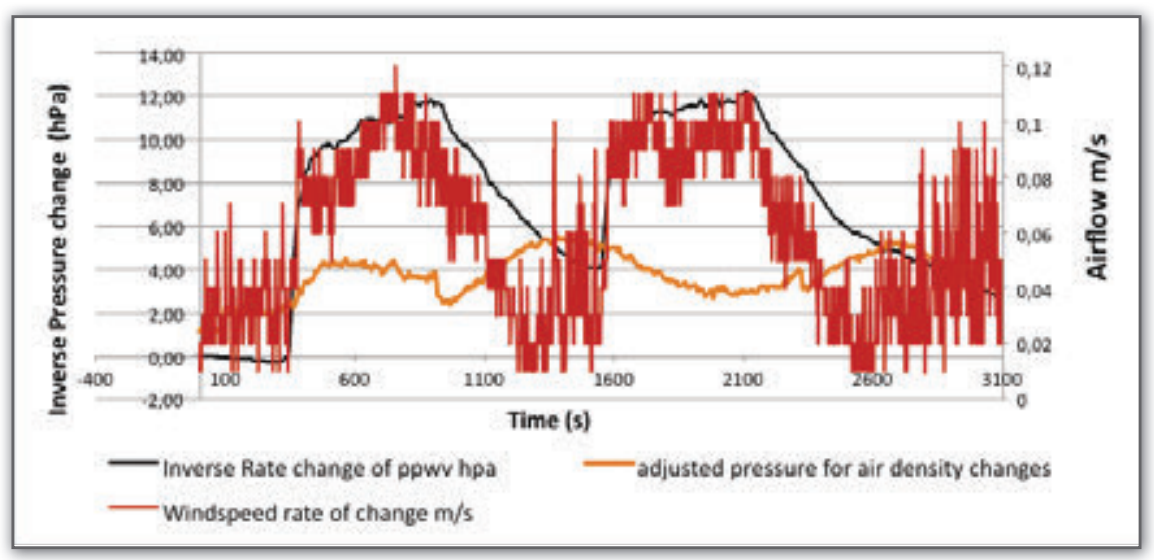

Note: The brown curve shows the pressure change as a result of air density in the right column being less dense than in left. Nevertheless, the clockwise airflow resulting from condensation overrides the air flow resulting from the density difference. Source: Author. 
Graph 56. Experiment, air density

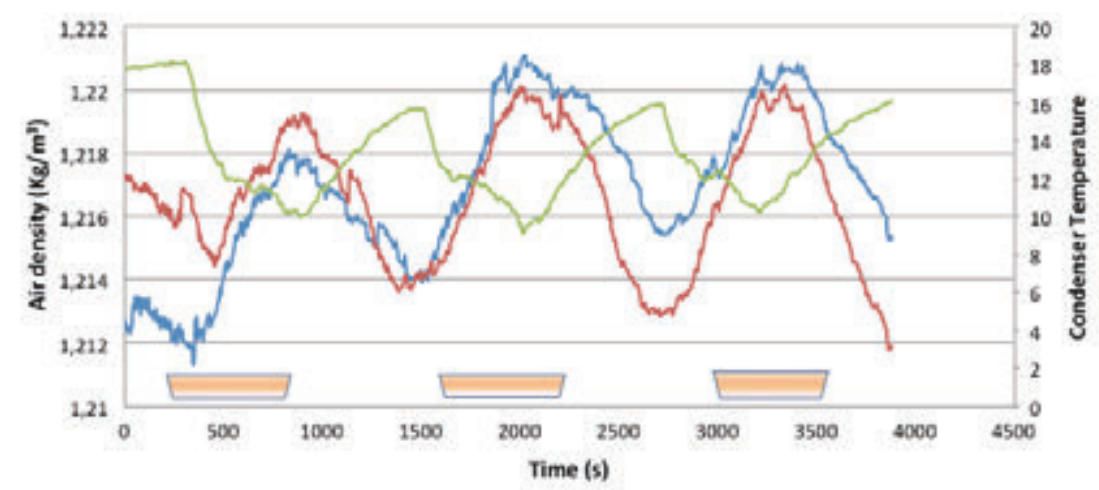

- Air density lower left - Air density lower right - Condenser Temperature

Note: A higher air density in the left column means that the clockwise airflow, as measured, runs against the inclination of the air mass to move in the counter-clockwise direction, hence giving credence to the notion that the pressure change caused by condensation is the primary driving force. Source: Author. 


\section{GONGLUSION}

Tn conclusion, if the interpretation of my findings can be 1 verified, that there is a connection between humidity as measured as an evaporative force $(\mathrm{hPa} / \mathrm{km})$ and between changes in wind speed, with the wind accelerating as the partial pressure force increases during the sunlight hours, admittedly with a lag period of 30 minutes or more, then that would definitely lend support to the Biotic Pump Theory of Makarieva and Gorshkov. In addition, it would add weight to the perception that the hydrological function of rainforests is far more important than their ability to act as sinks for atmospheric carbon dioxide. Indeed, ET is a cooling process, thereby contributing to reduce global warming and climate change.

Certainly the experimental results are unequivocal in showing a close correlation $(>0.9)$ between condensation, as measured through the change in partial pressure of water vapour, and the airflow. When the change in partial pressure is converted to velocity through a standard kinetic energy equation we see a close fit between that measured and that calculated. Moreover, the quantity change in the partial pressure in $\mathrm{hPa}$ is of the same order as theoretically derived by Makarieva and colleagues (Makarieva et al., 2013). That experimental finding would seem to go a considerable way in proving the general physics of the biotic pump theory. In addition it shows that the scalar difference between the experimental structure and the atmosphere outside (one thousand-fold difference) does not bring about anomalies; rather the physics is the same and the resulting dynamics may be similar. 
The implications are clear: we must include the principles underlying the biotic pump theory in our concerns over the climatic and hydrological consequences of deforestation, be that in the equatorial tropics or in higher latitudes. The biotic pump principle indicates that contiguous forests stretching from the ocean inland, across a continent, will modulate and moderate the airflows such as to reduce the strength of cyclonic winds, quite aside from their attributes as windbreaks. In using carbon balances and hence carbon trading as a measure of potential reductions in atmospheric carbon dioxide, we are in danger of neglecting the hydrological role of forests. A plantation which has no closed canopy nor under-storey may capture carbon dioxide during its growth, but it will not serve in maintaining gentle airflows nor a humidity curve in the lower atmosphere which is propitious for the transport of moisture and for generating rain in the interior of continents.

Without question, the fundamental work of Anastassia Makarieva and Victor Gorshkov has stimulated a number of research projects, not least that indicated in the pages of this monograph. The experiments would appear to show the validity of the general principle underlying the biotic pump; that it is the result of high rate of condensation.

Nevertheless, more work needs to be done, more evidence brought to bear before the climatological community will accept the biotic pump theory and its implications for modelling climate change, especially when incorporating the hydrological principles connected to continental rainforests. 


\section{REFERENCES}

Avissar, R., \& Werth, D. (2005). Global Hydroclimatological Teleconnections Resulting from Tropical Deforestation. Fournal of Hydrometeorology, 6(2), 134-145. doi: 10.1175/JHM406.1

Betts, R. A., Sanderson, M., \& Woodward, S. (2008). Effects of large-scale Amazon forest degradation on climate and air quality through fluxes of carbon dioxide, water, energy, mineral dust and isoprene. Philosophical Transactions of the Royal Society B, 363(1498), 1873-1880. doi: 10.1098/ rstb.2007.0027

Betts, R. A., Cox, P.M., Collins, M., Gash, J.H., Harris, P.P., Huntingford, C., Jones, C.D., et al. (2002). Amazonian forest die-backin the Hadley Centre coupled climate-vegetation model. Exeter, UK: UK Met Office, Hadley Centre.

Blyth, E., Gash, J., Lloyd, A., Pryor M., Weedon, G. P., \& Shuttleworth, J. (2010). Evaluating the JULES Land Surface Model Energy Fluxes Using FLUXNET Data. Fournal of Hydrometeorology, 11, 509-519. doi: 10.1175/2009JHM1183.1

Boyce, G. K., Brodribb, T. J., Feild, T. S., \& Zwieniecki, M. A. (2009). Angiosperm leaf vein evolution was physiologically and environmentally transformative. Proceedings of The Royal Society B, 276(1663), 1771-1776. doi: 10.1098/rspb.2008.1919

Boyce, C. K., \& Lee, J. E. (2010). An exceptional role for flowering plant physiology in the expansion of tropical rainforests and biodiversity. Proceedings of Royal Society B, 277, 3437-3443. doi: 10.1098/rspb.2010.0485

Boyce, C. K., Lee, J. E., Feild, T. S., Brodribb, T. J., \& Zwieniecki, M. A. (2010). Angiosperms helped put the rain in the rainforests: the impact of plant physiological evolution on tropical biodiversity. Annals of the Missouri Botanical Garden, 97(4), 527-540. doi: 10.3417/2009143 
Brubaker, K. L, Dara E., \& Eagleston, P. S. (1993). Estimation of Continental Precipitation Recycling. Fournal of Climate, 6(6), 1077-1089. doi: 10.1175/1520-0442(1993)006<1077:EOCPR>2.0.CO;2

Bunyard, P. (2011). ¿Es aleatorio que la tierra ha retenido su agua?. Recovery from http:// www.almamater.edu.co / sitio / Archivos / Documentos / Documentos/00000534.pdf

Bunyard, P. (2012). Biotic Pump, Fiction or Reality?. Awaiting publication.

Bunyard, P., Netchev, P., Peña, C., \& Redondo, J. (2012). The Barometric tidal wave, what is it? Work presented at 3rd International Meeting of STAHY, Tunis.

Butler, R. (2010). The Amazongate fiasco. Recovery from http://news.mongabay. com/2010/0204-amazongate.html

Charney, J., Quirk, W., Chow, S., \& Kornfield, J. (1977). A comparative study of the effects of albedo change on drought in semiarid regions. Fournal of Atmospheric Sciences, 34, 1366-1385. doi: 10.1175/1520-0469(1977)034<1366:ACSOTE >2.0.CO;2

Clark, D., Xue, Y., Harding, R., \& Valdés, P. (2001). Modeling the impact of land surface degradation on the climate of tropical North Africa. Fournal of Climatology, 14(8), 1809-1822. doi: 10.1175/1520-0442(2001)014<1809:MTIOLS>2.0.CO;2

Cochrane, M. A., Alencar, A., Schulze, M. D., Souza Jr., C. M., Nepstad, D. C., Lefebvre, P., \& Davidson, E. A. (1999). Positive feedbacks in the fire dynamic of closed canopy tropical forests. Science, 284(5421), 1832-1835. doi: $10.1126 /$ science.284.5421.1832

Cochrane, M. A., \& Laurance, W. F. (2002). Fire as a large-scale edge effect in Amazonian forests. Fournal of Tropical Ecology, 18(3), 311-325. doi: $10.1017 / \mathrm{S} 0266467402002237$

Collatz, G. J., Ball, J. T., Grivet, C., \& Berry, J. A. (1991). Physiological and environmental regulation of stomatal conductance, photosynthesis and transpiration: A model that includes a laminar boundary layer. Agricultural and Forest Meteorology, 54(1-2), 107-136. doi: 10.1016/0168-1923(91)90002-8 
Collatz, G. J., Ribas-Carbfdbo, M. \& Berry, J. A. (1992). Coupled Photosynthesis- Stomatal conductance model for leaves of C4 plants. Australian Fournal of Plant Physiology, 19(5), 519-538.

Cox, P. M., Betts, R. A., Jones, G. D., Spall, S. A., \& Totterdell, I. J. (2000). Acceleration of global-warming due to carbon-cycle feedbacks in a coupled climate model. Nature, 408, 184-187. doi: 10.1038/35041539

Cox, P. M., Huntingford, C., \& Harding, R. J., (1998). A canopy conductance and photosynthesis model for use in a GCM land surface scheme. Fournal of Hydrology, 212- 213, 79-94. doi: 10.1016/S0022-1694(98)00203-0

Cowling, S. A., Maslin, M. A., \& Sykes, M. T. (2001). Paleovegetation Simulations of Lowland Amazonia and Implications for Neotropical Allopatry and Speciation. Quaternary Research, 55(2), 140-149. doi: 10.1006/ qres.2000.2197

Cowling, S. A., Shin, Y., Pinto, E., \& Jones C. D. (2008). Water recycling by Amazonian vegetation: coupled versus uncoupled vegetation-climate interactions. Philosophical Transactions of The Royal Society B, 363(1498), 1865-1871.

Cruiziat, P. (2006). The Cohesion-Tension Theory at Work. In L. Taiz \& E. Zeiger (Eds.) Plant Physiology (5ft Edition). Sunderland, USA: Sinauer Associates.

Dickinson, R.E., Henderson-Sellers, A., Kennedy, P. J. (1993). BiosphereAtmosphere Transfer Scheme (BATS) Version le As coupled To The NGAR community climate model (NCAR/TN-387+STR). Recuperado de http: //nldr.library.ucar.edu / 8AEC9B39-5F17-4D68-A5AC544B0D767032/FinalDownload/DownloadId-D5B954C4A50F1603 829E143097E71E2F/8AEC9B39-5F17-4D68-A5AC-544B0D767032/ repository/assets/technotes/TECH-NOTE-000-000-000-198.pdf

Eamus, D., \& Shanahan, S. T. (2002). A rate equation model of stomatal responses to vapour pressure deficit and drought. BMC Ecology, 2(8). Recovery from http: //download.springer. $\mathrm{com} / \mathrm{static} / \mathrm{pdf} / 255 / \mathrm{art} \% 253 \mathrm{~A} 10.1186 \% 252 \mathrm{~F} 1472-6785-2-8$. pdf?auth66 $=1398442422 \_2 f 794719722324 \mathrm{cb} 3 \mathrm{~d} 761968 \mathrm{c} 668836 \mathrm{~b} \& \mathrm{ext}=$. pdf. doi: 10.1186/1472-6785-2-8 
Fearnside, P. M. (2000). Global warming and tropical land-use change: Greenhouse gas emissions from biomass burning, decomposition and soils in forest conversion, shifting cultivation and secondary vegetation. Climatic Change, 46(1-2), 115-158.

Feller, U. (2006). Stomatal Opening at Elevated Temperature: An underestimated regulatory mechanism? General and Applied Plant Physiology, 1-2, 19-31.

Feller, U., Anders, I., \& Mae, T. (2008). Rubiscolytics: fate of Rubisco after its enzymatic function in a cell is terminated. Fournal of Experimental Botany, 59(7), 1615-1624. doi: 10.1093/jxb/erm242

Fletcher, A. (2012). Operation OASIS = Overseas Arid Soil Irrigation Solution. Recovery from http: //andrewkfletchers.blogspot.co.uk/ 2012/03/ operation-oasis-andrew-k-fletcher.html

Garcia-Carreras, L., \& Parker, J. D. (2011). How does local tropical deforestation affect rainfall? Geophysical Research Letters, 38(19). doi: 10.1029/2011GL049099

Gat, J. R., \& Matsui, E. (1991). Atmospheric water balance in the Amazon basin: An isotopic evapotranspiration model. Fournal of Geophysical Research, 96(D7), 13179-13188. doi: 10.1029/91JD00054

Gimeno, L., Ribera, P., Nieto R., Pérez, J. F., Vidal, O., Torre de la, L., Gallego, D., et al. (2002). Imprints of the North Atlantic Oscillation on four unusual atmospheric parameters. Earth and Planetary Science Letters, 202(3-4), 677-692. doi: 10.1016/S0012-821X(02)00798-7

Haffer, J. (1969). Speciation in Amazonian Forest Birds. Science, 165(3889), 131-137. doi: 10.1126/science.165.3889.131

Henderson-Sellers, A., Dickinson, R., Durbridge, T., Kennedy, P., McGuffie, K., \& Pittman, A. (1993). Tropical deforestation: Modeling local-to regionalscale climate change. Journal of Geophysical Research: Atmospheres, 98(D4), 7289-7315. doi: 10.1029/92JD02830

Henderson-Sellers, A., McGuffie, K., \& Zhang, H. (2002). Stable isotopes as validation tools for global climate model predictions of the impact of Amazonian deforestation. Fournal of Climate, 15(18), 2664-2677. doi: 10.1175/1520-0442(2002)015<2664:SIAVTF>2.0.CO;2 
Hutyra, L. R., Munger, J. W., Nobre, C. A., Saleska, S. R., Vieira, S. A., \& Wofsy, S. C. (2005). Climatic variability and vegetation vulnerability in Amazonia. Geophysical Research Letters, 32(24), L24712. doi:10.1029/2005GL024981

Jacobs, C. (1994). Direct impact of atmospheric CO2 enrichment on regional transpiration (PhD thesis, Wageningen Agricultural University).

Kigomo, B. N. (2003). Forests and Woodlands degradation in dryland Africa: a case for urgent global attention. Paper submitted to the XII Forestry Congress, Québec City, Canada.

Kishore. (February, 2010). Definition of Stomata. Recovery from http:// www.kish.in/stomata/

Kleidon, A, \& Heimann, M. (2000). Assessing the role of deep rooted vegetation in the climate system with model simulations: mechanism, comparison to observations and implications for Amazonian deforestation. Climate Dynamics, 16(2-3), 183-199.

Kleidon, A. (2002). Testing the Effect of Life on Earth's Functioning: How Gaian Is the Earth System? Climatic Change, 52(4), 383-389. doi: 10.1023/A:1014213811518

Kleidon, A. (2004). Amazonian Biogeography as a Test for Gaia. In S. Schneider, J. Miller, E. Crist, \& P. Boston (Eds.), Scientists Debate Gaia: The Next Century (pp. 289-291). Oxford: MIT Press Scholarship Online. doi: 10.7551/mitpress/9780262194983.003.0027

Laurance, W. F., \& Williamson, G. B. (2001). Positive Feedbacks among Forest Fragmentation, Drought, and Climate Change in the Amazon. Conservation Biology, 15(6), 1529-1535. doi: 10.1046/j.1523-1739.2001.01093.x

Laurance, W. F., Lovejoy, T., Vasconcelos, H. L., Bruna, E. M., Didhman, R. K., Stouffer, P. C., Gascon, C., et al. (2002). Ecosystem Decay of Amazonian Forest Fragments: a 22-Year Investigation. Conservation Biology, 16(3), 605-618. doi: 10.1046/j.1523-1739.2002.01025.x

Lettau, H., Lettau, K., \& Molion, L. C. (1979). Amazonia's Hydrological Cycle and the Role of Atmospheric Recycling in Assessing Deforestation Effects. Monthly Weather Review, 107(3), 227-238. doi: 10.1175/1520-0493(1979)107<0227:AHCATR>2.0.CO;2 
Makarieva, A. M., \& Gorshkov, V. G. (2007). Biotic pump of atmospheric moisture as driver of the hydrological cycle on land. Hydrology and Earth System Sciences, 11, 1013-1033. doi:10.5194/hess-11-1013-2007

Makarieva, A. M., \& Gorshkov, V. G. (2009a). Condensation-induced dynamic gas fluxes in a mixture of condensable and non-condensable gases. Physics Letters A, 373(32), 2801-2804. doi: 10.1016/j.physleta.2009.05.057

Makarieva, A. M., \& Gorshkov, V. G. (2009b). Condensation-induced kinematics and dynamics of cyclones, hurricanes and tornadoes. Physics Letters A, 373(46), 4201-4205. doi: 10.1016/j.physleta.2009.09.023

Makarieva, A. M., \& Gorshkov, V. G. (2009c). Reply to A. G. G. A. Meesters et al.'s comment on "Biotic pump of atmospheric moisture as driver of the hydrological cycle on land. Hydrology and Earth System Sciences, 13(17), 1307-1311. doi: 10.5194/hess-13-1307-2009

Makarieva, A. M., \& Gorshkov, V. G. (2010). Potential energy of atmospheric water vapor and the air motions induced by water vapor condensation on different spatial scales. Biotic Regulation. Recovery from arXiv:1003.5466v1 .

Makarieva, A. M., Gorshkov, V. G., \& Li, B. (2006). Conservation of water cycle on land via restoration of closed-canopy forests: implications for regional landscape planning. Ecological Research, 21(6), 897-906. doi: 10.1007/s11284-006-0036-6

Makarieva, A. M., Gorshkov, V. G., \& Li, B. L. (2013). Revisiting forest impact on atmospheric water vapor transport and precipitation. Theoretical and Applied Climatology, 111(1-2), 79-96. doi: 10.1007/s00704-012-0643-9

Makarieva, A. M., Gorshkov, V. G., Sheil, D., Nobre, A.D., \& Li, B.-L. (2013). Where do winds come from? A new theory on how water vapor condensation influences atmospheric pressure and dynamics. Atmospherics Chemistry and Physics. 13, 1039-1056. doi: 10.5194/acp-13-1039-2013

Makarieva, M., Gorshkov, V. G., Sheil, D., Nobre, A. D., Bunyard, P., \& Li, B.-L. (2014). Why Does Air Passage over Forest Yield More Rain? Examining the Coupling between Rainfall, Pressure, and Atmospheric Moisture Content. Fournal of Hydrometeorology, 15(1), 411-426. doi: 10.1175/ JHM-D-12-0190.1 
Marengo, J. A. (2004). Interdecadal and long term rainfall variability in the Amazon basin. Theoretical and Applied Climatology, 78(1-3), 79-96. doi: 10.1007/s00704-004-0045-8

Marengo, J. A. (2006). On the hydrological cycle of the Amazon basin: A historical review and current state-of-the-art. Revista Brasileira de Meteorologia, 21(3), 1-19.

Marengo, J. A., Nobre, G.A., Tomasella, J., Cardoso, M.F, \& Oyama, M.D. (2008). Hydro-climatic and ecological behaviour of the drought of Amazonia in 2005. Philosophical Transactions of The Royal Society B Biological Sciences, 363(1498), 1773-1778. doi: 10.1098/rstb.2007.0015

Maslin, A. M., Ettwein, V. J., Boot, C. S., Bendle, J., \& Pancost, R. D. (2012). Amazon Fan biomarker evidence against the Pleistocene rainforest refuge hypothesis? Fournal of Quaternary Science, 27 (5), 451-460. doi: 10.1002/ jqs.1567.

Meteorological Office (s.f.). Meteorological data from 1961 to 2011 of Finland.

Molion, L. C. (1989). The Amazonian Forests and Climatic Stability Impact of deforestation on Amazonia. The Ecologist, 19(6), 207-210.

Morton, D. C., Nagol, J., Carabajal, C. C., Rosette, J., Palace, M., Cook, B. D., Vermote, E. F., et al. (2014). Amazon forests maintain consistent canopy structure and greenness during the dry season. Nature, 506(7487), 221-224. doi: 10.1038/nature13006

Myneni, R. B., Yang, W., Nemani, R. R., Huete, A. R., Dickinson, R. E., Knyazikhin, Y., Didan, K., et al. (2007). Large seasonal swings in leaf area of Amazon rainforests. Proceedings of the National Academy of Sciences of the United States of America - PNAS, 104(12), 4820-4823. doi: 10.1073/ pnas.0611338104

Negrón, R. I., Goulden, M. L., Myneni, R. B., Fu, R., Bernardes, S. \& Gao, H. (2008). An empirical approach to retrieving monthly evapotranspiration over Amazonia. International Journal of Remote Sensing, 29(24), 7045-7063. doi: 10.1080/01431160802226026

Nepstad, D. C., Carvalho de C. R., Davidson, E. A., Jipp, P. H., Lefebvre, P. A., Negreiros, G. H., Da Silva, E. D., et al. (1994). The role of deep roots 
in the hydrological and carbon cycles of Amazonian forests and pastures. Nature, 372, 666-669. doi:10.1038/372666a0

Penman, H.L. (1948). Natural Evaporation from Open Water, Bare Soil and Grass. Proceedings of The Royal Society A, 193(1032), 120-145. doi: 10.1098/ rspa.1948.0037

Penman, H. L. (1963). Vegetation and Hydrology. Farnham Royal: Commonwealth Agricultural Bureau .

Phillips, O. L., Aragão, L., Lewis, S. L., Fisher, J. B., Lloyd J., LópezGonzález, G., Malhi Y., et al. (2009). Drought Sensitivity of the Amazon Rainforest. Science, 323(5919), 1344-1347. doi: 10.1126/science.1164033

Phillips, O. L., Malhi, Y., Higuchi, N., Laurance, W. F., Núñez, P. V., Vásquez, R. M., Laurance, S. G., et al. (1998). Changes in the carbon balance of tropical forests: Evidence from long term plots. Science, 282(5388), 439-442. doi: 10.1126/science.282.5388.439

Pöschl, U., Martin, S. T., Sinha, B., Chen, Q., Gunthe, S. S., Huffman, J. A., Borrmann, D. K., et al. (2010). Rainforest Aerosols as Biogenic Nuclei of Clouds and Precipitation in the Amazon. Science, 329(5998), 1513-1516. doi: 10.1126/science.1191056

Poveda, G., \& Mesa, J. O. (2000). On the existence of Lloró (the rainiest locality on Earth): Enhanced ocean-land-atmosphere interaction by a low-level jet. Geophyscal Research Letters, 27(11), 1675-1678. doi: 10.1029/1999GL006091

Poveda, G., Jaramillo, A., Gil, M. M., Quiceno, N., \& Mantilla, R. I. (2001). Seasonally in ENSO-related precipitation, river discharges, soil moisture, and vegetation index in Colombia. Water Resources Research, 37(8), 21692178. doi: 10.1029/2000WR900395

Poveda, G., Bunyard, P., \& Nobre, G. A. (2008). Sobre la necesidad de un programa de investigación para el sistema Andes-Amazonia. Colombia Amazónica, 1, 129-142.

Poveda, G., Álvarez, D. M., \& Rueda, O. A. (2011). Hydro-climatic variability over the Andes of Colombia associated with ENSO: a review of climatic processes and their impact on one of the Earth's most 
important biodiversity hotspots. Climate Dynamics, 36(11-12), 2233-2249. doi: 10.1007/s00382-010-0931-y

Poveda, G., Jaramillo, L., \& Vallejo, L.F. (2014). Seasonal precipitation patterns along pathways of South American low-level jets and aerial rivers. Water Resources Research, 50(1), 98-118. doi: 10.1002/2013WR014087

Ramos da Silva, R., \& Avissar, R. (2006). The Hydrometeorology of a Deforested Region of the Amazon Basin. Fournal of Hydrometeorology, 7(5), 1028-1042. doi: 10.1175/JHM537.1

Rind, D. (1984). The influence of vegetation on the hydrologic cycle in a Global Climate Model. In J. E. Hansen, \& T. Takahashi (Eds.) Climate Processes and Climate Sensitivity (Vol. 5) (pp. 73-91). Washington: American Geophysical Union.

Roy, S., \& Avissar, R. (2000). Scales of response of the convective boundary layer to land surface heterogeneity. Geophysical Research Letters, 27(4), 533 536. doi: 10.1029/1999GL010971

Roy, S., \& Avissar, R. (2002). Impact of land use/land cover change on regional hydrometeorology in Amazonia. Fournal of Geophysical Research, 107(D20), LBA 4-1 - LBA 4-12. doi: 10.1029/2000JD000266

Salati, E. (1987). The forest and the hydrological cycle. In R. Dickinson (Ed.), The Geophysiology of Amazonia, Vegetation and Climate Interactions, (pp. 273-296). New York: Wiley-Insterscience Publication.

Salati, E., \& Vose, P. B. (1984). Amazon basin: A system in Equilibrium. Science, 225(4658), 129-138. doi: 10.1126/science.225.4658.129

Salazar, J. F., \& Poveda, G. (2008). Role of a simplified hydrological cycle and clouds in regulating the climate-biota system of Daisyworld. Tellus $B$, 61(2), 483-497. doi: 10.1111/j.1600-0889.2008.00411.x

Sellers, P. J., Berry, J. A., Collatz, G. J., Field, C. B., \& Hall, F. G. (1992). Canopy Reflectance, Photosynthesis, and Transpiration. III. A Reanalysis Using Improved Leaf Models and a New Canopy Integration Scheme. Remote Sensing of Environment, 42(3), 187-216. doi: 10.1016/00344257(92)90102-P 
Shuttleworth, W. J. (1988). Evaporation from Amazonian Rainforest. Proceedings of The Royal Society B, 233(1272), 321-346. doi: 10.1098/ rspb.1988.0024

Soares-Filho, B. S., Nepstad, D. G., Gurran, L. M., Gerqueira, G. G., García, R. A., Ramos, C. A., Voll, E., et al. (2006). Modelling conservation in the Amazon basin. Nature, 440, 520-523. doi: 10.1038/nature04389

Spracklen, D. V., Arnold, S. R, \& Taylor, C. M. (2012). Observations of increased tropical rainfall preceded by air passage over forests. Nature, 489, 282-285. doi: 10.1038/nature11390

Tyree, M. T. (1997). The Cohesion-Tension theory of sap ascent: current controversies. Fournal of Experimental Botany, 48(315), 1753-176.

University of Wyoming. (s.f.). Atmospheric Soundings. Recovery from http:// weather.uwyo.edu/upperair/sounding.html

Van der Hammen, T., \& Absy, M. L. (1994). Amazonia during the last glacial. Palaeogeography, Palaeoclimatology, Palaeoecology, 109(2-4), 247-261. doi: 10.1016/0031-0182(94)90178-3

Werth, D., \& Avissar, R. (2002). The local and global effects of Amazon deforestation. Fournal of Geophysical Research: Atmospheres, 107(D20), LBA 55-1 - LBA 55-8. doi: 10.1029/2001JD000717

Werth, D., \& Avissar, R. (2004). The regional evapotranspiration of the Amazon. Fournal of Hydrometeorology, 5(1), 100-109. doi: 10.1175/1525-7541(2004)005<0100:TREOTA>2.0.CO;2

Wood, R., Bretherton, C. S., Hartmann, D. L. (2002). Diurnal cycle of liquid water path over the subtropical and tropical oceans. Geophysical Research Letters, 29(23), 7-1 - 7-4. doi: 10.1029/2002GL015371

Xue, Y., Liou, K., \& Kasahara, A. (1990). Investigation of Biogeophysical Feedback on the African Climate Using a Twodimensional Model. Fournal of Climatology, 3(3), 337-352. doi: 10.1175/1520-0442(1990)003<0337:IOBFOT>2.0.CO;2 


\section{ACKNOWLEDGEMENTS}

Tam grateful to the University Sergio Arboleda (Bogotá, Colombia) and in particular to the Institute of Environmental Studies and Services (IDEASA) and Dra. Carmen Cecilia Noguera for their continued support of my research and musings related to the biotic pump theory of Drs. Anastassia Makarieva and Viktor Gorshkov, at the Institute of Nuclear Physics, St Petersburg, Russia, both of whom have cast a critical and appraising eye over my research findings. Their theoretical work and its application have been enormously stimulating and it touches on profound ecological truths with regard to the relationship between life and its environment.

I owe an enormous debt to the Good Energies Foundation and especially its director, Marcel Brenninkmeijer, for having had faith in my ideas and for the generous support without which I would never have been able to carry out my experiments on the biotic pump. In helping to set up the experimental structure, I am truly grateful to the physicist, Dr. Plamen Nechev. He had useful insights and his concerns that we would fail to find an airflow worth measuring made it all the more exciting when we did. My thanks, too, to Carlos Peña of the Faculty of Mathematics, Universidad Sergio Arboleda, for his interest and help in the project and to Max Tercel, now a biology student at Bangor University in Wales, for having helped with the experiment in its early phase, when we discovered, eureka-like, that condensation leads visibly to airflow, hence, a major step forward in demonstrating the validity and effectiveness of the biotic pump theory, in his 
M.Sc thesis Thomas Lafon, who now works for Entropika in Leticia, had some useful insights into the BP theory and I am grateful to him as well as too my wife, Jimena Sánchez, who, with her background as an engineer, helped put the experimental project together. Francis Dufort, who turns creative ideas into useful functions, added imaginatively to ways to capture raindrops. Finally, I would like to thank Carlos Caho, the editorial coordinator of scientific publications at the Sergio Arboleda University in Bogotá, Colombia, for his invaluable work in organising the text into a comprehensive whole. 


\section{Serie Investigación}

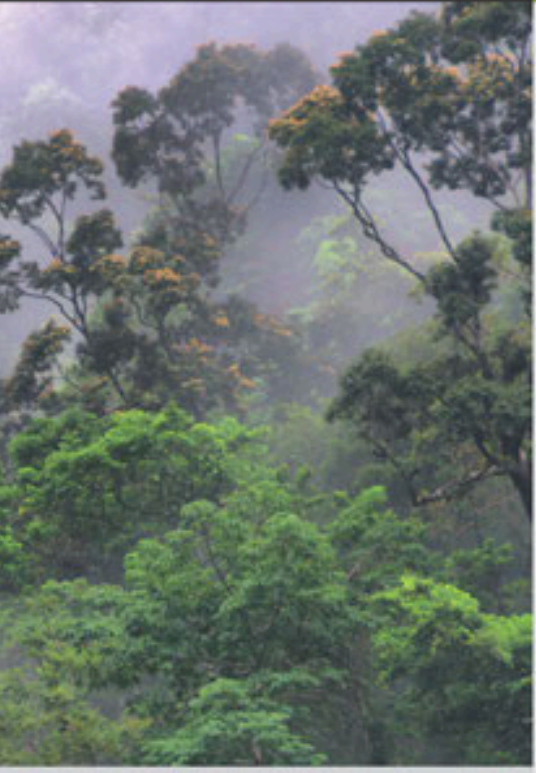

How the Biotic Pump links the hydrological

CYCLE AND THE RAINFOREST TO CLIMATE:

IS IT FOR REAL?

HOW CAN WE PROVE IT?

The Biotic Pump Theory, as set forward by Drs. Makarieva and Gorshkov, states that the primary force driving surface winds, certainly in the tropics, is induced by the negative changes in atmospheric pressure caused by condensation of water vapour when clouds form. The theory therefore runs contrary to the traditional view, as introduced in climate models, that surface winds are the sole products of differences in surface heating as well as of latent heat release during the process of condensation. Indeed, Makarieva and her colleagues claim that transitions in the phases of water play a far more important role in driving atmospheric dynamics than is currently recognised.

The implications of the Russian theory are important for a wide range of scientific fields as it involves the global regulation and distribution of water, and not least an association with the physiology of different types of vegetation. In effect, Makarieva and Gorshkov propose that forest cover can, by means of moisture evaporation and condensation, generate the large-scale pressure gradients, that create the ocean-to-land moisture convergence that supplies rainfall across continents, contingent on there being sufficient cover of closed canopy forest.

Our study therefore aims quantitatively and theoretically at assessing the validity of the Biotic Pump Theory over regions which have or had humid tropical/equatorial rainforest, such as in Costa Rica and the Amazon basin.

The study is highly relevant to the future of Colombia in as much as rainfall patterns are in great measure linked to the air mass circulation over the Amazon Basin. Clearly what the Amazon countries, especially Brazil and including Colombia, do to their rainforests will have far reaching con-sequences for the region and even for the globe.

The theory is a hydrological theory putting emphasis on the maintenance of a high level of evapotranspiration over the Amazon Basin, such as to supply the piedmont, cloud forests and the upper moorland páramos with adequate rainfall and humidity. For that hydrological process to continue, according to the biotic pump theory, it becomes imperative that rainforest be properly conserved and that regeneration in heavily deforested regions should be mandated, with urgency.

\section{UNIVERSIDAD SERGIO ARBOLEDA}

Carrera 15 No. 74-40. Tels: (571) 3257500 ext. 2131 - 322 0538. Bogotá, D.C. Calle 18 No. 14A-18. Tels: (575) 4203838 - 420 2651. Santa Marta 